\title{
A Classification of the Cultivated Varieties of Barley
}

\author{
A THESIS \\ Presented to the Faculty of the Graduate School \\ OF CORNell UNIVERSTTY FOR THE DEGREe OF \\ DOCTOR OF PHILOSOPHY
}

\section{BY \\ ROY GLEN WIGGANS}

Published by the N. Y. State College of Agriculture, September 1921,
Memoir 46

Published by the N. Y. State College of Agriculture, September 1921,
Memoir 46

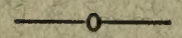

$-0$ 



\title{
A Classification of the Cultivated Varieties of Barley
}

\author{
A THESIS \\ Presented to the Faculty of the Graduate School \\ of Cornell University For the Degree of \\ DOCTOR OF PHILOSOPHY
}

BY

\section{ROY GLEN WIGGANS}




$$
\begin{aligned}
& \text { SBI91 } \\
& \text { BaW5 }
\end{aligned}
$$

By exchange Comell Unir Sulmany
1922

$\because \vdots$ 


\section{CONTENTS}

Work of other investigators. . . . . . . . . . . . . . . . . . 369

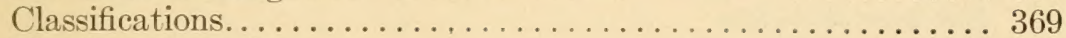

Number of species. .......................... 380

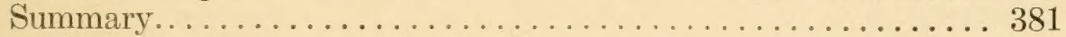

Material used in the present classification. . . . . . . . . . . . . 383

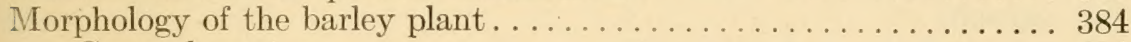

Gross characters. . . . . . . . . . . . . . . . . . . 384

Foliage. . . . . . . . . . . . . . . . . . . . . . . . . 384

Culm characters. . . . . . . . . . . . . . . . . . . . . 385

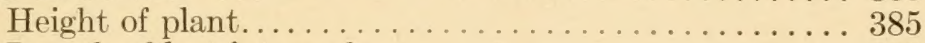

Length of last internode. . . . . . . . . . . . . . 386

Number of nodes. . . . . . . . . . . . . . . . . . . 386

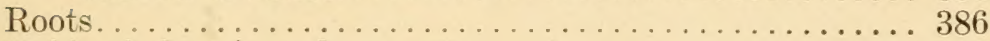

Habit of plant in early growth . . . . . . . . . . . . . . 387

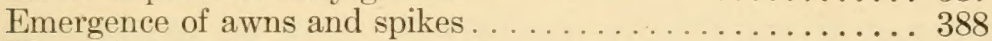

Time of maturity ........................ 388

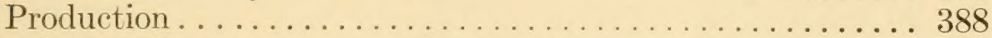

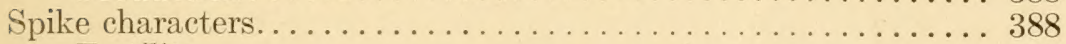

Fertility . . . . . . . . . . . . . . . . . . . . . . 389

Branch-headed barleys....................... 392

Density . . . . . . . . . . . . . . . . . . . . . . . . 393

Length of internodes of rhachis. . . . . . . . . . . . 394

Angle of inclination of kernel. . . . . . . . . . . . 397

Attitude of spike..................... . . 397

Articulation of internodes of rhachis . . . . . . . . . . . . . . . . . . . . . . . . 398

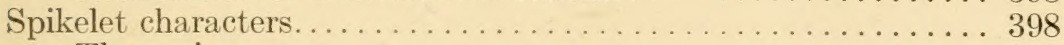

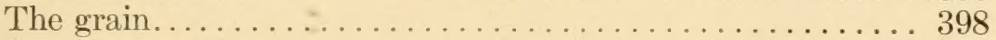

Composition . . . . . . . . . . . . . . . . . . . . 399

Size.............................. 399

Shape. . .......................... . . 400

Color. . . . . . . . . . . . . . . . . . . . . . 401

The lemma, or flowering glume... . . . . . . . . . . . . 403

Adherence of lemma and palea to caryopsis. . . . . . . . . 404

Terminal appendage .................... 405

Number of nerves of lemma................ 407

Barbing of lateral nerves of lemma............. 407

Base of lemma....................... 408

The outer glumes. . . . . . . . . . . . . . . . . . . . . 410

The rhachilla........................... 411

Summary .............................. 412 
Classification of barley forms........................ 413

Hordeum spontaneum........................ 415

Hordeum vulgare. ......................... 416

Hordeum intermedium. . . . . . . . . . . . . . . . . . . 430

Hordeum distichon ........................... 433

Hordeum deficiens............................ 443

Summary................................. 447

Acknowledgments ................................. 448

Bibliography............................... 449

Index to varieties and subvarieties.................. 453 
A CLASSIFICATION OF THE CULTIVATED VARIETIES OF BARLEY 



\section{A CLASSIFICATION OF THE CULTIVATED VARIETIES OF BARLEY}

\section{Roy Glen Wiggans}

The need for systematic classifications of the various farm crops has been recognized in recent years, due to the large increase in the number of varieties and the confusion in the nomenclature. It is the purpose of this study to make a classification of barleys that will aid agronomists, seedsmen, and farmers to identify the different varieties in common cultivation and to clear up the misuses of nomenclature.

Before a classification of any group of plants can be undertaken, it is necessary to have an accurate knowledge of the structure of the plants. For this reason, and because it is hoped that the descriptions may be of value to detailed studies in the future, the morphology of the barley plant is fully discussed in this paper.

\section{WORK OF OTHER INVESTIGATORS}

\section{CLASSIFICATIONS}

The numerous and extensive researches on barley already available have been made largely in Europe, and deal more with the malting and brewing qualities of the barley grown and the processes of manufacturing than with systematic classification. This work, however, has not been entirely neglected. Classifications have been presented by various European and American investigators. On close examination, these classifications are found to differ widely in arrangement and in the weight given the various characters that have been used in distinguishing between the species and also between groups of lesser importance. For these reasons, and in order (1) to make available the classifications of European investigators and (2) to give weight to the characters employed in the present classification, considerable space is devoted in this paper to reviewing the various classifications that have previously been presented.

The earliest classification of barleys of any importance was that of Linnaeus $(1748)^{1}$. Five years later (1753) he elaborated on his first work,

\footnotetext{
${ }^{1}$ Dates in parenthesis refer to Bibliography, page 449.
} 
recognizing four distinct species and two varieties of cultivated barleys, as given briefly in the following key:

A. All spikelets fertile.

B. Spikes dense.

Hordeum hexastichon $\mathbf{L}$.

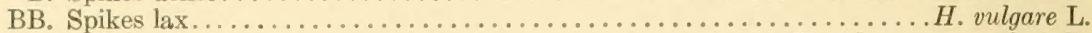

AA. Median spikelet fertile.

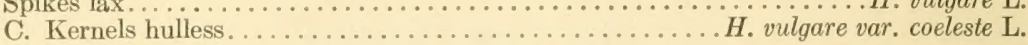

B. Spikes dense.

H. zeocriton L.

BB. Spikes lax. .

H. distichon L.

C. Kernels hulless.

.H. distichon var. nudum L.

In making his classification Linnaeus recognized three important taxonomic characters - fertility, density, and adherence of lemma and palea to the caryopsis. These three characters have been given important consideration in practically every classification made since, and the species established by Linnaeus have been the foundation of all subsequent work. All classifications previous to that of Linnaeus were necessarily based on very small collections, and as a consequence only two types of barley, the six-rowed and the two-rowed, were recognized. For this reason, nothing is to be gained by a review of the literature previous to 1753 .

No work was done on barleys for sixty-five years after the publication of Linnaeus' classification. Schübler (1818) named seven species by employing the same characters as were used by Linnaeus. The only addition he made was the separation for the first time of the Linnaean species distichon into erectum and nutans. This separation was made on density, thus giving three species of two-rowed barleys, zeocriton, erectum, and nutans, based on the density of the spike.

Following Schübler, Séringe (1819) recognized four species, all of which had been named by Linnaeus. Later (1841-42) he made subdivisions of the four species but failed to add anything of value to previous work.

Jessen (1855) presented a brief classification wherein he considered all cultivated varieties of barley as one species, namely, Hordeum sativum Jess. He was the first botanist to thus limit the number of species of cultivated barleys.

Heuze (1872), working with a much larger collection of barleys than his predecessors used, was able to expand and enlarge on the classifications previously presented. His work doubtless stimulated later workers, especially Körnicke, who published Die Saatgerste (1882) and later elaborated on this work in the Handbuch des Getreidebaues (Körnicke, 1885). 
The classification of Körnicke, as presented in 1885, is given briefly in the following key. ${ }^{2}$ He considered all cultivated varieties to belong to one species, Hordenm vulgare L., and established four primary groups within the one species, using fertility, terminal appendage, and number of rows or ranks as the chief characters.

A. All spikelets fertile............................ Hordeum polystichum Doll.

B. All spikelets awned.

C. Six-rowed barley, the spikes with six similar rows............ hexastichum L.

CC. Four-rowed barley, the spikes with four dissimilar rows; two opposite rows formed by the overlapping of two spikelets........... tetrastichum Keke.

BB. Only the middle spikelets awned, middle barley............ intermedium Kcke.

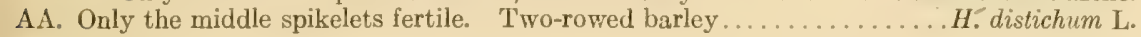

The varieties within the four sulspecies which Körnicke established are as follows:

1. Hordeum hexastichum $\mathrm{L}$.

A. Kernels hulled.

B. Outer glumes normal, linear.

C. Spike yellow.

D. Grain short......................... var. brachyatherum Keke.

DD. Grains long.

E. Spike pyramidal...................... var. pyramidatum Kcke.

EE. Spike with parallel sides .................... var. parallelum Kcke.

CC. Spike black.

D. Spike short, somewhat pyramidal.............var. Schimperianum Kcke.

DD. Spike long, with parallel sides................. var. gracilius Kcke.

BB. Outer glumes all or in part broadly lanceolate.

C. All outer glumes broadly lanceolate................ var, eurylepis Kcke.

CC. Only the outer glumes of the lateral spikelets broadly lanceolate.

AA. Kernels naked................................. var. revelatum Kcke.

2. Hordeum tetrastichum Keke.

A. Kernels hulled.

B. Glumes normal.

C. Spike yellow.

D. Grain straight............................ var. pallidum Sèr.

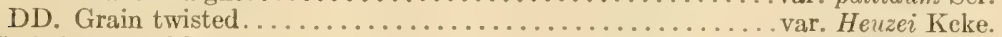

CC. Spike gray-blue ......................... var, coerulescens Sér.

CCC. Spike black.

D. Grain rough ............................. var. nigrum Willd.

DD. Grain smooth.............................. leiorrhynchum Keke.

BB. Glumes monstrous.

C. Grain long, strong................................ tortile Robert.

CC. Grain short, intermediate............................ cucullatum Keke.

CCC. Grain weak.................................... Har. Horsfordianum Wittm.

2The key is translated from the original German, but is rearranged in the standard form. 
AA. Kernels naked.

B. Glumes normal.

C. Spike yellow.

D. Spike long, narrow; kernel thin .var. coeleste L.

DD. Spike short; kernel thick.

E. Kernel blue-gray . . . . . . . . . . . . . . . var. himalayense Rittig.

EE. Kernel yellowish blue, thinner. . . . . . . . . . . var. Walpersii Keke.

CC. Spike gray-violet.......................... var. violaceum Keke.

BB. Glumes monstrous.

C. Only on middle spikelet.................... var. cornutum Schrader

CC. On all spikelets.

D. Awned. . . . . . . . . . . . . . . . . . . . . . . var. pseudotrifurcatum Langsd.

DD. Awnless................................... trifurcatum Schl.

3. Hordeum intermedium Kcke.

A. Spike thick, straight.

var. transiens Kcke.

AA. Spike weak, nodding.

var. Haxtoni Kcke.

4. Hordeum distichum L.

A. Rhachis at maturity remaining entire.

B. Spike normal.

C. Kernels hulled.

D. Spike with parallel sides.

E. Spike weak, narrow.

F. Spike yellow.

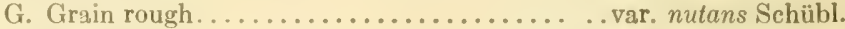

GG. Grain smooth. ...................... var. medicum Kcke.

FF. Spike blackish. . . . . . . . . . . . . . . var. nigrescens Keke.

FFF. Spike black.

G. Grain rough . . . . . . . . . . . . . . . var. nigricans Sér.

GG. Grain smooth..................... var. persicum Keke.

EE. Spike thick, short.

F. Yellow. . . . . . . . . . . . . . . . . . . . var. erectum Schübl.

FF. Black............................. contractum Kcke.

DD. Spike becoming smaller at point.

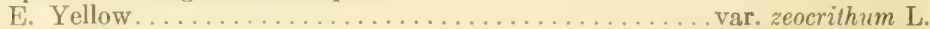

EE. Black. . . . . . . . . . . . . . . . . . . . . . . var. melanocrithum Kcke.

CC. Kerncls naked. ................................... nadum L.

BB. Spike abnormal.

C. Spike simple.

D. Flowers of side spikelets normal.

E. Outer glumes of middle spikelet normal......... var. heterolepis Kcke.

EE. Outer glumes of middle spikelet short lanceolate.... var. Braunii Kcke.

DD. Flowers of side spikelets entirely degenerated.

E. Outer glumes of middle spikelet short lanceolate.

F. Yellow . . . . . . . . . . . . . . . . . . . var. abyssinicum Sér.

FF. Black............................... mar. macrolepis A. Br.

EE. Outer glumes of middle spikelet normal.

F. Yellow. . . . . . . . . . . . . . . . . . . . var. deficiens Steud.

FF. Brown. .......................... Séringei Keke.

FFF. Black. ......................... . Steudelii Kcke.

CC. Spike branched.

D. Side spikelets normal . .................... var. compositum Keke.

DD. Side spikelets not normal . . . . . . . . . . . . . . var. ramosum Hochst.

AA. Rhachis at maturity falling apart................. var. sponlaneum C. Koch 
Under the preceding classification Körnicke brought together and described in detail 103 sorts which varied widely in structure and also in adaptation. Some of the varieties given in the classification were not represented in his collection, while others were represented by many sorts or subvarieties. Since its publication the grouping given by this author has been considered the best one on the subject of barley varieties. In general the treatment given is very satisfactory and has been sufficient in most cases to establish varieties on a firm basis. The most apparent weakness in the scheme is in the treatment of the main groups, where a clivision of the six-rowed form is made on the arrangement of the rows of spikelets. The characters given the most weight by this author in the subdivisions are: adherence of the lemma and the palea to the caryopsis, shape of the outer glume, color of the grain, shape of the grain, shape of the spike, roughness or smoothness of the grain, and character of the rhachis. Two later papers by Körnicke (1895 and 1909, the latter published posthumously by his son, M. Körnicke) appeared, neither of which adcled anything of value to the previous paper; in fact, they lacked the clearness that was evident in the earlier publication.

Voss (1885), in the same year as that in which the Handbuch des Getreidebaues appeared, also published a classification of barleys. Voss considered all cultivated varieties as one species, and followed Jessen (1855) in using Hordeum sativum as the species name. The subspecies, varieties, and subvarieties used by Voss are as follows: ${ }^{3}$

A. All flowers perfect and fertile.....................subspecies polystichon Döll.

1. Six-rowed barleys . .................................. hastichon L. a. Spikes white .................................. subvar. album b. Spikes black................................ subvar. nigrum

2. Parallel barleys................................... parallelum Kcke. a. Spikes white.................................. subvar. album b. Spikes black................................ subvar. nigrum

3. Unequal or odd-rowed barleys....................... var. inaequale Voss a. Spikes white................................. subvar. album b. Spikes black.................................. subvar. nigrum

4. Hull-less barleys. ................................ var. coeleste L. a. Erect barleys............................... subvar. erectum Voss b. Lax barleys.................................... subvar. flaccidum Voss c. Hooded barleys............................. subvar. trifurcatum Sér.

AA. Only the middle flowers fertile, side flowers staminate; two-rowed barleys.

a. Spikes white $\ldots \ldots \ldots \ldots$ var. zeocrithon $\mathrm{L}$.

b. Spikes black ........................................ subvar. nigrum

${ }^{3}$ Translated from the original German. 
6. Erect barleys............................... erectum Schübler

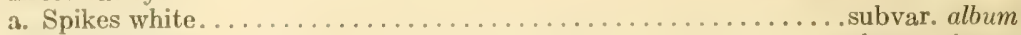

b. Spikes black............................................. nigrum

7. Nodding two-rowed barleys......................... nutans Schübler

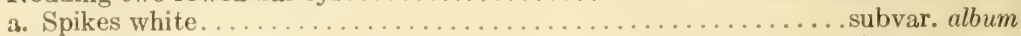

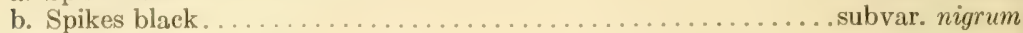

8. Naked two-rowed barleys.......................... var. nudum L.

AAA. Only the middle flowers fertile, side flowers entirely lost or stunted; deficient barleys.

subspecies deficiens Steud.

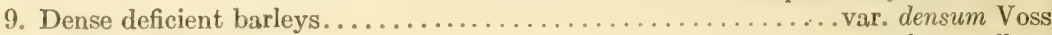

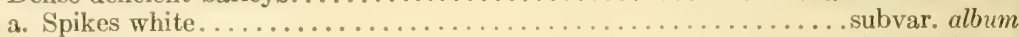

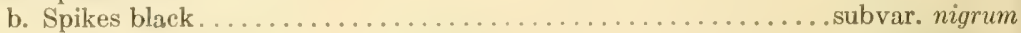

10. Loose deficient barleys. . . . . . . . . . . . . . . . . . . . . . . var. laxum Voss

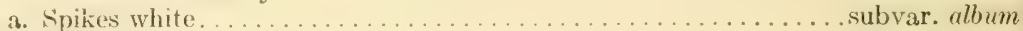

b. Spikes black............................................ nugrum

11. Wide deficient barldys............................ platylepis Voss

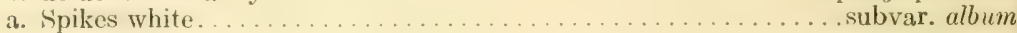

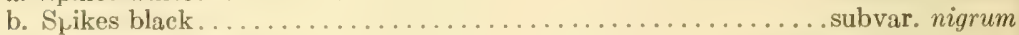

12. Long deficient barleys. . . . . . . . . . . . . . . . . var. macrolepis $\mathbf{A}$. Br.

a. Spikes white. . . . . . . . . . . . . . . . . . . . . . . subvar. album

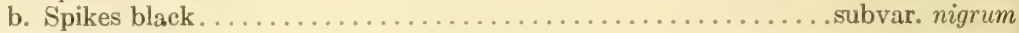

In the separation of his main groups Vuss used only one character, that of fertility, of which he recognizes three degrees. This is a decided advance over the group separation given by Körnicke, although the treatment of varieties by Voss is much inferior to that of Körnicke. In making varietal differences, Voss uses the following characters: shape of spike, arrangement of rows of spikelets, and color.

Atterberg. working from 1889 to 1899 , published several papers on barley classification, but it was not until 1899 that he presented anything differing materially from the work of previous investigators. In 1899 he published his Die Varietäten und Formen der Gerste, wherein he departed radically from the established systems. In designaing 188 forms he used only 33 different terms. He followed Jessen in placing all cultivated varieties in one species, Hordeum satimum. His scheme is as follows: ${ }^{4}$

\section{Subspecies (Unterarten) of Hordeum sativum}

A. Middle spikelets awned.

B. Glumes small.

Hordeum sativum commune

BB. Glumes large, about the length of the ripe grain, awns not considered.

AA. Middle spikelets awnless or hooded.

H. sat. macrolepis

B. Middle spikelets hooded. . . .

H. sat. furcatum

BB. Middle spikelets awnless. . . . . . . . . . . . . . . . . . . . . sat. inerme

\footnotetext{
4 Translated from the original German, but rearranged in the standard form for keys.
} 
Each subspreies was divided into the following groups (Abarten):

A. Glumes remaining attached to caryopsis at maturity.

B. Grains light-colored..................................... album

BB. Grains dark-colored. ............................... nigrum

AA. Glumes lost from caryopsis at maturity.

B. Grains light-colored ...................................... nudum

BB. Grains dark-colored . . . . . . . . . . . . . . . . . . . . . . . . . . . .

Each group was then divided into the following varieties:

A. All six spikelets fertile.

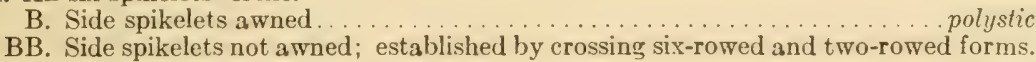

AA. Side spikelets infertile.

muticum

B. Glumes small, short, linear ........................... distichum

BB. Side spikelets rudimentary; outer glumes lacking or almost lacking; only small

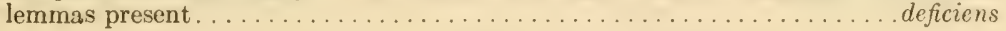

The varieties of six-rowed barleys were each further divided into the following subvarieties:

A. Average length of rhachis internode, $1.7-2.1 \mathrm{~mm}$. Spike very dense.... hexastichum AA. Average length of rhachis internode, $2.1-2.8 \mathrm{~mm}$. Spike average density . . parallelum AAA. Average length of rhachis internode, $2.7-4.0 \mathrm{~mm}$. Spike loosely formed ......vulgare

The varieties of two-rowed barleys were each further divided into the following subvarieties:

A. Average length of internode, $1.7-2.1 \mathrm{~mm}$. Spikes very thick ........... zeocrithum AA. Avcrage length of internode, $2.1-2.9 \mathrm{~mm}$. Spikes usually standing upright . . erectum AAA. Average length of internode, $2.8-4.0 \mathrm{~mm}$. Spikes loose, generally nodding at maturity. nutans

In the formation of his four subspecies, Atterberg used both the terminal appendage and the character of the outer glumes. Further divisions were made on color, adherence of lemma to caryopsis, fertility, shape of outer glumes, length of internodes, and density of spike. To make lesser groups than those given above, he used the character of the base of the kernel, the basal bristle, rough and smooth awns, and color.

This scheme of clasisification shows a familiarity with a wider range of types than does the work of any previous investigator. Atterberg could not have followed the systematic arrangement had he not possessed a collection in which the lesser factors constantly reappeared in important groups. The objection to the system is that confusion is bound to oceur (1) in the division of the subspecies and (2) in the repetition of the same terms in all the subdivisions, even though there are only 33 terms used. 
Atterberg considers the designation of 188 varieties by only 33 different terms as a decided improvement over previous elassifieations, but this seems to be a doubtful advantage.

In connection with the work of Atterberg, the Swedish, or Svalö, system of classification should be considered. Atterberg himself in 1859 laid the foundation for this system of elassification. His work was subsequently improved upon by Neergaard (1889), but it remained for Bolin (1893) to perfect the system and put it into practice. The system which Bolin worked out at that time has been used in Sweden ever since for the identification of the important varieties. Briefly the system is as follows: ${ }^{5}$

A. Two-rowed barley; all keinels broadest in the middle and symmetrical in contour.

B. Dorsal side of base of kernel with a slight horseshoe-like excavation or depression.

C. Rhachillae and lodicules long-haired.

Hordeum distichum nutans

D. Lateral nerves without teeth........................ Type $I$

DD. Lateral nerves with teeth.............................. Type II

CC. Rhachillae and lodicules short-haired, more or less woolly.

D. Lateral nerves without teeth........................ Type III

DD. Lateral nerves with teeth ........................ Type IV

BB. Dorsal side of base of kernel not exeavated but often pinched with a transverse crease or furrow............................. distichum erectum

C. Rhachillae and lodicules long-haired.

D. Dorsal nerves without teeth....................... Type $V$

DD. Dorsal nerves with teeth ................................. Type VI

CC. Rhachillae and lodicules short-haired, more or less woolly.

D. Dorsal nerves without teeth......................... Type VII

DD. Dorsal nerves with teeth......................... Type VIII

AA. Six-rowed barley; all kernels from outer rows of head slightly twisted; kernels from middle rows symmetrical but broadest nearer the tip, the bas sal half being somewhat elongated ....................................... tetrastichum pallidum

B. Rhachillae and lodicules long-haired.

C. Lateral nerves without teeth.

CC. Lateral nerves with teeth.

BB. Rhachillae and lodicules short-haired, more or less woolly.

C. Lateral nerves without teeth......................... Type XI

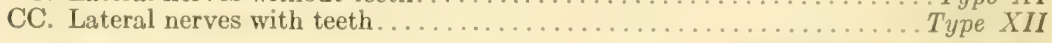

The great additions made by the investigations of these men were the diseoveries of the stable characters of the rhachilla, or basal bristle, and the lateral nerves. These two discoveries marked a real advance in the matter of barley classification. Many other studies were made on minor differences in varieties, which were not found to be constant.

Some years later (1906) Broili published a elassification of two-rowed barleys in which he used the svalof system to a very large extent, adeling

${ }^{5}$ Rearranged in the standard form for keys. 
little to the previous work. He, however, eriticized the Svalö investigators in regard to the constancy of the characters of the rhachilla and the dorsal nerves. This eriticism has been shown by subsequent investigators to be without foundation.

Beaven (1902) presented the first comprehensive classification of barleys in English. The main groups which he considered under the one species, Hordeum sativum, are as follows:

A. All spikelets fertile.

B. All spikelets normal.

C. Spike wide with short internodes................ Hordeum hexastichum L.

CC. Spike narrow with long internodes.......... vulgare L; H. tetrastichum Keke.

BB. Spikelets of median rows normal, spikelets of four lateral rows diminutive and without awns ............................. intermedium Koke.

C. Spike wide, with short internodes........................ var. Haxtoni

CC. Spike narrow, with long internodes..................... var, transiens

AA. Only the median spikelets fertile.

B. Four lateral rows infertile or staminate.

C. Spike wide, with short internodes........................ zeocriton L.

CC. Spike narrow, with long internodes..................... distichum L.

BB. Four lateral rows rudimentary and without floral organs (several Abysinian

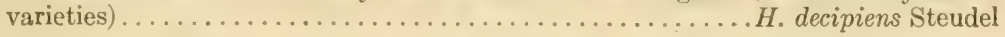

In his main divisions Beaven used these characters: fertility and width of spike, and length of rhachis internode. He used the name $I$. iulgare L. for $H$. tetrastichum Kicke., and divided the two-rowed barleys into zeocriton. L. and distichum L. to correspond with the two forms of six-rowed barleys. He did not make a division of the decipiens group. In his description of varieties he used character of the spike (normal or abnormal), shape of the spike, color of the grain, terminal appendage, and character of the awn. His varietal descriptions include many recently developed varieties, especially those of Karl Hansen, which in several cases were not yet well established.

Regel (1906, 1908, 1910) differed from earlier workers (1) by basing his minor groups on races varying somewhat in envirommental adaptations, (2) by recognizing only two densities, (3) by considering blue and purple as forms of white varieties, and (4) by making smooth awns a very minor character.

Harlan (1914) made a study of barleys somewhat paralleling that of the Svalöf investigators. He made no classification, but gave the characters that are of taxonomic value a thorough study. He was able to verify the findings of many previous investigators its to the value of certain 
characters in classification as well as in genetic studies. Probably the most important addition to the knowledge of barleys which he gave was that in regard to pigmentation, which is reviewed later, in the discussion of the morphology of the barley plant.

The grouping suggested by Carleton (1916) is as follows:

Hordeum $\left\{\begin{array}{l}\text { spontaneum, K. Koch, distichum, Linn., two-row barley. } \\ \text { polystichum, Döll }\left\{\begin{array}{l}\text { vulgare, Linn., common or nodding six-row barley. } \\ \text { intermedium, 'Keke., hybrid barley. } \\ \text { hexastichum, Linn., club or erect six-row barley. }\end{array}\right.\end{array}\right.$

Carleton mentions one other type, Hordeum distichum deficiens, of which there are two forms, but he does not consider it as one of the main groups. Under each of the above groups (arleton separated varicties by the use of the following characters: fortility, color of the grain, shape of the spike, character of the awns, and habit of early growth. He gives only a brief consideration to the general classification, and contributes little to previous works.

A little later (1918) Harlan presented a classification which is to be commended in many respects. This is given here in detail:

Key to the species

All spikelets fertile (6-row barley).

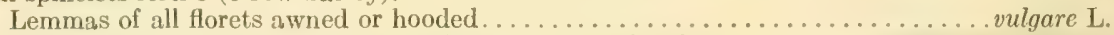

Lemmas of lateral florets bearing neither awns nor hoods.......... intermedium Kicke.

Only the central spikelets fertile (2-rowed barley).

Lateral spikelets eonsisting of outer glumes, lemma, palet, rachilla, and usually rudiments

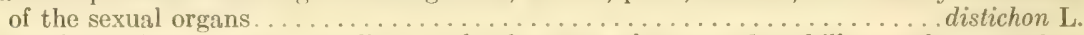

Lateral spikelets reduced, usually to only the outer glumes and rachilla, rarely more than one flowering glume present, and never rudiments of sexual organs...... deficions Steud.

This scheme is founded on the one character fertility, that of density being eliminated entirely. It likewise considers barley as consisting of four distinct species, on the grounds (1) that clearness is better secured by making the species a smaller unit, (2) that no group of wild plants of such wide variation is united under a single species, and (3) that there is abundint evidener that at least two parents were involved in the production of the forms now domesticated. The only diffieulty in separating the main groups comes in a few cases in which the variety is more or less intermediate in character. As Harlan has pointed out, 
this condition arises very seldom in the existing varieties. It may, however, cause difficulty in the future as the number of varieties increases. By the use of the adherence of the lemma and the palea to the caryopsis, the terminal appendage of the flowering glume, and the color of the grain, Harlan has describer eight varieties in each of his species as follows:

Hordeum vulgare.

Key to the varieties

Kernels hulled.

Lemmas awned.

Tiernels white, blue, or purple. . . . . . . . pallidum.

Kernels black. . . . . . . . . . . . . n. . . . . . . . . .

Lemmas hooded.

Kernels white, blue, or purple...................... horsfordianum.

Iiernels blirk. . . . . . . . . . . . . . . . . . . . . . . 4. atrum.

Kernels naked.

Lemmas awned.

Kernels white, blue, or purple................ 5. coeleste.

Kiernels black.

6. duplinigrum.

Lemmas hooded.

Kernels white, blue, or purple................. 7. trifurcatum.

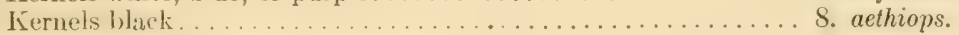

Hordeum intermedium.

Kernels hulled.

Lemma of central floret awned or awnless.

Kernels white, blue, or purple................ 9. haxtoni.

Kernels blick. . . . . . . . . . . . . . . . . . . . . . . .10. mortoni.

Lemma of central floret hooded.

Kernels white, blue, or purple........................ subcornutum.

Kernels black. . . . . . . . . . . . . . . . . . . . . 12. atricornulum.

Kernels naked.

Lemma of central floret awned or awnless.

Kernels white, blue, or purple.................. nudihaxtoni.

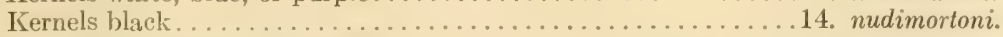

Lemma of central floret hooded.

Kernels white, blue, or purple......................... cornutum.

Kernels black..................................... subaethiops.

Hordeum distichon.

Kernels hulled.

Lemmas awned or awnless.

Kernels white, blue, or purpie.................... palmella.

Kernels black. .............................. nigricans.

Lemmas hooded.

Kernels white, blue, or purple...................... angustispicatum.

Kernels black. .................................. rimpaui.

Kernels naked.

Lemmas awned or awnless.

Kernels white, blue, or purple.................. nudum.

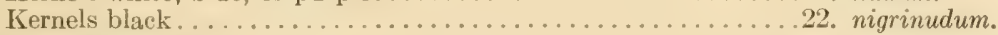

Lemmas hooded.

Kernels white, blue, or purple.................... laxum.

Iiernels black.

24. nigrilaxum. 
Hordeum deficiens.

Kernels hulled.

Lemmas awned or awnless.

Kernels white, blue, or purple.................. deficiens.

Kernels black. . . . . . . . . . . . . . . . . . . . . . 26. steudelii.

Lemmas hooded.

Kernels white, blue, or purple.................. triceros.

Kernels black. . . . . . . . . . . . . . . . . . . . . 2S. tridux.

Kernels naked.

Lemmas awned or awnless.

Kernels white, blue, or purple................... 29. nudideficiens.

Kiernels black

30. decorticatum.

Lemmas hooded.

Kernels white, blue, or purple...................... sublaxum.

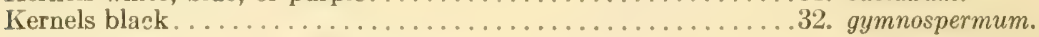

For further divisions within the thirty-two varieties, Harlan used wilth of the outer glume, color of the kernels, character of the awns, density, and width and attitude of spike, in the order named. Thus, density, which has been given such an important place in all previous classifications, is here used only for a minor varictal distinction. No attempt is made in this publication by Harlan to distinguish eommercial varieties.

\section{NUMBER OF SPECIES}

Although there is a consensus of opinion that fertility should be used as one, if not the only, character in making up the main groups of barley, there is by no means the same harmonious agreement in regard to the number of species. (On the one hand, there is a group consisting of Linnacus (175:3), Schübler (1818), Séringe (1819), ('arleton (1916), and Harlan (1918), who have considered cultivated barleys as forming from three to seven species; on the other hand, Jessen (1855), Körnicke (1885), Voss (1885), Atterberg (1899), and Munro and Beaven (1900), have preferred to group all barleys under one species.

In general, species in cultivated crops should be based on their origin, as far as is possible. This general rule cannot be followed absolutely because of the uncertainty in regard to the progenitors of many groups of plants. After the species have been established, the subspecies and the groups should if possible be based on the order of evolution. This, like the establishment of the species, is uncertain to a large degree, and thus the classification becomes more and more artificial.

In the establishment of species in the case of barleys, the very earliest classifications cannot have much weight because of the smallness of the 
collections and the lack of research in regard to their origin. Körnicke was the first to present the theory that all domesticated barley originated from one wild species, Hoideum spontaneum, and on this basis he made one species, Hordeum vulgare. Jessen, however, had previously considered all barley to belong to one species, Hordeum sativum Jess. Voss, Atterberg, and Beaven. following Körnicke's theory, considered barley as only one species but followed Jessen in terminology. In more recent years considerable evidence has been produced which indicates at least two wild ancestors for cultivated barley. The best discussion of this subject is by Schulz (1913), who presents the theory that by the accumulation of several small variations from the wild species $H$. spontaneum, a new wild species, $H$. ischnatherum, was produced which is widely distributed in the Tigris-Euphrates region. This form as it is found presents several variations in the charicters of side spikeicts, just as does the wild species $H$. spontaneum, but in general it is much nearer the six-rowed type than is $H$. spontaneum. Schulz offers the further theory that by the accumulation of still more variations from $H$. ischnatherum, the cultivated forms of the six-rowed barleys have been derived, and in a similar manner the cultivated forms of the two-rowed barleys also have been derived from $H$. spontaneum. His opinion in regard to the origin of the intermediate forms between the common six-rowed and the common two-rowed barleys is that they arose by crossing. He thinlis that the deficient forms arose directly from H. spontaneum, and not from any cultivated forms of two-rowed barleys.

\section{SUMMARY}

From the foregoing review of the various classifications, the progress after Linnaeus may be briefly summarized as follows:

1. The division of Hordeum distichon $L$. into $H$. erectum and $H$. nutans by Schübler.

2. The grouping of all barley varieties into one species by Jessen.

3. The conception of the variety as a unit, by Körnicke, and the establishment of a large number of varieties on a firm basis. (Körnicke's main groups, however, were not an improvement over the groups previously established.)

t. The new system of Atterberg, whereby 188 varieties were designated by the use of 33 terms. (It is doubtful whether this was an advance.) 


\begin{tabular}{|c|c|c|c|c|c|c|c|c|c|c|c|}
\hline 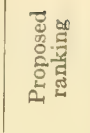 & 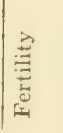 & 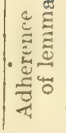 & . & 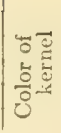 & 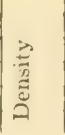 & 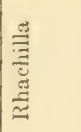 & 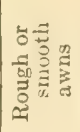 & 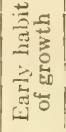 & 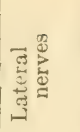 & 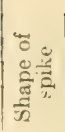 & نَّ \\
\hline 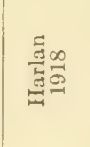 & 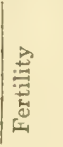 & 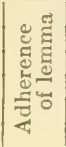 & 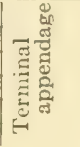 & 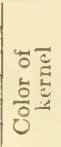 & 苛莺 & 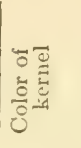 & 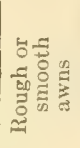 & 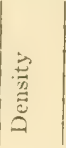 & 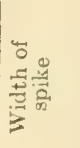 & 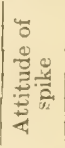 & \\
\hline 茪 & 志 & 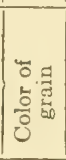 & 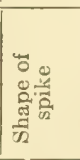 & 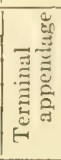 & 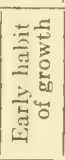 & & & & & & \\
\hline 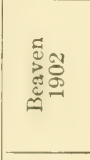 & 总 & 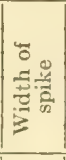 & 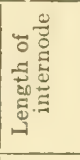 & 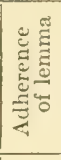 & $\begin{array}{l}\square \\
0 \\
0 \\
0 \\
0 \\
0\end{array}$ & 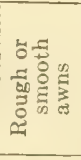 & $5^{\frac{8}{3}}$ & 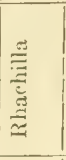 & & & \\
\hline 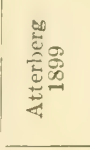 & : & | & 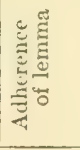 & $\begin{array}{l}0 \\
0 \\
0 \\
0 \\
0\end{array}$ & 竞 & 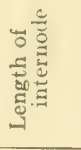 & 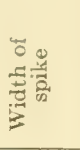 & 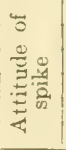 & 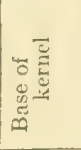 & 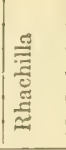 & 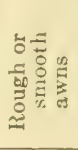 \\
\hline 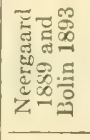 & 总 & 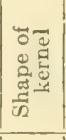 & 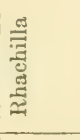 & 氙 & & & & & & & \\
\hline $\begin{array}{r}2 \\
0 \\
0 \\
-\infty \\
-\infty\end{array}$ & 恚 & 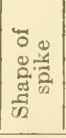 & 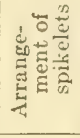 & 它 & & & & & & & \\
\hline 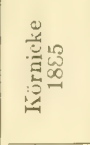 & 总 & $\mid$ & 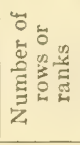 & 莺 & $5^{\frac{e^{2}}{3}}$ & 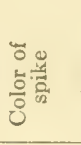 & 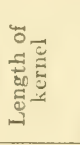 & 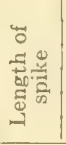 & 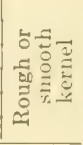 & 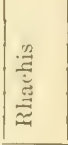 & \\
\hline$\frac{0}{n=0}$ & 言 & $\stackrel{\breve{z}}{3}$ & 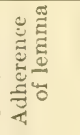 & & & & & & & & \\
\hline 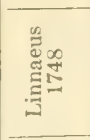 & 言 & 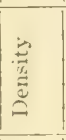 & 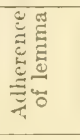 & & & & & & & & \\
\hline 崖 & - & $\therefore$ & $\infty$ & $\Rightarrow$ & $\therefore$ & 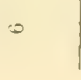 & is & $\infty$ & c. & 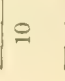 & $=$ \\
\hline
\end{tabular}


5. The classification of cultivated varieties by Beaven, wherein the treatment of the main groups was superior to that of Körnicke.

6. The discovery by Neergaard of the stability of the long- and the short-haired rhachillas, and the smooth and the barbed lateral nerves.

7. The rescarches of Harlan in regard to pigmentation in barleys.

8. The reclassification of barleys by Harlan wherein the main groups were established on the basis of fertility alone.

The relative weight given the different characters by the various investigators are summarized in the table on the opposite page. It is seen that there is a very marked lack of agreement in the use of the various characters for classification purposes, with the one exception of fertility, which is used as a basis of separation for the main groups or species in every case but one.

\section{MATERIAL USED IN THE PRESENT CLASSIFICATION}

In the present study 627 specimens were under observation, many of which were alike in name and in all observable morphological characters. These so-called varieties were largely collected in 1915 by Professor E. C. Montgomery, of Comell Lniversity, for the purpose of classification. The most valualble individual collections were those obtained from the California Experiment Station at Berkeley, California, the E. Clemens Horst Company of San Francisco, and the Okonomisch-botanische Garten of Halle University in Ciemany. From these three sources alone an aggregate of 475 specimens wre obtained, including all the types of any economic importance and practically all the rarer types. This original collection has been enlargei by additions from the Department of Plant Breeding at Comell University, from the Office of Foreign Seed and Plant Introductions and the Office of Cereal Investigation of the United States Bureau of Plant Industry, from the state agricultural experiment stations, particularly those of Virginia and Wisconsin, and from other minor sources, all of which have aided materially in completing the collection.

The collection has been in the hands of the writer since 1915 and has been grown each year in rod rows, one foot apart. Since yield was not a factor in the present study, the rate of planting was adjusted in all cases so that good development of individual plants might be obtained. 


\section{MORPHOLOGY OF THE BARLEY PLANT}

The first thing necessury in making a key for a mroup of plants is a detailed study of the morphological characters of the plants. This sturly is necessary for two reasons - to acquaint the investigator with the plants with which he expects to work, and to learn the characters that are not influenced by envirommental conditions. These are the characters that must be given the important places in the classification. Therefore a consideration of the morphologieal characters is of much importance in this paper. The various discussions herein not only include a deseription of the individual characters, but also consider their value taxonomically and the use made of them in the present and in previous classifications. However, the relative taxonomic value of the various characters is not given any weight in the arrangement of this section.

The morphologieal characters as discussed herein are divided into threo groups and are treated according to the following order: gross characters, spike characters, and spikelet characters.

\section{GROSS CHARACTERS}

The gross characters of barley, which include color, shape, and size of the leaves, number and size of cuhns, roots. and some other characters, are the least valuable among the three groups of characters from a taxonomic standpoint. The differenees in these characters are usually not sufficient to warrant taxonomie divisions. Furthermore, they are the most variable of all the chatacters under different envirommental conditions. Their chief value is to be found in varietal descriptions.

\section{Foliage}

The foliage of barley varieties presents a rather wide range of variations, all of which are difficult not only to deseribe but also to recognize. Viariations oceur in color, length, wilth, and number of leaves. Förnicke (1855), in his varietal descriptions, used four sharles of green bright, dark, bluish, and yellowish. Diffeulties immediately arise in such descriptive terms, because the personal factor is ton great in describing or recognizing such a character for it to have much value. Other investigators have recognized difficulties in using such characters, and as a 
consequence have used color of foliage with much precaution. The length and the width of the leaves are variables which, like color, are largely dependent on environment and are limited in their use in the same way. For them to be of any value, accurate statistical work must be done. As a rule, when significant differences are found, it is between the larger groups, where no such detailed observations are necessary for the distinction. The most marked variation in leaves is between the spring and the winter harleys, which are discussed later. The variation in the number, exclusive of the basal leaves, is identical with the number of nodes, which is discussed in connection with culm characters.

\section{Culm characiers}

The culms of barley. vary in several characters, but, in general, greater variations are produced by different environments than exist between closely related forms. For this reason these variations are, like the variations in the foliage, of minor importance in classification. Their only value is in varietal description. Such characters as height of the plant, number of culms to the plant, diameter of the culms, thickness of the culm wall, number of nodes, and length of the last internode, have been used more or less extensively in descriptions. Körnicke (1885, 1895, and 1909) made use of many varying vegetative characters in descriptive work.

\section{Height of plant}

The height of certain varieties in a particular locality varies as much as 100 per cent and for this reason may be of importance locally, but these same varieties grown in another region may have a reverse relationship in regard to height. This has been well shown by Harlan, who in 1911 selected thirteen pedigreed barleys representing a wide range of types and planted them at four widely separated points. He found a marked regional response For example, Odessa was short and unpromising in Minnesota and little better in California, but was very tall and vigorous in both Montana and North Dakota. The Abyssinian varieties, on the contrary, grew well in California but were very short elsewhere, as is seen from the accompanying table taken from Harlan (1914): 
Influence of Geographical Location on the Length of the Culm in 13 Representative Selections of Bardey Grown at Folr Widely Separated Points, the Selections Being Arranged in the Order of Their Height at Each Point

\begin{tabular}{|c|c|c|c|}
\hline $\begin{array}{l}\text { St. Paul, } \\
\text { Minnesota }\end{array}$ & $\begin{array}{l}\text { Williston, } \\
\text { North Dakota }\end{array}$ & $\begin{array}{l}\text { Moccasin, } \\
\text { Montana }\end{array}$ & $\begin{array}{l}\text { Chico, } \\
\text { California }\end{array}$ \\
\hline 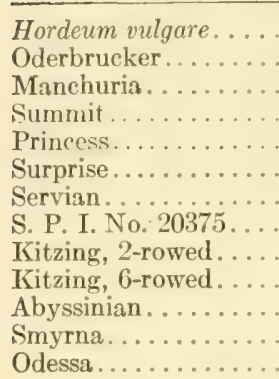 & 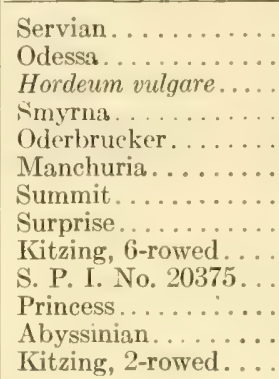 & 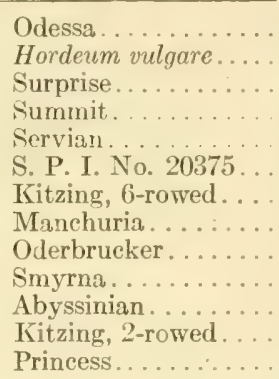 & $\begin{array}{l}\text { S. P. I. No. } 20375 \\
\text { Oderbrucker } \\
\text { Abyssinian } \\
\text { Servian } \\
\text { Simyrna } \\
\text { Manchuria } \\
\text { Summit } \\
\text { Odessa } \\
\text { Kitzing, 6-rowed } \\
\text { Princess } \\
\text { Kitzing, 2-rowed } \\
\text { Surprise } \\
\text { Hordeum vulgare }\end{array}$ \\
\hline
\end{tabular}

\section{Length of last internode}

The relation of the spike to the leaf sheath depends entirely on the length of the last internode - the one on which the spike is borne. The shorter the last internode, the less the spike will be exserted. The failure of the spike to be exserted from the leaf sheath has been used repeatedly in describing such barleys as the Smyrna and Prineess varieties. The fact that this character oceurs in the same varieties in widely differing localities is evidence enough that it is a true rarietal character, but there is considerable variation within the variety. It is, however, characteristic enough in a few instances to determine a variety. In the present classification the length of the last intemode is used in varietal descriptions.

\section{Number of nodes}

The number of nodes varies from three to seven in difierent varieties, but in all cases there is sufficient variation within the varieties to cause an overlapping, thus making the character uncertain. The number of leaves to a culn is identical with the number of nodes and consequently varies in the same way.

\section{Roots}

So far as it was deiermined, there are no varictal differences of roots that can be employed in classification. The ratio between tops and roots 
may vary to some extent between varieties, but similar variations occur within the rariety as a result of local conditions. Consequently, root characters are of no value either for classification or for descriptive purposes.

\section{Habit of plant in early growth}

The habit of the plant in early growth is very important because it is by this character that spring and winter varieties are separated. The difference appears both in the number and the attitude of the culms and in the number of leaves. The ordinary spring varieties of barley have a small number of culms which stand erect at all stages of growth, and only a few hasal leaves. Winter varieties, on the other hand, have a large number of eulms and leaves which are more or less decumbent during the early part of the development of the plant. It is at this stage that such rarieties pass the winter period. In the spring, when new growth begins, a few of the many eulms elongate, producing the flowering stalks and the grain of the plant, while the others remain undeveloped and sooner or later disappear as a vital part of the plant.

If these same varieties are seeded in the spring, a large tuft of leaves and very short culms are produced early in the season. The plants will remain at this stage for a considerable period before the flowering stalks are produced; in some cases, in fact, the flowering stalks entirely fail to appear, while those that do appear are usually infertile or produce very little grain. For this reason, it seems that a dormant period is needed for the proper development of these varieties.

An intermediate condition, which may be called semi-erect, is also found in some varieties, in which the number of culms and leaves is above the average for barleys and the culms tend to spread out to some extent. All of such varieties are, however, spring varieties. This character can be used only in varietal description.

The distinction between winter barleys and spring barleys was made by Kiörnicke (1885) and by Carleton (1916) in describing varieties, but has never been used as an important distinction between large groups of varieties. In the present classification the habit of the plants in early growth is used only in minor separations. 


\section{Emergence of awns and spikes}

The date at which the head appears is a note that has been generally taken by all burley breeders as well as by those studying varietal differences. Nore recently this has been replaced by a note on the date of appearance of the awns. Harlan (1914) showed that the latter is more nearly accurate and easier to obtain than the former. This has proved to be true in the present investigation. The only objection to using the date of the emergence of the awns, instead of the date of the appearance of the head, is that hooded and awnless varieties cannot be compared with awned varieties. This is not a serious objection, however, as this character can be used only to distinguish strains within a variety. The relationship of strains in this regard varies with the locality. In the few cases of awnless and hooded varieties, it is necessary to use the date of the appearance of the spike as the distinguishing character. The date of appearance of either the awn or the spike is so variable that it has no taxonomic value.

\section{Time of maturity}

Ordinarily the time of maturity is correlated with the date of emergence of the awns, but, as is the case with most other correlated characters, some exceptions oceur. This character is of value at times, not only in distinguishing different varieties or strains in a given environment, but also in defecting mixtures in the field. A pure strain will mature all spikes within a very few days. This character is much more reliable when used in connection with early-maturing than with late-maturing varieties. Late-maturing varieties are often ripened abnormally by unfarorable weather conditions. This character is used in the present classification only in distinguishing strains otherwise similar, and in varietal descriptions.

\section{Production}

The yield of varieties, although in a given region varying from very small to very large, cannot be employed for elassification purposes because it is almost wholly dependent on enviromment. Consequently, production has no place in the present investigation.

SPIKE CHARACTERS

The characters of the spike, including variations in fertility, density, and rhachis, are far more important from the standpoint of classification 
than the gross characters already discussed. Some of these spike characters which are the most conspicuous and the easiest to recognize, have been used in all previous barley classifications. In most instances either density or fertility has been given first place in the formation of groups.

The differences in the characters of the spike are great and have been found to be constant under different environmental conditions. Recause of these facts they have proved to be of much taxonomic value, and are so considered in the present classification.

\section{Fertility}

Barley varicties, as stated above, have been divided into groups according to the fertility of the spikelets, by all investigators who have worked on their classification. The first pre-Linnaean divisions were made on this character when only two groups were recognized, the two-rowed and the six-rowed. Linnaeus likewise followed this scheme, but used in connection with it the density of the spike, thereby making four groups or species. In 1885 Steudel (cited by Körnicke, 1885) fully described a third degree of fertility, which he designated as deficiens. Körnicke (1885) recognized a fourth degree of fertility in his group, known as intermedium. Thus, four definite stages of fertility have been recognized as important in the formation of groups in the case of barley.

In order to understand the variation in fertility, it is necessary first to know the structure of the barley heal. Barley, in common with all other members of the genus Hordeum, produces three single-flowered spikelets at each node of the flattened rhachis. Structurally the spikelets are very similar, each having two outer glumes, a lemma, and a palea, which inclose the sexual organs. In all cultivated barleys, the central spikelet of the series of three at each internode is always fertile. The variation in fertility is found only in the side spikelets, which present four stages of fertility, as has already been stated. These different conditions of fertility are as follows: (1) all three spikelets equally fertile, with the lemmas of each projected into a terminal appendage, either an awn or a hood as the case may be, and with the kernels of the side spikelets almost as large as the kernels of the medium spikelets (fig. 51, A and B, and fig. $69, H$.vulgare); (2) all three spikelets fertile, but the lemmas of 


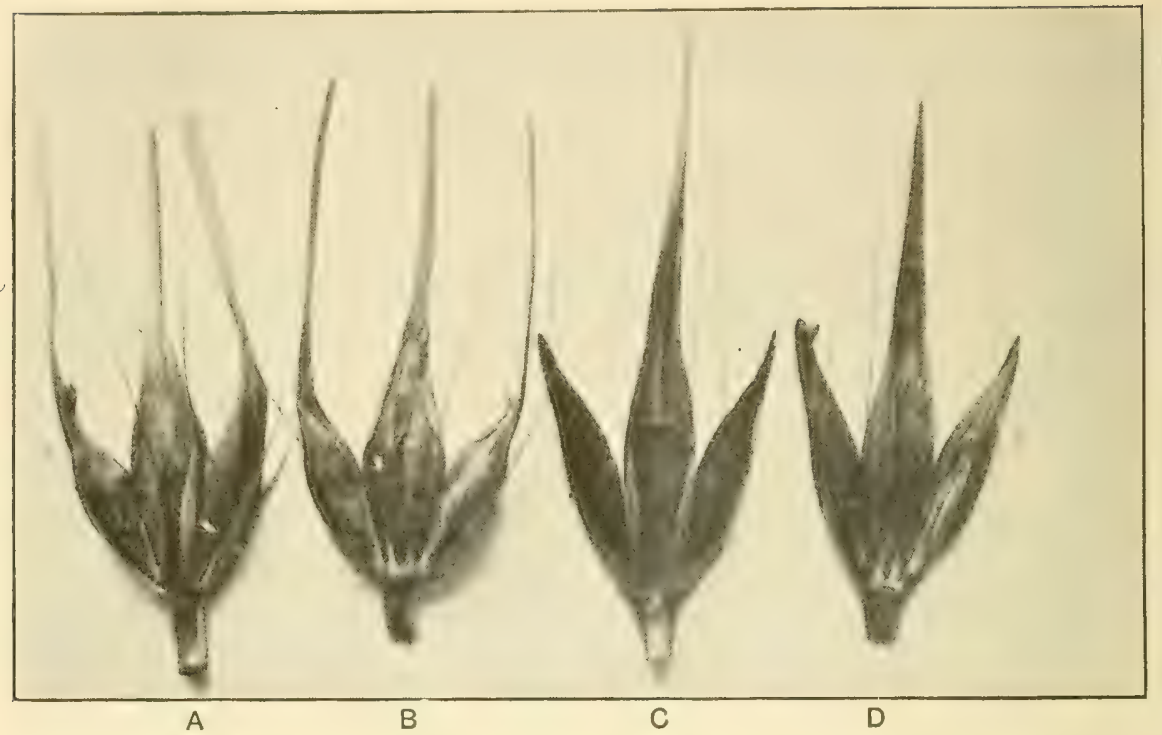

Fig. 51. TIE STRUCTURE OF SIX-ROWED BARLEYS

A. Dorsal view of perfect enndition of fertility, where all spikelets are equally fertile and awned; $B$, vontra! view of same; $C$, dorsal view of second condition of fertility, where side spikelets are fertile hut about one-half the size of median spikelets and not awned; D, ventral view of same

the side spikelets without terminal appendages, ending cither in a point or bluntly, and the kernels of the side spikelets about one-half the size of the kernels of the median spikelets (fig. 51. (' and D)); (3) the side spikelets infertile, but possessing rudimentary sexuil organs and all the structural parts of the fertile spikelets exeept the terminal appendages of the lemma (fig. 52, A and B); (4) the side spikelets infertile, without rudimentary sexual organs and with all structural parts very much reduced. In some cases, only the two outer glumes and a rudimentary rhachillat remain as evidence of the side spikelet (fig. 52, ( and D). The relative position and size of the spikelets in the various types is diagranmatically shown in figure 53.

These four conditions of fertility, previously recognized, have remained practically stable since they were first described. For this reason, and because they have been eonstantly used in all early classifications, they 
are of the greatest taxonomic value. Some intermediates between these stages have been described from time to time by different authors, especially Körnicke (18S5). Most of these which were the results of crosses have proved to be unstable and have gone out of existence as varieties. Crosses between two of the above-named conditions of fertility give in the second generation practically all steps between the two parent types, but these intermediates have proved heterozygous in future generations and have broken up in a similar manner to the original firstgeneration cross.

In the present classification, these four conditions of fertility are used as the first and most important character in the subdivision of cultivated barleys, for three reasons: (1) stability in all environmental conditions; (2) ease of recognition; and (3) weight given by all earlier investigators.

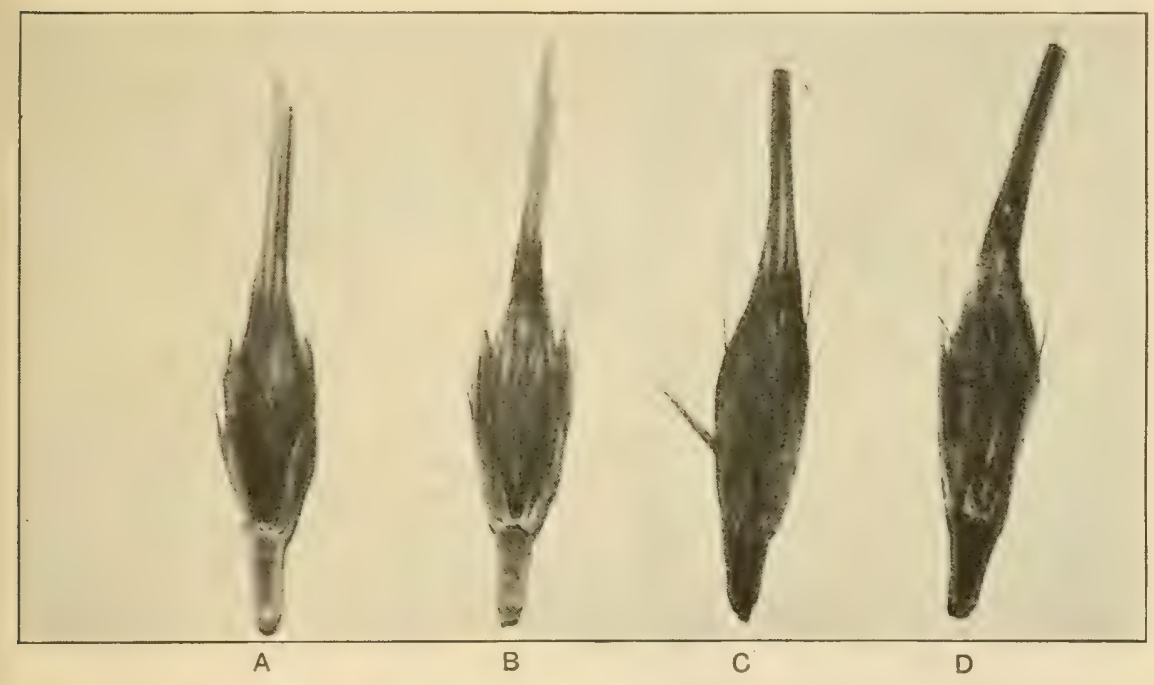

Fig. 52. The Structure of two-Rowed Barleys

A, Dorsal view of third condition of fertility, where side spikelets are infertile but possess all structural parts except terminal appendage of lemma; $\mathrm{B}$, ventral view of same; $\mathrm{C}$, dorsal view of fourth condition of fertility, where side spikelets are very rudimentary; $\mathrm{D}$, ventral view of same 


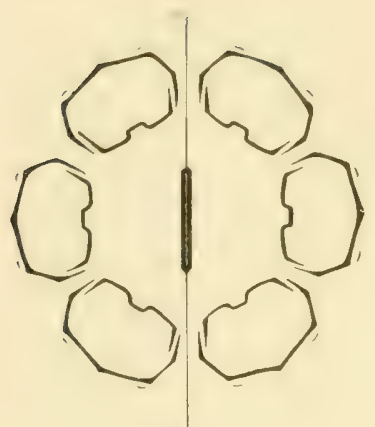

A

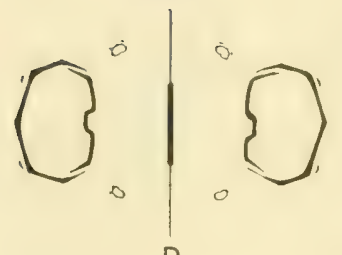

D

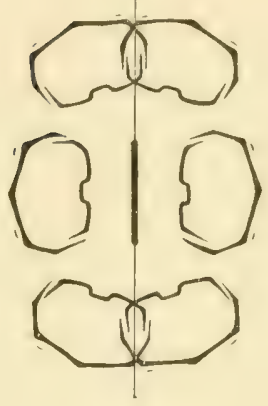

B

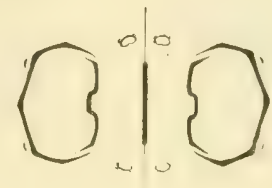

$E$
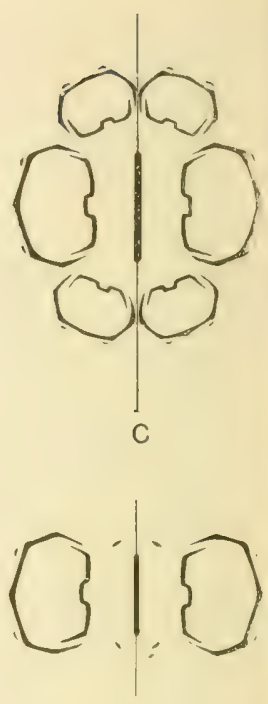

F

Fig. 53. DIAGRAMMATIC SKETCH OF CROSS SECTIONS OF SPIKES OF VARIOUS TYPES OF BARLEY A, $H$. vulgare (dense form); B, $H$. vulgare (lax form); C, H. intermedium; D, H. distichon (dense form); E, H. distichon (lax form); F, H. deficiens

\section{Branch-headed barleys}

(One other structure sometimes arises in barleys, which has caused deseriptions to be written of what were termed seven-rowed, cight-rowed, or nine-rowed barleys. Such a condition, which might be called a stagr of fertility, is brought about by repetitions of the three spikelets at a nocke. In other words, insteat of one series of three spikelets at each node of the rhatchis, there are three series (fig. 54). In the ease of the two-rowed barleys, if this oceurs regularly a six-rowed barley would be produced, but instead of only three subikelets at one internode, all of which were fertile, there would be three fertile and six infertile spikelets. If the same thing were to happen in the ease of the six-lowed barleys, an eighteenrowed barley would result. At each node of the rhachis nine kernels would appear. No instanees have been reported in which there was such a replieation at every noxle. 'The changer usually romes at or neatr the base of the spike, and at only a small number of nodes. A further deviation oceurs when a true branch is formed which bear's spikelets at 
each internode just as the main axis of the spike does. These likewise arise near the base of the spike.

Occasionally such deviations as are mentioned above are more or less constant, but more often they are found to be variable, due to environmental conditions. In either case they have no economic importance and very little taxonomic value. Consequently they are not used in the present classification as characters of importance in separating groups or even varieties.

\section{Density}

The density of the spike in barley, by which is meant the number of florets to the unit length of rhachis, has been employed by all taxonomists in the classification of barleys, in one form or another. In the greater number of cases it has been given equal weight with fertility in the formation of either species or subspecies. In fact, density has been considered by many authors as a result of varying degrees of fertility. This, however, can easily be disproved by making comparative weights of the kernels of the lateral and central spikelets of either common or erect six-rowed varieties. There is .just as much difference between these two groups of spikelets in the erect varieties as in the common. The groups according to density have generally been divided into dense and lax forms. For the sake of varietal description, Körnicke (1885) even mentioned a division of the dense forms into dense and very dense.

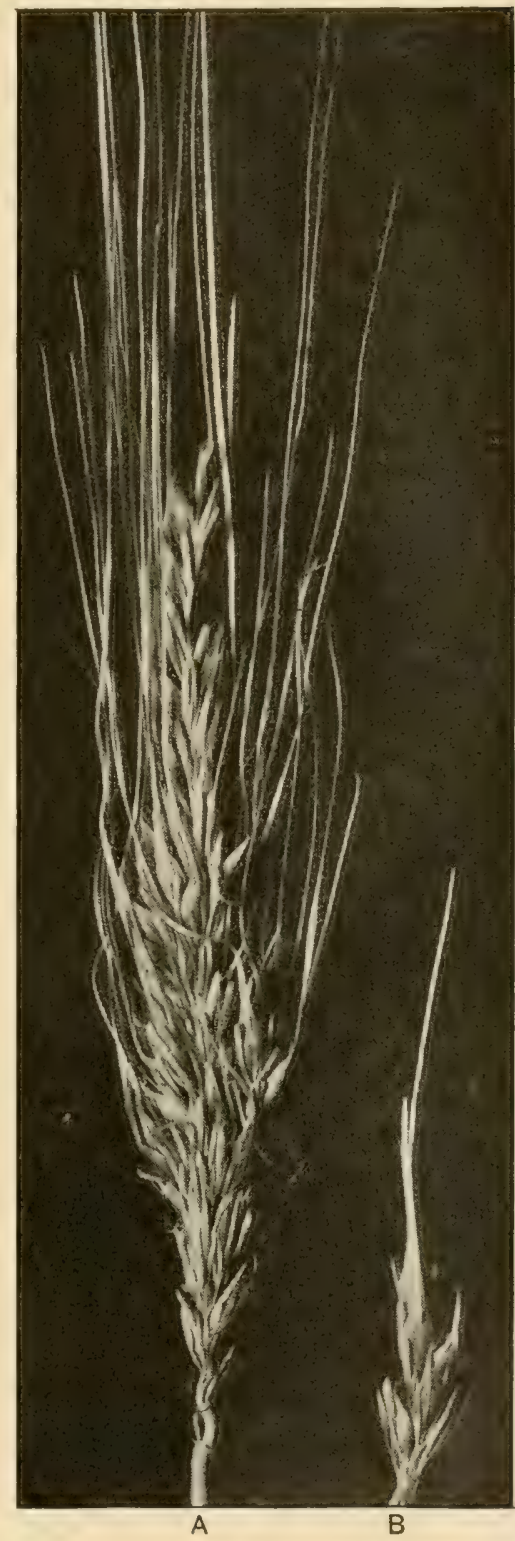

FIG. 54. TWO-ROWED BARLEY

A, Spike of branch-headed two-rowed barley; B, one internode of the rhachis with its abnormalities 
It was not until Atterberg (1899) presented his new system of classification that the density of the spike was made a character of minor importance. In the earlier works, density and fertility were given about the same weight. In Atterberg's new system, density was considered only after the characters

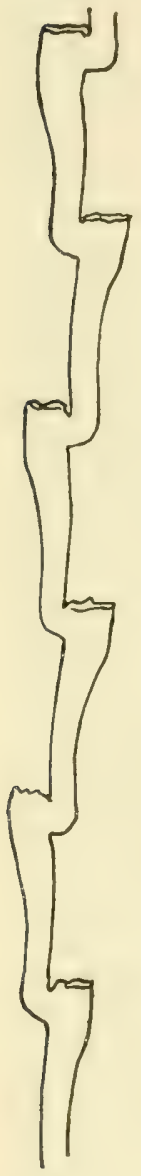

A

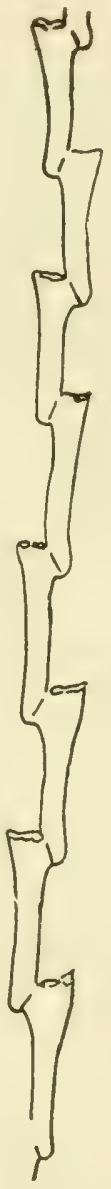

$\mathrm{B}$

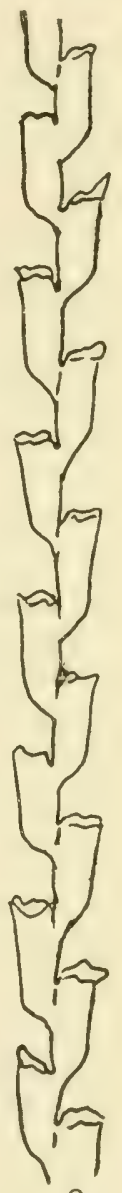

C

of terminal appendage, outer glume, fertility, and side spikelets. - Following Atterberg, both Beaven and the investigators at Svalöf went back to the old system of considering fertility and density as practically of equal importance. In Harlan's recent paper (1918), density is again employed only as a distinguishing characteristic between subvarieties.

That there is a decided variation in this character of the spike in barley varieties cannot be denied. The difficulty in the use of this character lies in the intergradations between the dense and the lax forms. In a large collection of barleys it is possible to find practically all degrees of density, from the very lax to the very dense. This difficulty has been mentioned by earlier writers. Körnicke, however, based his several subdivisions on the variation in the density of the spike. In the present classification, density is used in the separation of rather large groups of commercial varieties but is not considered as important as either fertility, adherence of glumes to the caryopsis, terminal appendage, or color.

\section{Length of internodes of rhachis}

The length of the internodes of the rhachis varies directly with, and is the deciding factor in, density. This character INTERNODES OF BARLEY OF DIFFERENT DENSITIES $(X 6)$

A, Lax; B, erect; C, very dense 
A Classification of the Cultivated Varieties of Bariet 395

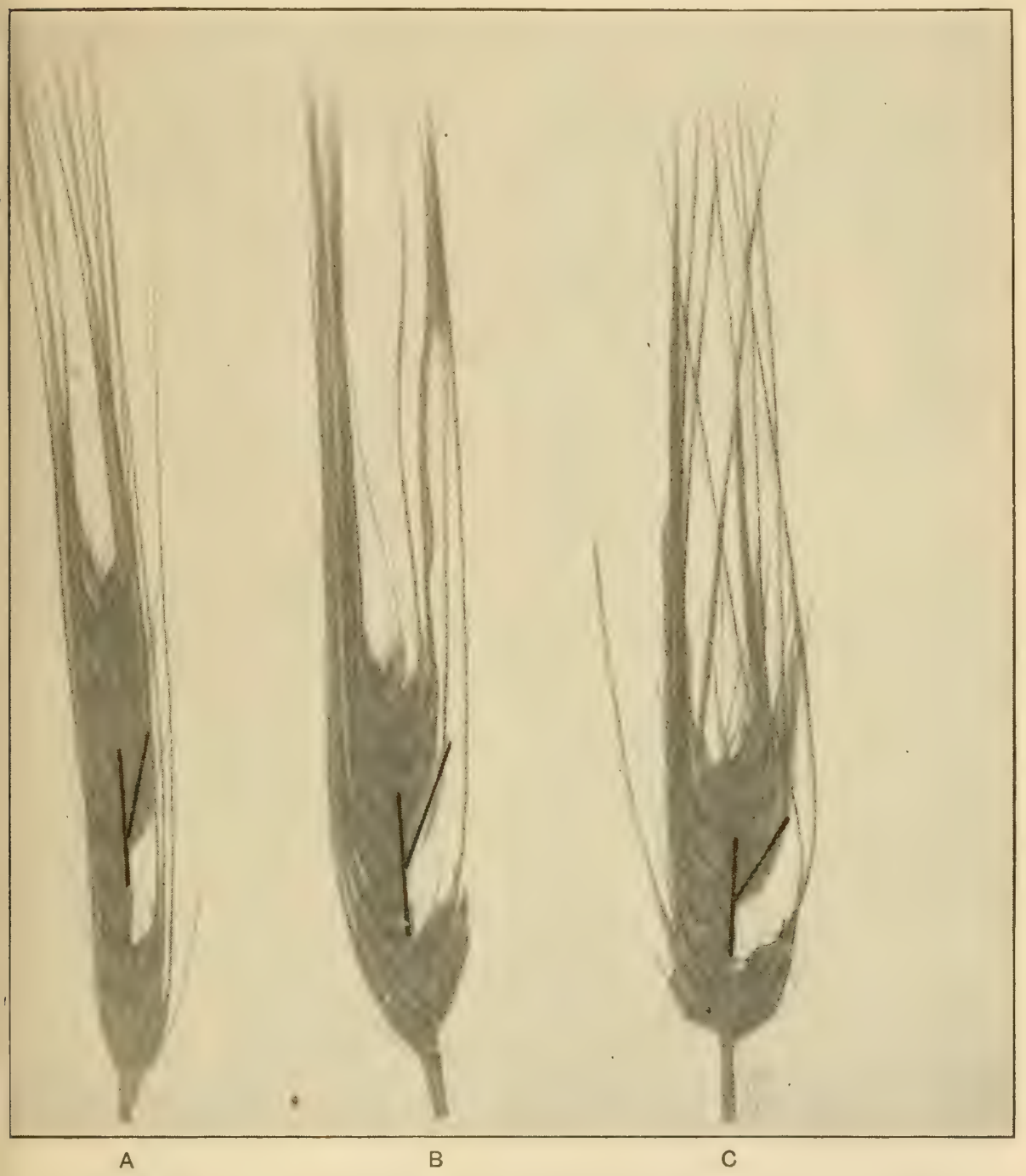

Fig. 56. VARIATION IN THE ANGLE OF INCLINATION OF. KERNEL With RHACHIS

A, Chevalier; B, Goldthorpe; C, Fan barley 
has been used in the determination of density by several investigators, especially Atterberg (1899) and Harlan (1914). Atterberg used the average length of the internodes as the chief character in separating his sulyvarieties. In the present elassification, the length of internodes has been found very useful. In two-rowed forms, three quite distinct groups were found centering around the lengths $3.3,2.5$, and 1.7 centimeters to ten internodes, or, in other words, giving a ratio of almost 2:1.5:1 (fig. 55). In the six-rowed forms the very dense group was not so distinct. Variations from the general averages were found in many eases. These lesser rariations ean be used only in descriptions of varieties under like environmental conditions, and would not necessarily hold if the specimens were grown in different localities. The larger differences, however, are little influeneed by environment and can consequently be used in classification with a considerable degree of certainty.

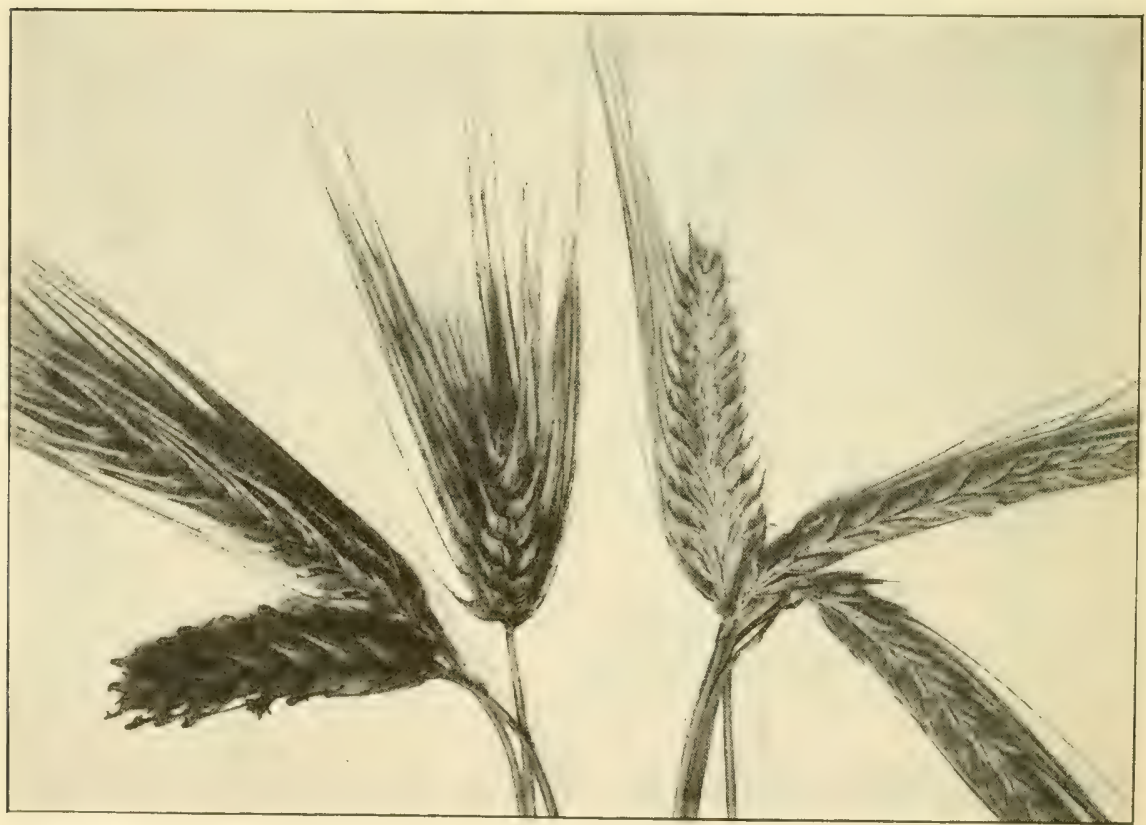

Fig. 57. variations in the ATtitude OF the SPIKE IN LAX AND DENSE FORMS 
Angle of inclination of kernel

The angle of inclination of the kernel is only another expression of density. It increases directly with the density and inversely with the length of the internode. The shorter the internode, the greater is the angle of inclination of the kernel (fig. 56). This character is, however, harder to determine and less accurate than the length of the internode. For this reason, length of internode is given preference in the present study in the determination of density. The angle of inclination, nevertheless, has been used by the Svalöf investigators in describing varieties.

\section{Attitude of spike}

The variations in the attitude or the relative position of the spike in regard to the culm, some of which are shown in figure 57 , are likewise closely correlated with the length of the internodes of the rhachis, and for this reason may be disregarded in most casses. They are of value in descriptions of varieties and in the comparison of widely different types. One advantage which this character in its extreme conditions has over the length of the rhachis internodes is that of ease in determination. It is not reliable, however, except under very favorable growing and ripening conditions, and is used in the present classification only in connection with the

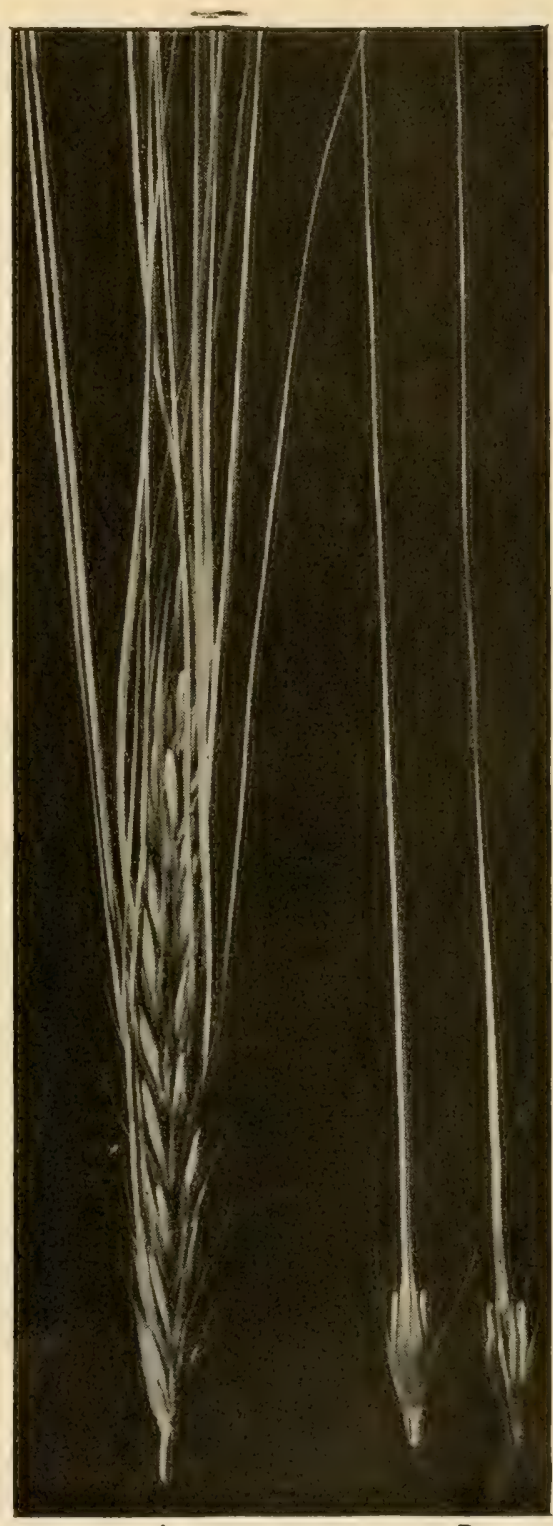

A

B

Fig. 58. hordeum spontaneum

A, Entire spike; B, one internode of rhachis with spikelets attached 
length of the internode. This charaeter has been used in connection with density by practically all previous investigators.

\section{Articulation of internodes of rhachis}

In the wild types of harley known at present, the rhachis separates at maturity into as many segments as there are internodes in the rhachis. This separation is by disarticulation and not by rupture (fig. 58). Each separate segment remains attached to one spikelet. In the cultivated types of barley this separation does not take place; the rhachis either remains entire, or, if threshed, may be broken to pieces by rupture but seldom by disarticulation. In either case, however, no part of it remains with the spikelets. Nevertheless, there is considerable variation in this character of the rhachis in cultivated barleys. Although no part of the rhachis remains with the threshed grain, there is a tendency in certain rarieties for the rhachis to separate easily into the various segments at maturity. This difference is a matter of degree, and as a consequence camnot be used as an important taxonomic character. But it has considerable value in varietal distinctions. and is used in that connection in the present paper.

This character has not been used by previous investigators either as a group characteristic or as a varietal difference.

\section{SPIKELET CHARACTERS}

The spikelet in the case of barley presents several characters which are very important from the standpoint of classification, second only to the two principal spike characters already discussed. 'The most valuable spikelet characters in barley are those of the caryopsis, the glumes, and the rhachilla. These present wide differenees, many of which have been found to remain constant under all environmental conditions. They have found second place in classifications because of difficulty in determination, and in some cases of intermediacy

\section{The grain}

The term grain, as used in this paper, when applied to hulled barleys includes both the caryopsis and the adhering lemma and palea; but when the term is applied to hull-less varieties, only the caryopsis is con- 
sidered. In other words, grain is the term applied to the threshed product. The grain of barley presents several important characters, both commercially and taxonomically - composition, size, shape, and color.

\section{Composition}

The composition of barley grain of the hulled varieties is a subject that has been given much study in connection with malting. The composition of hull-less varieties has not, however, been given equal consideration. For this reason, and because the same variations occur in each form, data for only the hulled type are given herein. Beaven (1902), and Le Clere and Wahl (1909), report a large number of analyses of barleys. From these data it is apparent that composition is influenced much more by environment, rainfall, temperature, sunshine, and fertilizers, than by the variety. The following table from Le Clere and Wahl illustrates this fact:

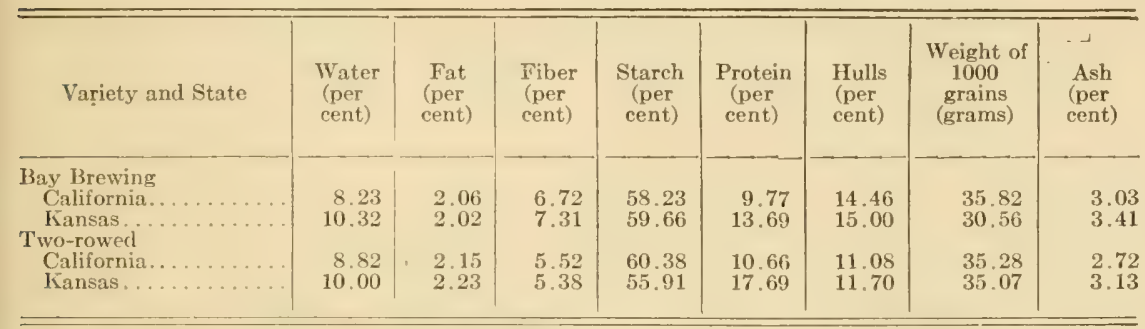

The difference in the composition of the same variety in different localities is much greater than the difference in the composition of different varieties in the same locality. This is especially true of water, protein, and ash contents. These data verify previous work along the same line. Regardless of this truth, there is a strong tendency for some varieties to possess heritable differences in composition. This character may in some instances be used in differentiating varieties that are grown under exactly the same environment, but in a classification of barley varieties it has little place. In the present investigation the composition of the grain is not used.

\section{Size}

The average size of the grain has been used by agronomists generally in describing varieties and strains, but the differences are usually very 
small in elosely related samples, making iis value doubtful. It is, however, more significant in the ease of widely different gioups. But in such instances other more reliable and less variable characters are usually pasent. For these reasons, and because it varies greatly with the enviromment, it is used in the present classification only in varietal descriptions.

The valiation of the size of grain within a variety may, however, be significant ats an aid in determining the groups to which a variety belongs, if the sample is threshed. All grains are of approximately the same size in the two-row groups. while in the six-rowed groups one-third of the grains are notieca! y lirger than the other two-thirds, and in the intermediate group one-third are approximately twice the size of the other two-thirds. These distinctions are valuable only in connection with threshed grain. In the case of threshed samples of hull-less types, this variation in size may be the only way of distinguis.ning two-rowed from six-rowed varie: ies. With threshed samples of hulled types, however, the shape of the grain, as descubel later, is more reliable in determining groups.

\section{Shape}

The difference in shape of the grain between the two-rowed and the six-rowed hulled types has become well established as a group distinetion (fig. 59). The grains from the lateral spikelets are all more or less twisted in the six-rowed varieties, while those from the central spikelets are all symmetrical in contour. In the two-rowed varieties all the grains are symmetrical in contour, sinee they are produced by the central spikelets. There is a difference even between the shape of the grains of the tworowed varieties and the grains of the central spikelets of the six-rowed varieties. The grains of the central spikelets of the six-rowed varieties are broarlest near the tip, while those of the two-rowed varieties are broudest near the base. This difference has been used by the Swedish investigators as a group distinction, and is used in the present investigation only for a study of threshed grain. It has no value in identifying threshed samples of hull-less barley, because all grains are symmetrical, due to lack of compression by the glumes.

The differeness in shape to be found between varieties in the lesser groups are very small and must be based on measurements of the various 

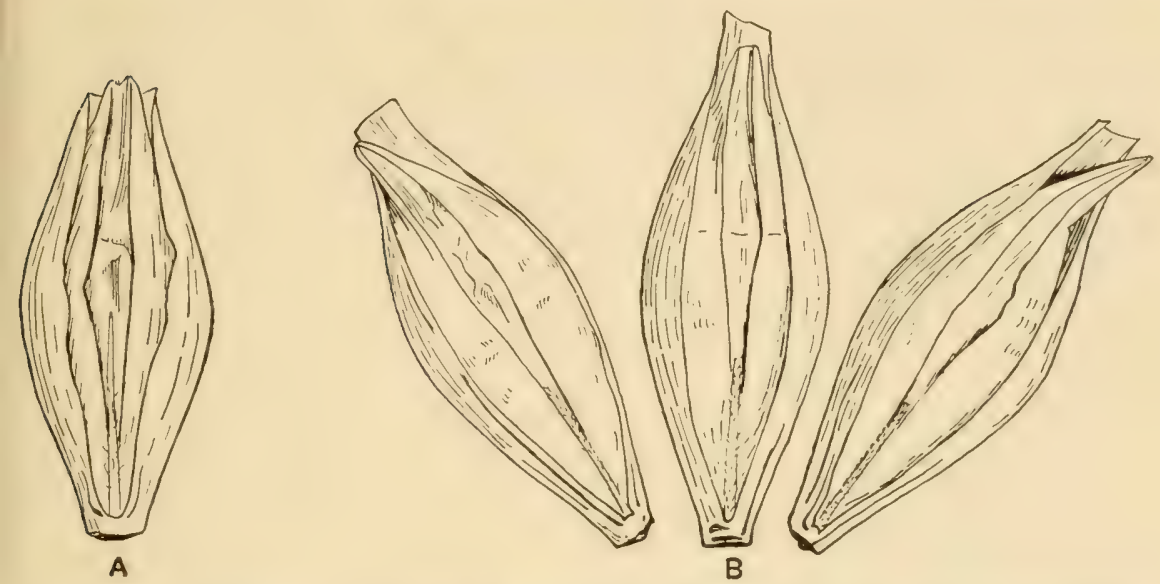

Fig. 59. difference in appearance of ventral view, of grain of two-rowed barlet AND OF GRAIN OF LATERAL SPIKELETS OF SIX-ROWED BARLEY

A, Grain of two-rowed barley; B, grain of lateral spikelets of six-rowed barley

dimensions. The most reliable and least influenced by environmental conditions, as found by Harlan (1914), is in length. By this measurement it is possible in a few instances to distinguish between certain very similar varieties or strains. This character is used only in varietal description in the present classification.

Color

The color of both the caryopsis and the glumes (lemma and palea) has been used in practically all classifications that have appeared. The use, however, has not been consistent, probably because the nature of the pigmentation of barley was not understood. The following colors have been used in classifications by various investigators: white, yellow, black, violet, purple, and blue-gray. The use of color by Beaven (1902) may be given as a typical instance:

Colour of (1) the paleae*; (2) the seed (caryopsis).

(a) Yellow or white paleae and seed.

(b) Yellow or white paleae with bluish-grey seed.

(c) Brown paleae.

(d) Black paleae. The colour of the seed (caryopsis) when naked in the two latter cases also varies.

*Beaven used the term paleae to include both lemma and palea. 
It remined for IIarlan (1914) to make a detailed study of the pigmentation of barleys. This work has aided materially in giving an understanding of the variations in color, and in clearing up inconsistencies. As a result of his work, Harlan found that all pigmentation was the result of only two pigments, anthocyanin and a melanin-like pigment. He found four color conditions to exist as a result of the total absence or the different location and combination of the pigments, as follows:

1. (a) Hulled varieties without pigment in either lemma or aleurone layer.

(b) Ifull-less varieties without pigment in the aleurone layer or in the pericarp.

Either of these conditionis results in a white or a yellow barley. - 2. (a) Hulled varicties with a blue aleurone layer showing through the superimposed lemma.

(b) Hull-less varieties with a blue aleurone layer showing through a pericarp containing no pigment.

Either of these conditions results in a blue barley.

3. (a) Hulled varieties with purple lemmas.

(b) Hull-less varieties with blue aleurone and red pericarp.

Either of these conditions results in a purple barley.

4. (a) Hulled varieties with black lemmas.

(b) Hull-less varieties with black pericarp.

Either of these conditions results in a black barley.

Another color condition sometimes appears in immature white or yellow barleys. The lack of maturity causes the development of a greenish color which is probably not due to any pigment. The blue and purple color conditions mentioned above are due to one pigment, anthocyanin. In an acid condition this appears red and in an alkaline condition it appears blue. The combination of the two produce purple. The black color is due to the molanin-like pigment, which is unchanged by treatment with either an acid or an alkali. The brown color as used in some classifications is without (loubt a black, and consequently has in most cases, if not in all, very little taxonomic value.

(olor as used in the present classification follows the grouping as given ahove. Because of the ease of recognition and the distinct condition of color, it is given an important place herein in making the various groups. The blue conclition is the only one which is at times diffieult to recognize. In the casc of hulled barleys, the color may be obscured by weathering 
at harvest time unless conditions are very favorable. In these instances it is necessary to remove the glumes in order to detect the color. If there is still doubt in regard to the presence or the absence of the blue pigment, the question may be determined by a simple chemical test which consists in dropping into a weak acid solution some kernels whose seed coats have been cut througin. In a ferv minutes, according to the strength of the solution, a pink ring will appear in the region of the aleurone layer if any pigment is present; if no pigment is present there will be no color.

If barleys under study are immature, another difficulty may arise in determining color, since pigmentation is developed in the last stages of maturity. If harvest takes place too soon the development is somewhat arrested, and this may cause difficulty.

Pigmentation likewise oceurs in other parts of the plant, particularly in the leaves and the stems. The pigment concerned is usually, if not always, anthocyanin. The appearance of coloration is, however, not normal in most cases and is never reliable as a taxonomic character. It usually appears as a result of arrested development, hastened maturity, or other abnormal conditions due to malnutrition.

\section{The lemma, ${ }^{6}$ or flowering glume}

No other single structure in barley gives so many morphologically important characters as does the lemma. Some of the characters of this strueture have been used by all investigators who have attempted c.ither classifications or descriptions since the time of Limnaeus. Their relative importance has not been the same in all cases, but without exception the separation of large groups his been made by the use of one or more of the lemma characters.

The color of the lemma has already been discussed in connection with the color of grains, and need only be mentioned here. The remaining important lemma characters, the variations of which are constant in different varieties or groups, are the adherence of the lemma and the palea to the caryopsis, the terminal appendage, the number of nerves, the barbing of the lateral nerves, and the base. These characters are discussed in the above order.

6 The term lemma is used throughout this paper instead of the term flowering olume." Not only is lemma a shorter term than flowering glume, but it serves to distizguish this structure from the outer glumes of the spikelet. It is also the term now commonly used by agronomists. It is, however, morphologically the same as the outer, or empty, glumes, all of which are reduced structures on the main axis of the spikelet. The palea differs from the other glumes of the spikelet by arising from the secondary axis of the spikelet (fig. 60). 
Adherence of lemma and palea to caryopsis

Two very different and easily distinguishable conditions exist in regard to the adherence of the lemma and the palea to the caryopsis. The condition that is probably the more characteristic and the more primitive

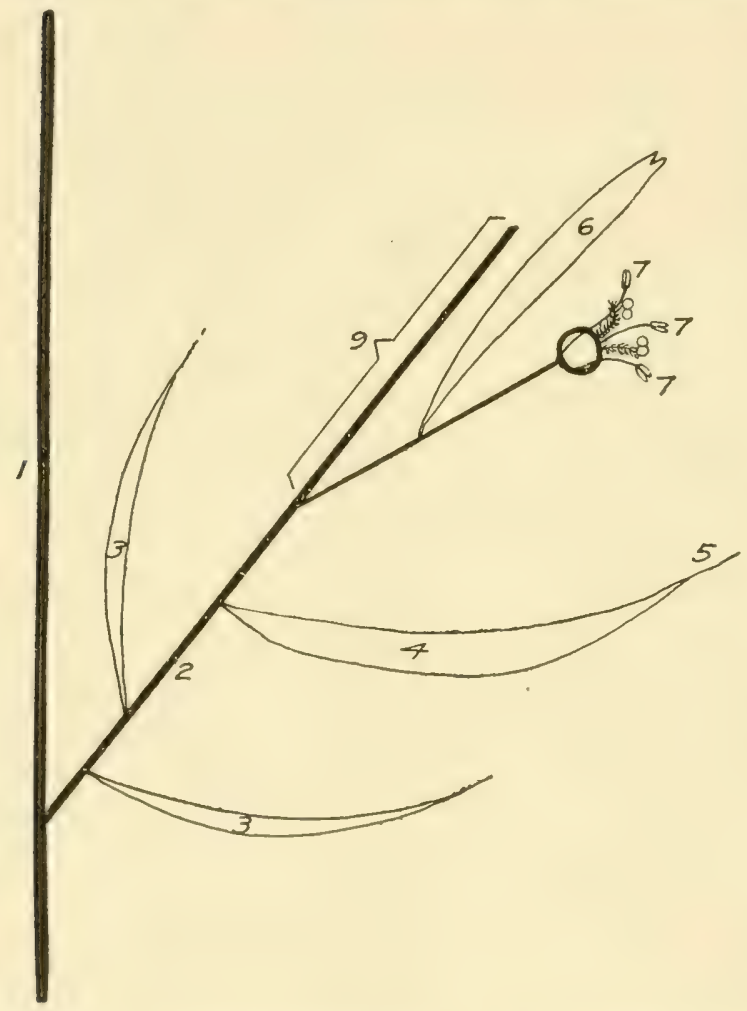

Fig. 60. Diagrammatic SKETCH OF BARLEY SPIKELET is the one in which both the lemma and the palea are grown fast to the caryopsis at maturity. This union takes place near the time of maturity, when the caryopsis has reached its maximum size. Varieties with this characteristic are known as hulled barleys. In contrast to these, some varieties fail to form a union between the lemma and palea and the caryopsis. In such cases the caryopsis at maturity is easily separated from the lemma and the palea. Varieties with this characteristic are known as hull-less, or naked, barleys.

These contrasting

1 , Rhachis, or primary axis of spike; 2 , primary axis of spike- characters were first let; 3 , outer glumes; 4, lemma of flowering glume; 5 , awn; 6 , recorded by Linnaeus
palea; 7 , stamens; 8 , pistils; 9 , rhachilla

(1753). By their use he made two groups each of lax six-rowed and lax two-rowed barleys, but did not consider them sufficiently important for the establishment of species. They have since been used in all classifications as important taxonomic characters. 
There is never any question in determining this character in mature grain because intermediates do not occur. Even in crosses the intermediate condition is not found, a fact which is not true with many other characters in hybrids. No established variety from crosses of hulled and hull-less types shows intermediacy. Because this character can be readily observed both in threshed and in unthreshed grain, and because of the total lack of intermediates, it is second to no other character taxonomically; but because of precedence and the probable evolutionary development, it is given second place in the present classification.

\section{Terminal appendage}

The terminal appendage of the lemma in barleys may be divided into three types: the normal, or awned (fig. 66), the awnless (fig. 68), and the hooded (fig. 67, $\mathrm{B}$ and $\mathrm{D})$.

The normal type is produced simply by an

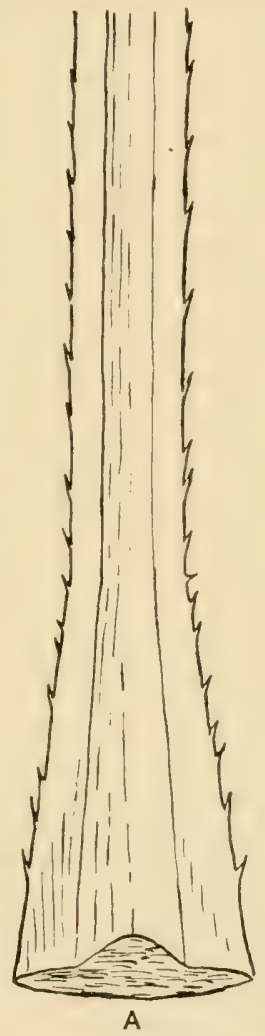

Fig 61. VARIATION IN BARBING OF AWNS

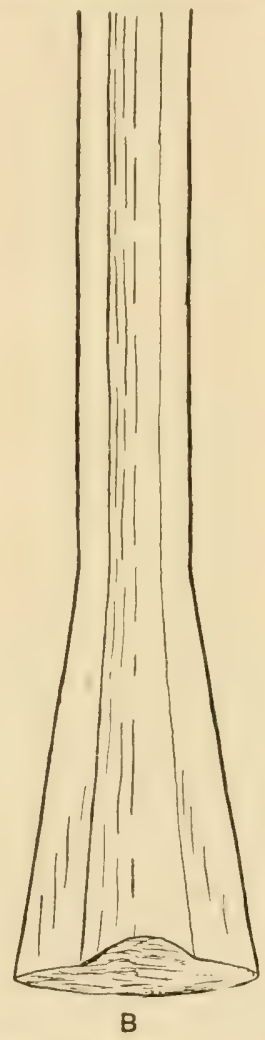

A, Barbed; B, smooth

extension of the vascular system of the lemma inte a long, pointed process known as the awn, or beard. The awns of most barleys are barbed from the base to the tip. This, however, does not hold for all varieties. A few cultivated varieties have smooth awns (fig. 61, B), and many more are being produced by hybridization. The smooth-awned 
(haracter seems to he of recent origin, as it was not described by the atrly writers on this subject. Recently Körnicke (1885), Regel (1968), and Harlan (1918) have described this condition as characteristic of some varieties. Professor F. P. Bussell, of the Department of Plant Breeding at Comell University, has recently produced a smooth-ilwned type from a cross between two varieties with barbed awns. This character, whenever found, seems to be constant and is of considerable importance in distinguishing varieties, and is so used in the present classification. In certain varieties the awns are only sparingly barbed or are barbed only for a part of their length. Usually the upper third is barbed in such cases, while in ther varieties, particularly in the dense-headed types, the barbing is very profuse. Thus, considerable variation is found in the degree of barbing. These lesser variations have little taxonomic value, as they are usually associated with more important characters. They have never been used in previous classifications. In the present classification they are used in varietal description.

A marked difference likewise occurs in both the deciduousness and the rigidity of the awns of different varieties. Some varieties, when mature, drop their awns very readily, and by threshing time the spilies are practically bare of awns. Most varieties, however, hold their awns very securely, some being broken off with difficulty even by threshing. This second condition is usually associated with a very rigid, coarse awn. These differences can be used only in varietal descriptions.

Some noticeable variations oceur between varieties in the length and in the width of awns, but these are significant in varietal descriptions only when associated with other characters.

In the awnless type, as the term signifies, the lemma ends either in a point or bluntly. The awnless lemmas are always found on the sterile side spikelets of the two-rowed barleys, and oceasionally on the fertile side spikelets of the six-rowed. The awnless type was deseribed by Körnicke (1885), and has been used since in describing certain types and often in differentiating large groups and even species.

The third type of terminal appendage is found on what are known as hooded borleys. Here the normal awn is replaced by a trifurcate structure known as the hood. The morphological significance of this 
appendage is not fully understood, but it seems that there is a partial repetition of the spikelets of a node, the three parts of the appendage representing the lemmas of the three spikelets. These glume-like structures frequently bear rudimentary sexual organs, but are seldom if ever fertile. The origin of this type is unknown, but it dates well back in cultivated barleys, since it was described by both Schübler (1818) and Séringe (1819). Since that time it has been used by all investigators along this line. The hooded condition usually appears on all fertile spikelets, but in certain six-rowed forms only the median spikelets are hooded. The only variation of importance in the hooded types is that found in the location of the hood. Commonly this structure is sessile, but in certain varieties it is elevated on an awn to a greater or less extent.

The three main types of barleys in regard to terminal appendage are of very great importance in the systematic grouping of cultivated barleys, both because of their constancy and because of the ease of determination. They are second only to fertility and adherence of the lemma and palea to the caryopsis, in the present classification.

\section{Number of nerves of lemma}

It is generally characteristic of the entire Hordeum genus to have five nerves in the lemma -- one dorsal, and two lateral on either side, all of which are usually rather obscure. In cultivated varieties of barley, the number occasionally is increased from five to seven, and in some cases the nerves become very conspicuous. The latter variation is a matter of degree and can be used only in varietal descriptions. The increase in the number of nerves is, however, very definite and noticeable. For this reason it could be used in making more important divisions were it not for the fact that it occurs very infrequently.

Neither the variation in the number of nerves nor that in their prominence has been used in previous classifications for the purpose of forming main divisions or in describing varieties. In the present classification these variations are employed in order to separate certain varieties in the larger groups.

Barbing of lateral nerves of lemma

The variation in the character of the two lateral nerves next to the dorsal nerve was first pointed out by Neergaard (1889). After careful 
study, he found that in certain varieties these nerves were toothed or barbed, while in other varieties they were perfectly smooth (fig. 62). This character proved to be constant and reliable. As a consequence it has been used widely in Sweden in recent years in differentiating certain varieties which were similar in all readily observable characters. Some workers following Neergaard, particularly Broili (1906), have held that this character was not constant, while others have supported Neergaard. As a consequence of this doubt as to the constancy of the character, it has not been used widely by recent investigators. In the present

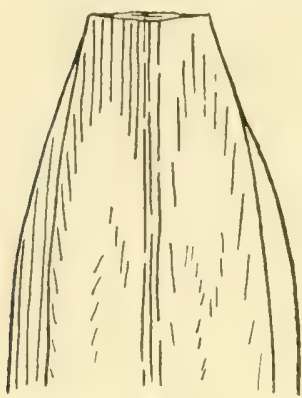

A

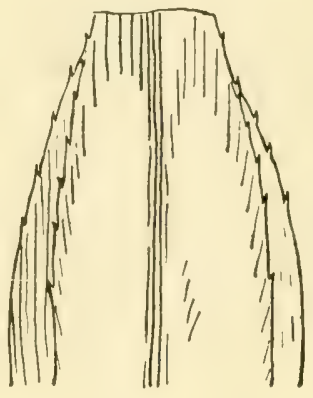

B

Fig. 62. VARIATION IN BARBing OF LATERAL NERVES OF LEMMA

A, Smooth lateral nerves; $B$, barbed lateral nerves classification it is used to make rather important divisions of agricultural varieties, particularly of the two-rowed sorts.

In employing this character, it is necessary in many cases to use a hand lens in order to be sure of the presence or the absence of the barbs. The character varies in a similar manner to the barbs on the awns. In some varieties the barbs extend along the lateral nerves nearly to the base of the kernel, while in other varieties there is a complete ahsence of barbs. Between these two conditions there are practically all degrees of barbing. This character, however, seems to be independent of the barbing of the awns, as some smooth-awned varieties have harbed lateral nerves and many varieties with barbed awns have smooth lateral nerves.

\section{Base of lemma}

The variation in the shape of the base of the lemma was first used to distinguish large groups of barleys by the Swedish investigators. They differentiated the erect compact forms from the nodding lax forms of tworowed barleys by the character of the base. The first work on the Swedish system was begun by Atterberg (1889) and Bolin (1893). The narrow 
Inx forms of the two-rowed barleys are characterized by a slight horseshoeshaped depression at the base on the dorsal side of the kernel (fig. 63, A and B). (As reported by Atterberg and Bolin, this difference was for hulled varieties only.) Associated closely with this character is the type of basilar connection of the kernel to the rhachis. The attachment is reduced to a narrow band of tissue, which separates at maturity leaving a smooth surface. Contrasted with these two characters of the narrow

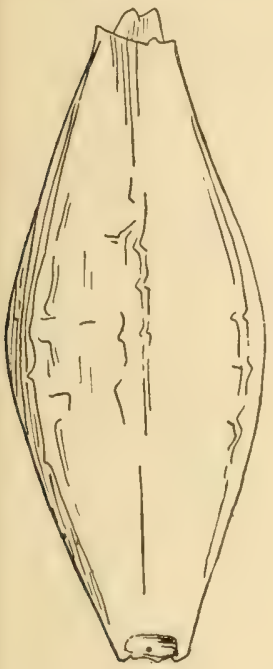

A

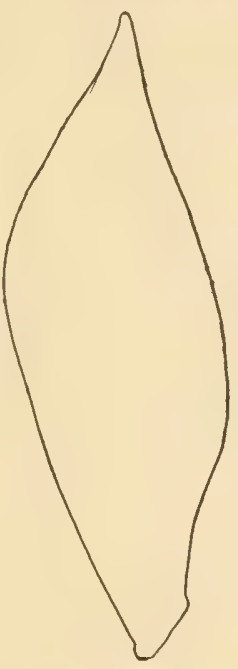

B

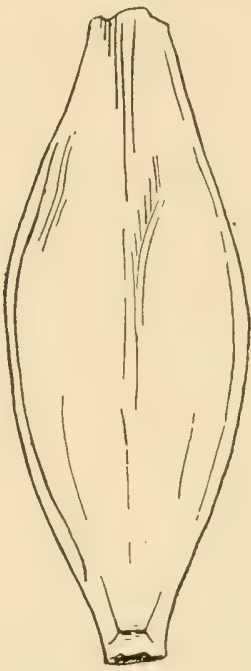

C

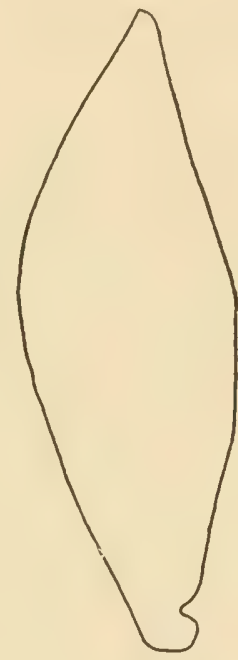

D

Fig. 63. VARIATION in Shape of Lemma base

A, Dorsal view of lemma base of lax-headed barley, showing horseshoe-like depression; $\mathrm{B}$, lateral view of same; $\mathrm{C}$, dorsal view of lemma base of dense-headed barley, showing cross crease; D, lateral view of same

lax forms, the dense erect forms have a base which is often pinched in appearance, with a transverse crease or furrow just above the point of attachment but with no horseshoe-like depression (fig. 63, C and D). The basilar connection associated with this type of lemma is broader, and when separated leaves a rougher surface than does the basilar connection of the lax forms.

Although these characters have been used for differentiating only threshed two-rowed hulled types, they hold equally true for threshed six- 
rowed hulled barleys and for hull-less types which are still in the spike. Their value in classification is somewhat limited because they are associated so closely with density.

\section{The outer glumes}

Each spikelet in barley, in common with practically all members of the grass family, is subtended by a pair of empty glumes, or bracts (fig. 60). These glumes in the case of barley are usually covered with fine hairs, are lanceolate in shape, and end either in arvn points or in short awns. However, all three of these characters of the outer glumes vary.

Occasionally varieties appear with expanded outer glumes which are almost ovate in shape. This ovate shape appears in a few varieties on all six of the outer glumes, in other's on the outermost two, and in rarer cases on the middle spikelet only. The shape of the outer glumes was first used by Kömicke (1885) for the separation of varieties, but was not considered of very great importance. More recently Beaven (1902) and Harlan (1918) have given it more weight as a taxonomic character. Another variation in shape of the outer glumes, which has not been previously described so far as the present writer knows, is in the terminal appendage. In very rare cases, hoods appear instead of awns on the two outermost outer glumes. This variation has been found in only one variety, and at present it has no value in classification.

Again, varietal differences oceur in the length of awn on the outer glumes. This was first illustrated by Munro and Beaven (1900). In some cases the awns on the outer glumes are almost as long as the awns on the lemmas. This variation may occur on the outer glumes of the two lateral spikelets, on the inedian spikelets only, or in rare cases on all three spikelets of both the two-rowed and the six-rowed types.

The difference in hairiness of the outer glumes is only in degree. In many varieties the glumes are well covered with long, straight hairs, while in many others the hairs are much shorter and not nearly so abundant; in rare cases the glumes are practically glabrous. These variations, so far as olservations have gone, are always associated with similar but more apparent characters of the rhachilla.

All the variations in the characters of the outer glumes are of minor importance in classification, either because they occur so rarely or because 
they are elosely associated with other structural characters. For these reasons they are used in the present classification only in varietal descriptions.

\section{The rhachilla}

The rhachilla, which is often known as the basal bristle, is the prolongation of the primary axis of the spikelet heyond the last floret - in the ease of barley the only floret. The entire structure of a barley spikelet is shown diagrammatically in figure 60. In perfectly sessile harleys the rhachilla is the only evidence of the primary axis of the spikelet. It is more or less hidden in the groove on the ventral side of the kernel, remaining undisturber in the case of hulled barleys when the grain is threshed. The rhachilla presents one pair of differentiating characters which is of very great taxonomic value. In one group of varieties the rhachilla is short and is

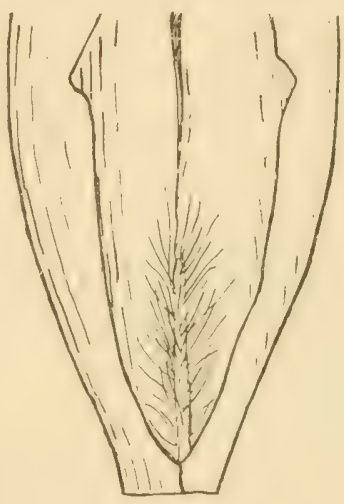

A

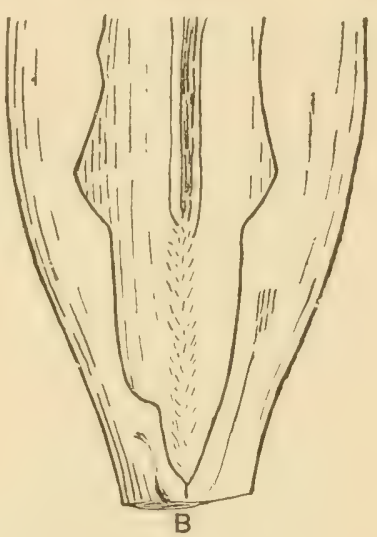

Fig, 64. THE RHACHILLA

A, Long-haired rhachilla; $B$, short-haired rhachilla' abundantly covered with long, straight, hairs; while in another group it is almost twice as long and is covered sparingly with short, curly hairs, giving a woolly appearance to the whole structure. This difference is illustrated in figure 64 .

This pair of characters, like the variation in the character of the barbing on the lateral nerves, was discovered by the Swedish investigators. They have found the variation in the rhichilla even more reliable and of greater value than the variation in the barbing of the lateral nerves, in the identification of barley varieties grown in Swerlen. In the present classifieation this pair of characters is employed in the separation of the lesser groups of varieties. 
Oceasionally another variation occurs in the rhachilla, in that a rudimentary second floret is produced. This variation has been used oceasionally in describing varieties, but, so far as the observations made in the present study go, it is of little or no value. It seems to be the result of either a sterile first floret or poor adaptation. Whenever it appears it is usually in connection with poorly developed heads, not as a characteristic of any variety or group of varieties.

\section{SUMMARY}

In order to eliminate possible confusion in regard to the characters used in the present classification and to gain some idea of their relative importance, the following brief summary of their use herein is given:

To distinguish species and subspecies:

1. Articulation of rhachis

2. Fertility of lateral spikelets

3. Presence of sexual organs in side spikelets

4. Presence of terminal appendages on lemmas of side spikelets

To distinguish the several varieties within large groups:

1. Adherence of lemma and palea to caryopsis

2. Variations in terminal appendage

3. Color

4. Density of spike as determined by

a. Base of lemma, or flowering glume

b. Length of rhachis internode

c. Width of spike

5. Character of rhachilla

6. Presence or absence of barbs on awns

7. Habit of early growth

8. Presence or absence of barbs on lateral nerves of lemma

To distinguish the subvarieties or strains within the more important varieties:

1. Attitude of spike

2. Date of emergence of awns and spikes

3. Time of maturity

4. Outer glumes

5. Grain characters:
a. Composition
b. Size
c. Shaps

6. Variations in size and color of foliage

7. Culm characters:
a. Length of last internode
b. Total length of cuim
c. Number of nodes

8. Variation in articulate character of rhachis

9. Branch-headed character

10. Productivity

Many of the last-named characters are influenced to such a degree by environment that they cannot be used alone to make differentiations, 
but when combined with other characters they may be employed in separating subvarieties. These characters are more valuable in varietal description than for any other purpose, and can be employed only for local identification.

\section{CLASSIFICATION OF BARLEY FORMS}

The classification as given in the following pages is very largely of cultivated varieties, this being the main purpose of the study. Some unimport ant varieties are included, howerer, in order to make the classification more nearly complete. It has likewise been considered better to construct the keys to groups and varieties in such a way that they may easily be expanded to include new introductions and new productions which are certain to arise. For this reason, and because of a lack of specimens possessing all the possible combinations of characters, the keys are left incomplete, some divisions failing to appear in certain instances.

The cultirated specios of barley (fig. 65), and the one wild species (Hordeum spontancum, fig. 58) which is most closely related, may be distinguished according to the following key:

A. Rhachis articulate.

PAGE

AA. Rhachis non-articulate.

B. All spikelets fertile.

C. Lemmas of all spikelets awned or hooded, kernels of all spikelets equal or

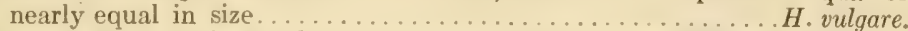

CC. Lemmas of central spikelets awned or hooded, lemmas of lateral spikelets bearing neither awns nor hoods, kernels of lateral spikelets much reduced in size.

Hordeum sponianeum. 415

BB. Only the central spikelets fertile.
C. Lateral spikelets possessing non

. (x) $H$. intermedium 7.430

C. Lateral spikelets possessing nonfunctional rudimentary sexual organs......

CC. Lateral spikelets much reduced in structural parts and possessing no rudi-

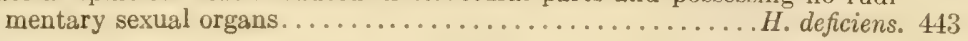

The general relationship of the species insy be graphically shown as follows:

\begin{tabular}{c|c|c}
\hline Family & Genus & Species \\
\hline Gramineae & Hordeum & $\begin{array}{c}\text { spontaneum } \\
\text { vulgare } \\
\text { intermedium } \\
\text { distichon } \\
\text { deficiens }\end{array}$ \\
\hline \hline
\end{tabular}

7 The $(\mathrm{x})$ before $H$. intermedium indicates the hybrid origin of this species, also that it is not of equal rank with the other species. 


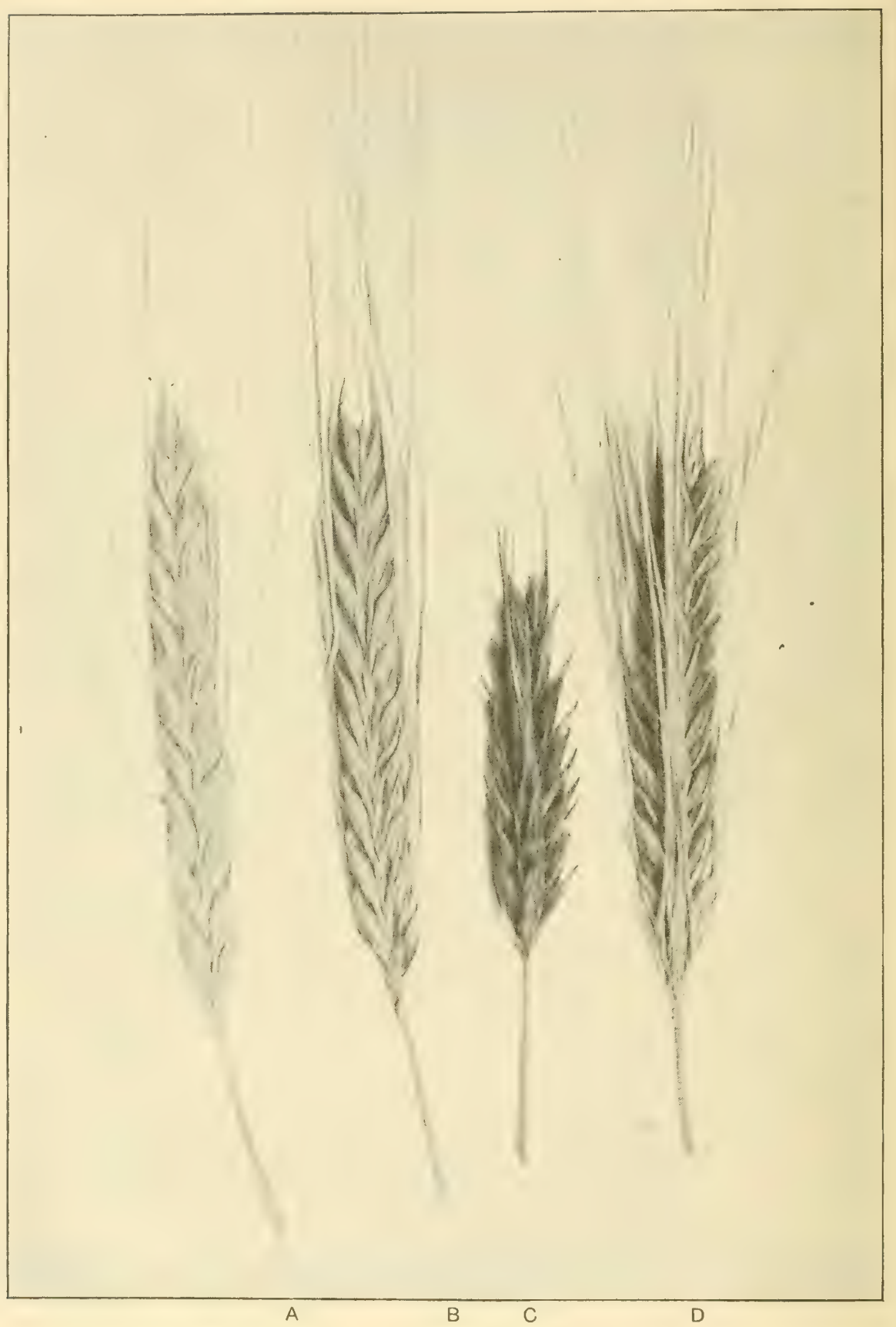

Fig. 65. Four cultivated species of Barley

A, Hordeum deficiens; B, H. distichon; C, H. intermedium; D, H. vulgare 
In the present elassification the number of species of eultivated varieties is placed at four, one of which, $H$. deficiens, is at present of lesser agronomic importanee than the others. These groups are given the species distinction largely because (1) all the hest evidence seems to point to the very early origin and to the parallel development of these types; (2) the numerous distinct varieties are less confusing when placed in four rather than in one species; (3) most of the earlier investigators have used more than one species. It is evident, however, that these species are not so distinet as are many species of other plants, especially in the wild state, since in many cases interspecies crosses are impossible. In barley, the species as designated in the present classification readily cross.

\section{HORDEUM SPONTANEUM}

IIordeum spontaneum C. Koch (fig. 58) differs from all the cultivated forms of barley by the articulation of the rhachis. At or near maturity the rhachis separates at each node but the segments remain attached at the upper end to the spikelets. The rhachises of cultivated barleys, on the other hand, do not readily disarticulate at maturity. If the spikelets are foreed apart, they break loose from the rhachis and leave it entire. It seems that in the evolution of cultivated barleys the rhachis has become solidified into a single structure.

The character of the brittle rhachis is found in several wild grasses, among the most interesting of which is the wild wheat of Palestine, the possible progenitor of cultivated wheats. This characteristic makes these grasses especially adapted for reseeding, and may account for the continued existence of these forms in nature.

$H$. spontancum has been known to botanists for many years, having been described by Post (1\$53), by Boissier (1S54), and by Hochstetter (1848). By both Boissier and Post it was designated as Hordeum Ithaburense. It may be briefly described as follows:

Leaves weak, linear, tapering at tip; spikes awned, flattened, tworanked; rhachis brittle, plumose; lateral spikelets pointed, without awns, staminate, pedieillate; central spikelet awned, perfect, sessile; awns very long and excessively barbed; dorsal nerves of flowering glumes of lateral spilielets smooth; outer glumes of all spikelets very hairy, awned; awns $1 \frac{1}{2}$ times as long as lateral florets; rhachilla long, covered with long, straight hairs; kernel long, slender. 
The only interest in this type from an economie standpoint lies in the possibility of its being the ancestor of some if not all of the cultivated barleys.

HORDEUM VULGARE

Hordeum vulgare L. (figs. 66 and 67 ), one large species of cultivated barleys, is differentiated from the wild species just described principally

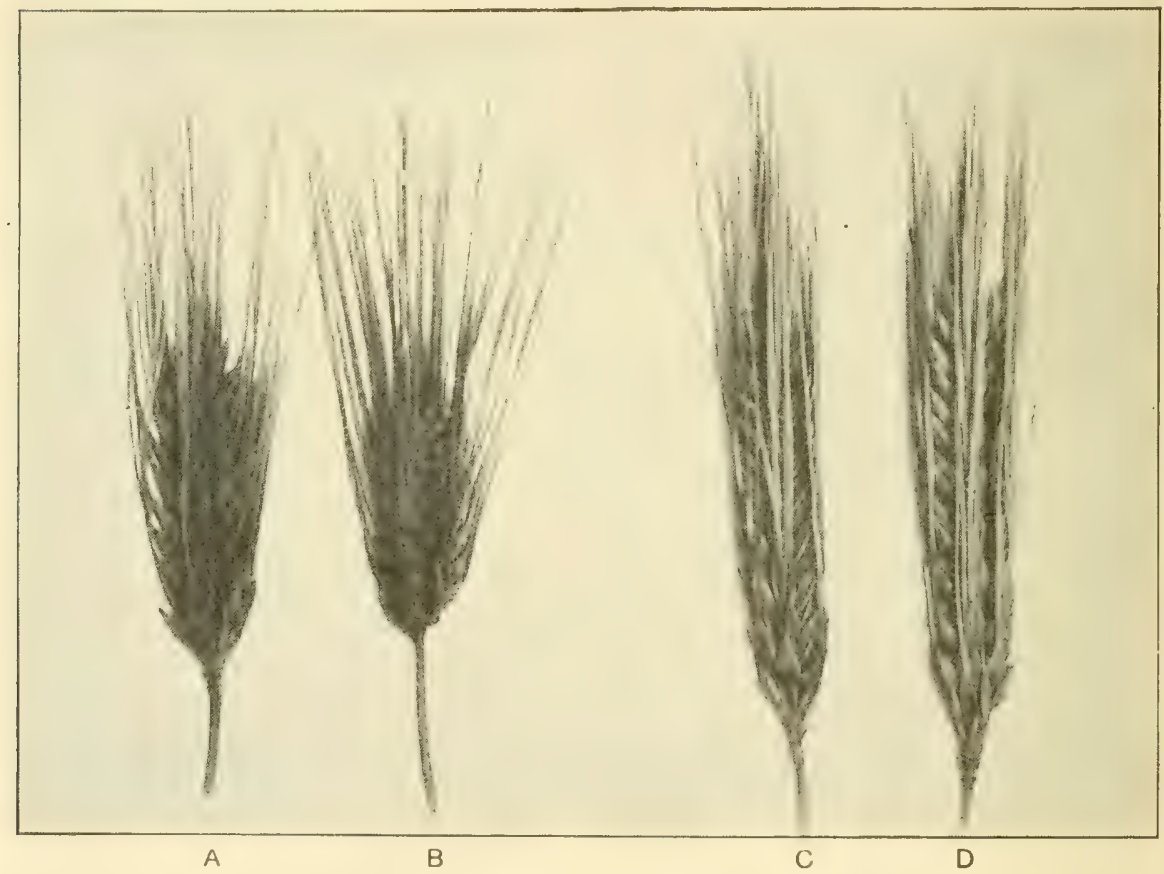

Fig. 66. VARIETIES OF HORDEUM VUlGare

A and B, Dense hulled forms; C, lax hulleri; D, lax hull-less

by the presence of a solidified rharehis, one which holks together at maturity and remains intact even though the kemels are broken off. Another important differenee between the two is found in the fertility of the spikelets. In $I I$. vulgure all three spikelets at each nole of the rhachis are fertile, thus forming six rows of fertile spilielets instead of two. The species may be briefly described as follows: 
Spike erect and nodding, six- or four-ranked according to arrangement of spikelets: rhachis, or central axis of spike, made up of a number of short internodes which are solidified at the joints; spikelets arranged in groups of three at eatch joint in the rhachis, all equally fertile, all awned or hooded, all sesile or nearly so, awns usully barbed; lateral nerves of flowering glumes barbed or smooth; rhachilla hairy; grains of lateral

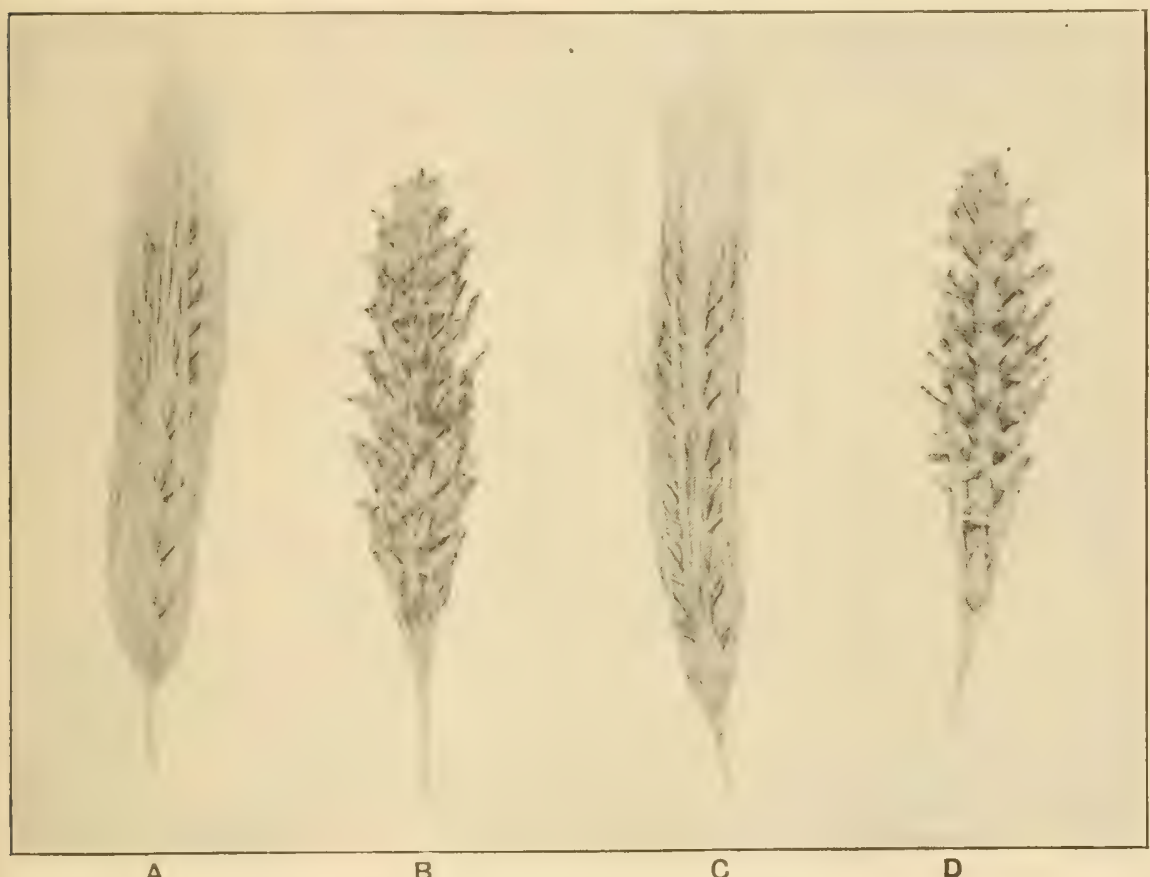

Fig. 67. VARIETIES OF HoRdeUM VUlgare

A, Lax, hulled, awned; B, lax, hulled, hooded; C, lax, hull-lens, awned; D, lax, hull-less, hooded spikelets equal or nearly equal in size to grains of eentral spikelets; grains varying in size and shape from long and slender to short and plump; grains either hulled or hull-less.

$H$. vulgare includes practically all the important cultivated varieties of the six-rowed barleys. It is more important in the United States than any other species, although both intermedium and distichon are grown 
rather extensively. Virretics of the mulgare type are found to do best. in Minnesota, IVisconsin, Illinois, Iowat, and Nobratska. The culture of this species is by no menus limiterl to the United states; it is grown wherever iarley is aultivated to any extent, and in buropean countries it ranks second only to distichon.

A. Kernels hulled.

\section{Key to varieties of $H$. vulgare ${ }^{8}$}

B. Lemmas awned.

C. Kernels white, blue, or purple.

D. Spike narrow, lax, nodding; internodes of rhachis long $(3.0-4.5 \mathrm{~cm}$. to ten internodes); base of lemma with horseshoe-like depression.

E. Rhachilla beset with long, straight hairs.

F. Awns baibed.

G. Spring habit of early growth.

H. Lateral rows of spikelets overlapping more at tip than at base of spike; kernels medium to small in size, under $1 \mathrm{~cm}$. in length; heads nodding; awns showing tendency toward deciduousness.

I. No pigment in aleurone layer, white or yellow ..........

Manchuria Selection 420

II. Pigment present in aleurone layer, blue.... Featherston. 421

HH. Lateral rows of spikelets overlapping the same from base to tip of spike; kernels long and coarse, usually $1 \mathrm{~cm}$. or more in length; straw coarse and short under New York environment; awns stiff and harsh, having no tendency toward deciduousness.

II. Pigment present in aleurone layer, blue.... . . Moroccan. 421

GG. Winter habit of early growth.

H. Lateral rows of spikelets overlapping more at tip than at base of spike; kernels medium to small in size, under $1 \mathrm{~cm}$. in length; heads nodding; awns showing tendency toward deciduousness.

II. Pigment present in aleurone layer, blue.

EE. Rhachilla beset with short, fine hairs.

Mammoth Winter. 422

F. Awns barbed.

G. Spring habit of early growth.

H. Lateral rows of spikelets overlapping more at tip than at base of spike; kernels medium to small in size, under $1 \mathrm{~cm}$. in length; heads nodding; awns showing tendency toward deciduousness.

I. No pigment in aleurone layer, white or yellow. .

Manchuria-Oderbrucker. 422

II. Pigment present in aleurone layer, blue.... O. A. C. 21.423

8 The naming of all groups and varieties conforms to the rules of varietal nomenclature adopted by the American Society of Agronomy at its annual meeting held November 12-13, 1917, and reported in the Journal of the society, volume 9, no. 9, 1917, with the exception of the cases in which numbers are used, both those given by the Office of Foreign Seed and Plant Introduction, United States Department of Agriculture (S.P.I), and the selection numbers employed by the author. It is considered better to use such numbers to denote specimens with a given group of characters until a variety of commercial importance with the same characters is found, rather than to fix permanent names to the already existing non-important specimens. Appropriate varietal names may be readily fixed at any later date. 
PAGE

HH. Lateral rows of spikelets overlapping the same from base to tip of spike; kernels long and coarse, usually $1 \mathrm{~cm}$. in length; straw coarse and short under New York environment; awns stiff and harsh, hoving no tendency toward deciduousness.

I. No pigment in aleurone layer, white or yellow . Mariout. 423

II. Pigment present in aleurone layer, blue... Bay Brewing. 424

GG. Winter habit of early growth.

H. Lateral rows of spikelets overlapping more at tip than at base of spike; kernels medium to small in size, under $1 \mathrm{~cm}$. in length; heads nodding; awns showing tendency toward deciduousness.

I. No pigment in aleurone layer, white or yellow.........

II. Pigment present in aleurone layer, blue............. 425

German Winter. 425

DD. Spikes broad, dense, erect; internodes of rhachis short $(1.5-2.8 \mathrm{~cm}$. to ten internodes); base of lemma cross-creased.

E. Rhachilla beset with long, straight hairs.

F. Awns barbed.

G. Spring habit of early growth.

H. Outermost glumes of side spikelets very broad.

I. No pigment in aleurone layer, white or yellow.........

Triumph. 425

HH. All outer glumes the same size.

I. No pigment in aleurone layer, white or yellow; side spikelets sessile.................. Utah Winter. 425

II. Pigment present in aleurone layer, light blue; foliage dark green...................... S. P. I. 41159. 426

GG. Winter habit of early growth.

H. Density $2.5 \mathrm{~cm}$. or less to ten internodes of rhachis.

I. No pigment in aleurone layer, white or yellow........

Short Six-rowed Winter. 426 .

EE. Rhachilla beset with short, fine hairs.

F. Awns barbed.

G. Spring habit of early growth.

H. Density $2.5 \mathrm{~cm}$. or less to ten internodes of rhachis.

CC. Kernels black.

I. No figment in aleurone layer, white or yellow. . Chilian. 426

D. Spike narrow, lax, nodding; internodes of rhachis long $(3.0-4.5 \mathrm{~cm}$. to ten internodes); base of lemma with horseshoe-like depression.

E. Rhachilla beset with long, straight hairs.

F. Awns barbed.

G. Spring habit of early growth........................... 426

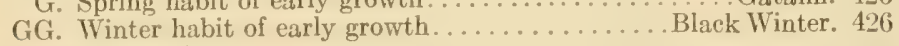

FF. Awns smooth.

BB. Lemmas hooded.

G. Spring habit of early growth............ Black Summer. 426

C. Kernels white, blue, or purple.

D. Spike narrow, lax, nodding; internodes of rhachis long $(3.0-4.5 \mathrm{~cm}$. to ten internodes); base of lemma with horseshoe-like depression.

E. Rhachilla beset with short, straight hairs.

F. Spring habit of early growth.

G. No pigment in aleurone layer, white or yellow...... Success. 427 
PAGE

DD. Spike broad, dense, erect; internodes of rhachis short $(1.5-2.8 \mathrm{~cm}$. to ten internodes); base of lemma cross-creased.

E. Rhachilla beset with long, straight hairs.

F. Spring habit of early growth.

$\mathrm{G}$. No pigment present in aleurone layer, white or yellow.......

AA. Kernels hull-less.

Selection $259 .^{9} 427$

B. Lemmas awned.

C. Kernels white, blue, or purple.

D. Spike narrow, lax, nodding; internodes of rhachis long $(3.0-4.5 \mathrm{~cm}$. to ten internodes); base of lemma with horseshoe-like depression.

E. Rhachilla beset with long, straight hairs.

F. Awns barbed.

G. Spring habit of early growth.

H. No pigment in aleurone layer, white or yellow.

I. Lateral nerves smooth... . . . . . . . . . . . . . Coeleste. 427

II. Lateral nerves barbed ................ Hansee Hulless. 427

HH. Pigment present only in aleurone layer, blue ..........

Guy Mayle. 428

HHH. Pigment present in aleurone and pericarp lœyers, purple...

Black Hulless. 428

EE. Rhachilla beset with short, fine hairs.

F. Awns barbed.

G. Spring habit of early growth.

H. No pigment in aleurone layer, white or yellow.

I. Awns $10 \mathrm{~cm}$. or more in length....... Italian Hulless. 428

II. Awns $5 \mathrm{~cm}$. or less in length............ S. P. I. 41156. 429

DD. Spike broad, dense, erect; internodes of rhachis short $(1.5-2.8 \mathrm{~cm}$. to ten internodes); base of lemma cross-creased.

E. Rhachilla beset with long, straight hairs.

F. Awns barbed.

G. Spring habit of growth.

BB. Lemmas hooded.

HH. Pigment present in aleurone layer, blue... .S. P. I. 41157. 429

C. Kernels white, blue, or purple.

I. Spike narrow, lax, nodding; internodes of rhachis long $(3.0-4.5 \mathrm{~cm}$. to ten internodes); base of lemma with horseshoe-like depression.

E. Rhachillas beset with long, straight hairs.

F. Spring habit of growth.

G. No pigment present in aleurone layer, white or ycllow......

CC. Kernels black.

White Hulless.

DD. Spike narrow, lax, nodding; internodes of rhachis short $(1.5-2.8 \mathrm{~cm}$. to ten internodes); base of lemma with horseshoe-like depression.

E. Rhachillas beset with long, straight hairs.

F. Spring habit of growth.................. Selection 308. 430

\section{Lescriptions of varieties}

Manchuria Selection. - Foliage medium green; culms strong, average in size and length; erect in early habit of growth; spilies well out of

\footnotetext{
${ }^{9}$ Selection numbers as used in this and the following keys are either applied to selections made from mixed specimens or to unnamed specimens which are of no commercial value at present.
} 
last leaf sheath at maturity; medium to early in maturity; length of ten internodes of rhachis, $3.0-4.5 \mathrm{~cm}$; spikes nodding; angle of inclination of kemel with rhachis, small; lateral rows of spikelets overlapping more at tip than at base of spike; grain short and usually plump, white or yellow in color, hulled, awned; awns showing only slight tendency toward deciduousness; lemma barbed, base with horseshoe-like depression; rhachilla beset with long, straight hairs.

The followisg key separates the subvarieties of the variety Manchuria Selection:

A. Early in maturity: amns medium strong, with slight tendency toward deciduousness; spikes usually nodding more than $90^{\circ}$; straw strong.

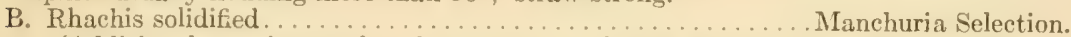
(Additional specimens found under the following names: Australian Early, Bernards, Black Two-rowed, Ouchac.)

BB. Rhachis somewhat brittle when kernels are broken apart.

C. Foliage medium green

(An additional specimen found under the name Norwegian Bjorneleyg.)

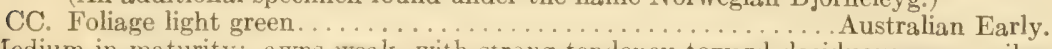
AA. Medium in maturity; awns weak, with strong tendency toward deciduousness; spikes

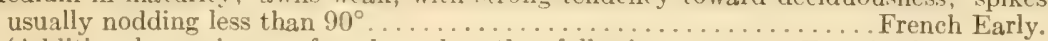
(Additional specimens found under the following names: French Gerste aus Denmark, Long-grained Winter.)

Fentherston.- The raricty Featherston is distinguished from Manchuria Selection by possessing light pigment in the aleurone layer, which gives a light blue color to the liemels. Otherwise the two varieties are very similar.

The following key separates the subvarieties of the variety Featherston:

A. Very early in maturity; culms very short; spike and awns short. . . . . S. P. I. 18922. AA. Medium to early in maturity; culms, spikes, and awns medium in length.

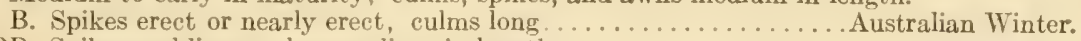

BB. Spikes nodding; culms medium in length.

C. Spikes long and very nodding; rhachis solidified.

CC. Spikes medium in length and slightly nodding; rhachis slightly brittle.......

Gerste aus Morocco.

(An additional specimen found under the name Mezoeijes Handgerste aus Lngarn.)

Moroccan.- Foliage medium green; culms coarse and short under New York conditions; erect in early habit of growth; spikes well out of sheath of last leaf at maturity; medium to early in maturity; spikes lax, length of ten internodes of rhachis $3.0-4.5 \mathrm{~cm}$; angle of inclination of kernel with rhachis, small; lateral rows of spikelets overlapping the same from tip to base; grain long and coarse, over $1 \mathrm{~cm}$. in length, light blue in color, hulled, awned; awns stiff and harsh, having no tendency 
foward deciduousness; lemma barbed, base showing horseshoe-like depression: rhachilla beset with long, straight hairs; very poorly adapted to New York environment.

The following key separates the subvarieties of the variety Morocean:

A. Very early in maturity; culms and spikes very short.

B. Heads erect or inclining only slightly.

C. Density of spike less than $3.4 \mathrm{~cm}$. to ten internodes of rhachis......... Marwar. (Additional specimens found under the following names: S. P. I. 41160, S. P. I. 41161, S. P. I. 41158.)

CC. Density of spike more than $3.4 \mathrm{~cm}$. to ten internodes of rhachis........ Guzerat. (Additional specimens found under the following names: Australian Imperial, India Cawnpur, India Punjake, Indian Sind.)

BB. Heads nodding.

C. Outer glumes short-awned, total length of awn and glume two to three times that of lemma .............................................

CC. Outur glumes awn-pointed, total length of awn and glumes searcely more than

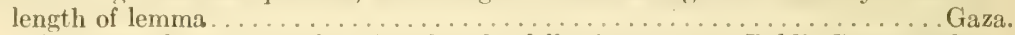
(Additional specimens found under the following names: Beldi, Canary Island, Tripolitan.)

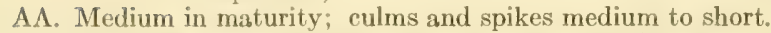

B. Outer glumes short-awned, total length of awn and glume more than twice that

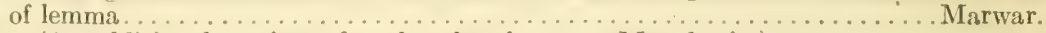

(An additional specimen found under the name Manchuria.)

BB. Outer glumes awn-pointed, total length of awn and glume scarcely more than length of lemma

Moroccan.

(Additional specimens found under the following names: Algeria, German Hanna, Spanish Sierra Yiqua, Tunisian.)

Mammoth. Winter.-Foliage medium green; culms medium to long; winter hathit of early growth; early-maturing when compared with spring batreys; spike nodding and lax, $2.8-4.0 \mathrm{~cm}$. to ten internodes; lateral rows of spikelets overlapping almost completely at tip of spike; kernels slightly pigmented, medium in size, plump; lemma awned, horseshoe-shaped at hatse; outer glumes extending slightly beyond kernel; rhachilla beset with long, straight hairs.

Additional specimens were found under the following names: Eckendorfer Mammoth Wintergerste, Friedrichswerther Mammoth Wintergerste, Klein Wanzlehener Wintergerste, Wustermarsch Wintergerste.

Manchuriu-()derbruclier (Plate XXXIV, 1).- The variety ManchuriaGelerbuclier is distinguished from Manchuria selection by the character of the rhachilla, which is beset with short, fine hairs more or less recurved at the tip, thus presenting a woolly appearance. Also, the rhachilla is usually from 30 to 60 per eent longer. This variety presents more subvarieties than does Manchuria Selection, as is seen by the accompanying 
key. Manchuria-Oderbrucker is by far the most important variety of barleys in the United States. It is the learling variety in the large barley-rowing section comprising Minnesota, Wisconsin, Nebraska, Iowa, and Illinois.

The following key separates the subvarieties of the variety ManchuriaOderbrucker:

A. Outer glumes awn-pointed, scarcely extending beyond lemma ............. Odéssa. AA. Outer glumes short-awned, extending to two or more times the length of lemma.

B. Lateral nerves not barbed; awns deciduous or nearly so; foliage light green.......

BB. Lateral nerves barbed; awns slightly deciduous; foliage medium green.

C. Early in maturity; culms short....................... Norwegian II.

(Additional specimens found under the following names: French Early, Norwegian Bamsleyg, Norwegian Bjorneleyg.)

CC. Medium in maturity and in length of culms.......... Manchuria-Oderbrucker. (Additional specimens found under the following names: Australian Winter, California Portuguese, Canada, Canadian Fancy, Eagle, Featherston Selections, French Early, Gerste aus Ajaccio, Gerste aus Lulea, Idaho Callow, Kleine Warthebruch, Manchuria, Manchurian, Manchuria Selections, Manchury, Minnesota 6, Oderbrucker, Red River, Red's Triumph, Rumanian Autumn, Schlesische Zeilgerste, Siberian, Swedish Six-rowed, Swiss Spring, Turkish Albanian, Wisconsin 5, Wisconsin 6, Wisconsin Pedigree.)

CCC. Late in maturity; medium to long culms.............. Roumanian Spring.

(Additional specimens found under the following names: Heavy Moldavian, Odessa, Roumanian Autumn, Silver King.)

O. A. C. 21 (Plate XXXIV, 2).- The variety O. A. C. 21 differs from Manchuria-Oderbrucker only by possessing pigment in the aleurone layer, which gives the grain a light blue color. Some variation exists between the subvarieties within this variety, as is shown by the following key:

A. Lateral nerves smooth or rith very few barbs.

B. Awns with strong tendency toward deciduousness...... South African Cape Early. (An additional specimen found under the name Russian Livonian.)

BB. Awns without tendency toward deciduousness........ Gerste aus der Mandschursi. (An additional specimen found under the name Manchury.)

AA. Lateral nerves barbed.

B. Early in maturity

S. P. I. 40648.

(An additional specimen found under the name S. P. I. 40649.)

BB. Medium in maturity .................................. A. C. 21 . (Additional specimens found under the following names: Blue Ribbon, Brachyura Kurze Sechszeilige Gerste, Canada, Ganadian 21, Canadian Western, Common, Featherston 507, Gerste aus Dalekartien, Gerste aus Japan, Heines Vierzeilige Gerste, Imp. Manchuria, Indian Sind, Oderbrucker, Odessa, Silver King, South Russian, S. P. I. 40645.)

BB. Late in maturity.

(An additional specimen found under the name Gerste aus Cypern.)

Mariout. - Foliage dark green; culms short and small; erect in early growth; early in maturity; spike erect or nearly so, rather dense; grain 
large and long, without pigment; lemma awned; awns very stiff and harsh; five nerves of lemma conspicuous, lateral nerves barbed; base of lemma with horseshoe-like depression; outer glimes short, narrow, awn-pointed; rhachilla sparingly beset with rather short, straight hairs.

The following key separates the subvarieties of the variety Mariout:

A. Outer glumes short, awn-pointed, scarcely extending beyond lemma; length of ten internodes $2.9-3.1 \mathrm{~cm}$; awns very stiff and harsh ................ Mariout.

AA. Outer glumes short-awned, length of awn and glume more than twice that of lemma; length of ten internodes $3.4-3.9 \mathrm{~cm}$.

B. Medium in maturity .................................... Yerli. (Additional specimens found under the following names: Sandrel, Smyrna, Sr:yrna Yerli, Turkish (Rhodes to Sea of Marmora), Turkish Alasheir, Wisconsin Winter.)

BB. Late in maturity

Bay Brewing (Plate XXYIV, 3).- Foliage varying from light to dark green in different subvarieties; culms rather coarse nul short in New York environment; erect in early growth; heads fully emerged at maturity from sheath of last leaf; medium to late in maturity; spikes lax but not nodding as much as in Manchuria-Oderbrucker; lateral rows of spikelets overlapping the same from base to tip of spike; grain long and coarse, usually over $1 \mathrm{~cm}$. in leigth; pigment in aleurone layer; grain hulled, awned, awns stiff, harsh, barbed, usually having no tendency toward deciduousness; nerves of lemma barbed; base of lemma with horseshoe-like depression; rhachilli beset with short, fir:e hairs, usually more or less recurved at tip.

This variety is second among all the varieties of $I I$. vulgare in economic importance, although it is not adipted to New York conditions. It is particularly well adipted to the Pacific Coast States, where it is growi extensively.

The following key separates the subvarieties of the variety Bay Brewing:

A. Foliage medium to dark green; medium to liate in maturity; leaves medium in length and width; erect in early growth.

B. Outer glumes awn-pointed, length of awn and glume about the same as lemma.

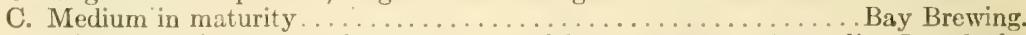

(Additional specimens found under the followng names: Australian Loosdorfer

(Early), Austrian, Algerian, Beldi, Blue Virginia, Calfornian, California Moravian, California Portuguese, California Prolific, Chili, Grecian, Guatemalan Tontonicipan, Maltese Island, Morocean, Ouchac, Peru, Poda, South African Cape Early, South African Six-rowed, Swiss, Tunisian.)

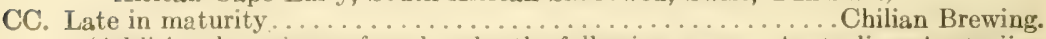

(Additional specimens found under the following names: Australian, Austraiian Prosowetz, Cape.) 
BB. Outer glumes short-awned, length of awn and glume two or more times length

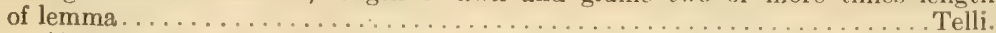

(Additional specimens found under the following names: Featherston, Grecian Hordeum sp., Montana, Tenkan, Turkish Smyrna Lowland.)

AA. Foliage light green; very late in maturity; leaves long and very broad, giving a leafy appearance; somewhat spreading in early growth.

B. Strong tendency toward brittle rhachis

BB. Solidified rhachis.

Netherlans. Swiss.

Idaho Winter.-Characterized by winter habit of early growth, early maturity, short-haired rhachilla, barbed awns, rather long spikes, lateral rows of spikelets overlapping almost completely at tip of spike, and nonpigmented grain.

The following key separates the subvarieties of the variety Idaho Winter:

A. Outer glumes awn-pointed, length of awn and glume from one to two times that of lemma.

B. Foliage medium green; outer glumes extending beyond lemma.......... Groninger.

BB. Foliage light green; outer glumes about same length as lemma...... Idaho Winter. AA. Outer glumes short-awnod, total length of awn and glume about three times that of

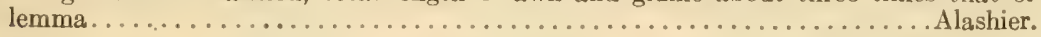

German Tïnter.- Distinguished from Idaho Winter by having kernels with pigment in the aleurone; otherwise the same.

Triumph.- Foliage light green; culms medium to long; ercet in early growth; late in maturity; average density $2.4-2.6 \mathrm{~cm}$. to ten internodes; spikes long, somewhat nodding; grain nonpigmented, short; lemma awned; awns barbed, showing strong tendency toward deciduousness; nerves of lemma barbed; base of lemma showing cross crease; lateral spikelets somewhat pediceliate; two outer glumes of side spilielets farthest from median spikelet very broad, about one-half width of lemma; rhachilla beset with long, straight hairs.

Utah Winter (Plate XXXIV, 4).-Distinguished from Triumph by having all outer glumes the same size, darker green foliage, shorter, denser spikes (average density 1.8-2.2 cm. to ten internodes), earlier maturity, nondeciduous awns, and sessile side spikelets. Representatives of the Utah Winter variety do not behave as do winter barleys in New York environment.

The following key separates the subvarieties of the variety Utah Winter:

A. Foliage very caark green; late in maturity; outer glumes narrow and short-awned, total length of awn and outer glume about twice that of lemma; awns nearly parallel...... (An additional specimen found under the name Californian.)

Utah Winter. 
AA. Foliage medium green; medium to early in maturity; outer glumes broad and shortawned, total length of awn and outer glume about three times that of lemma; awns spreading.

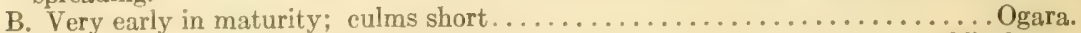
BB. Early to medium in maturity; culms very short ................ Hitakawa. (An additional specimen found under the name Chilian.)

S. P.I.41159.- Distinguished from L'tah Winter by having a pigmented aleurone layer and pedicellate side spikelets.

Short Six-roved Winter (Plate XXXIV. 5).- Foliage medium green; culms medium to long; winter habit of growth; early in maturity when seeded in fall, but very late when seeded in spring; spike dense, $2.2 \mathrm{~cm}$. to ten intemodes, and erect; angle of inclination of grain with rhachis large; grain rather large and somewhat coarse; lemma thick, awned, cross-creased at base; awns barbed, spreading, rather stiff; rhachilla beset with long, straight hairs.

Chitian.-Distinguished from Utah Winter by having grain with a pigmented alcurone layer, and short, fine-haired rhachilla.

An additional specinen was found under the name Japanese Hitakawa.

Gatami (Plate XXXIV, 6).-Foliage light green; culms medium to short, fine, rather weak; erect in early growth; spikes well out of sheath of last leaf at maturity; medium in maturity; spikes lax, 3.4-3.6 cm. to ten internodes, noding; grain small, dark gray in color, black pigment sometimes absent from base of lemma; lemma adhering closely to caryopsis, awned; awns barbed, medium to long, stiff; five nerves of lemma conspicuous; lateral nerves barbed; base of lemma with horseshoelike depression; outer glumes narrow, awn-pointed; rhachilla beset with long, straight hairs.

Black Winter.- Foliage nedium green; culms long, strong; winter habit of early growth, searcely maturing any seed when sown in the spring; early in maturity when fall-sown but late when spring-sown; spikes lax, 3.5-3.8 cm. to ten internodes, nodeling, very long; rows of side spikelets overlapping almost completely at tip of spike; grain long, black, more or less glaucous; lemma athering closely to caryopsis; five nerves of lemma searecly distinguishable; lateral nerves barbed; base of kernel with horseshoc-like depression; outer glumes narrow, awn-pointed; rhachilla beset with long, straight hairs.

Bluck summer (Plate XXXV, 7).-Foliage light greer ; culms medium to short, fine, rather weak; spikes well out of sheath of last leaf at maturity; nedium to late in maturity; spikes lax, $3.4-3.6 \mathrm{~cm}$. to ten 


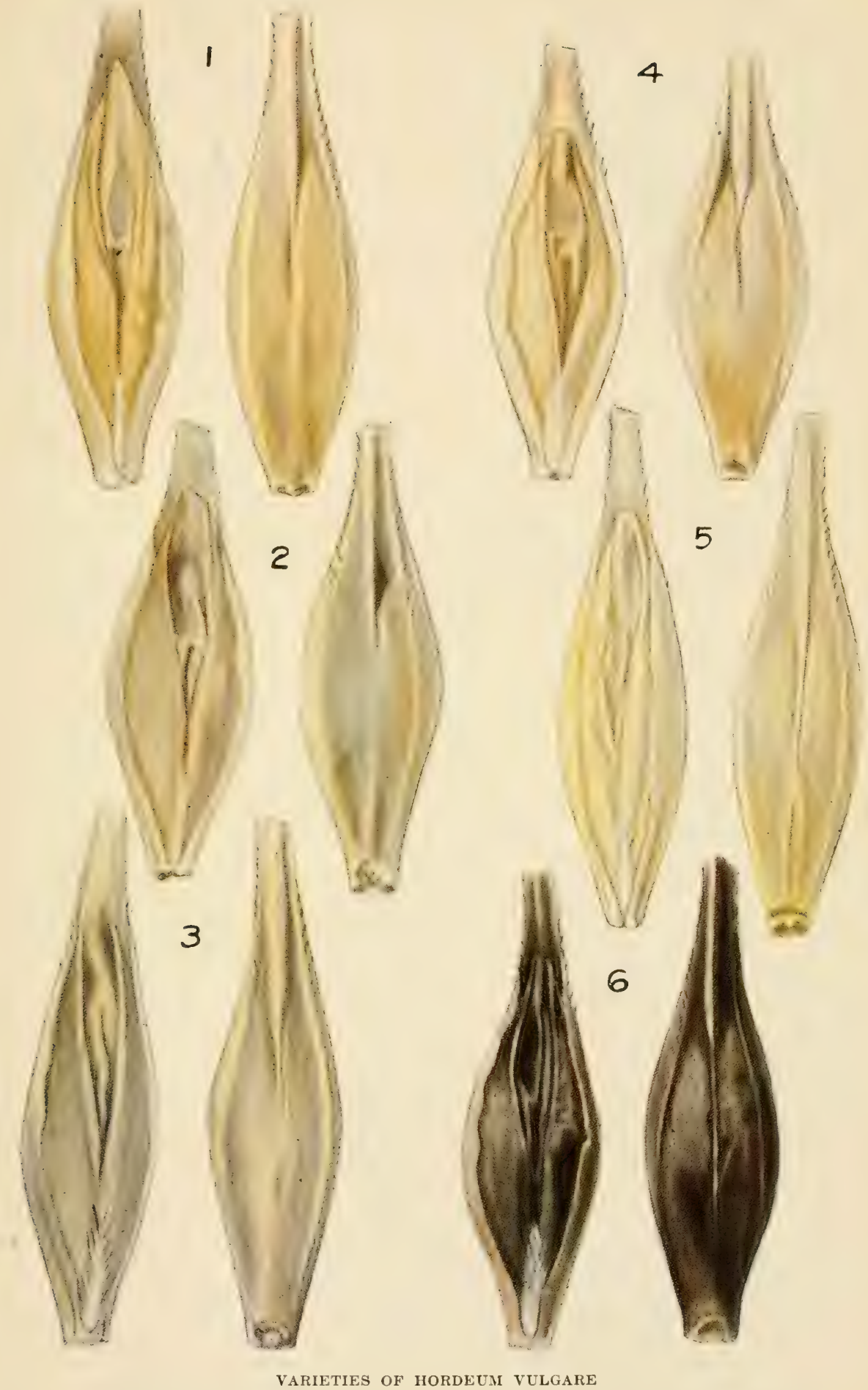

1. Manchuria-Oderbrucker; 2, O. A. C. 21; 3, Bay Brewing; 4, Utah Winter; 5, Short Sixrowed Winter; 6, Gatami 


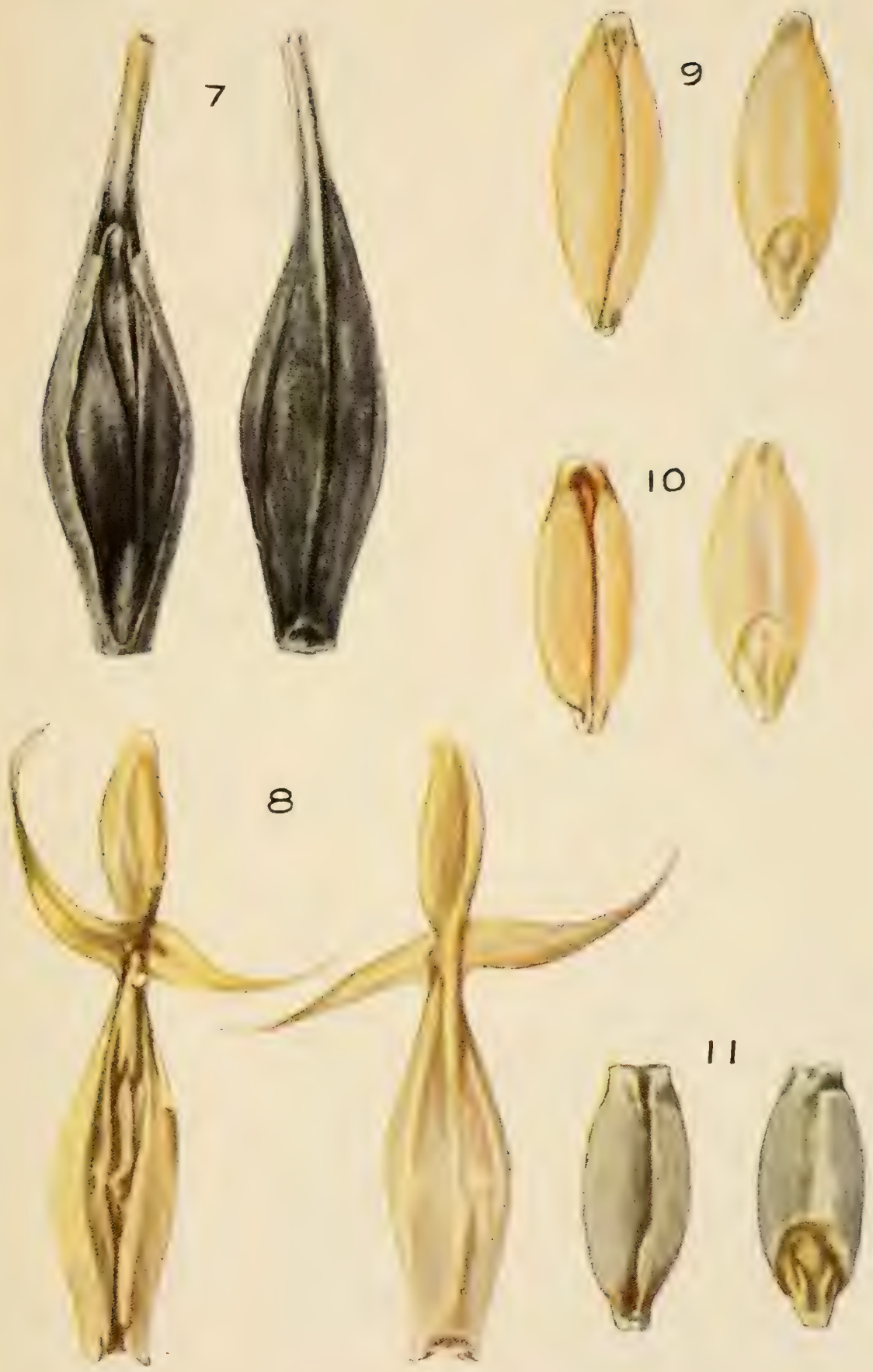

VARIETIES OF HORDEUM VULGARE

7, Black Summer; 8, Success: 9, Coeleste; 10, Hansee Ifulless: 11, Guy Mayle 


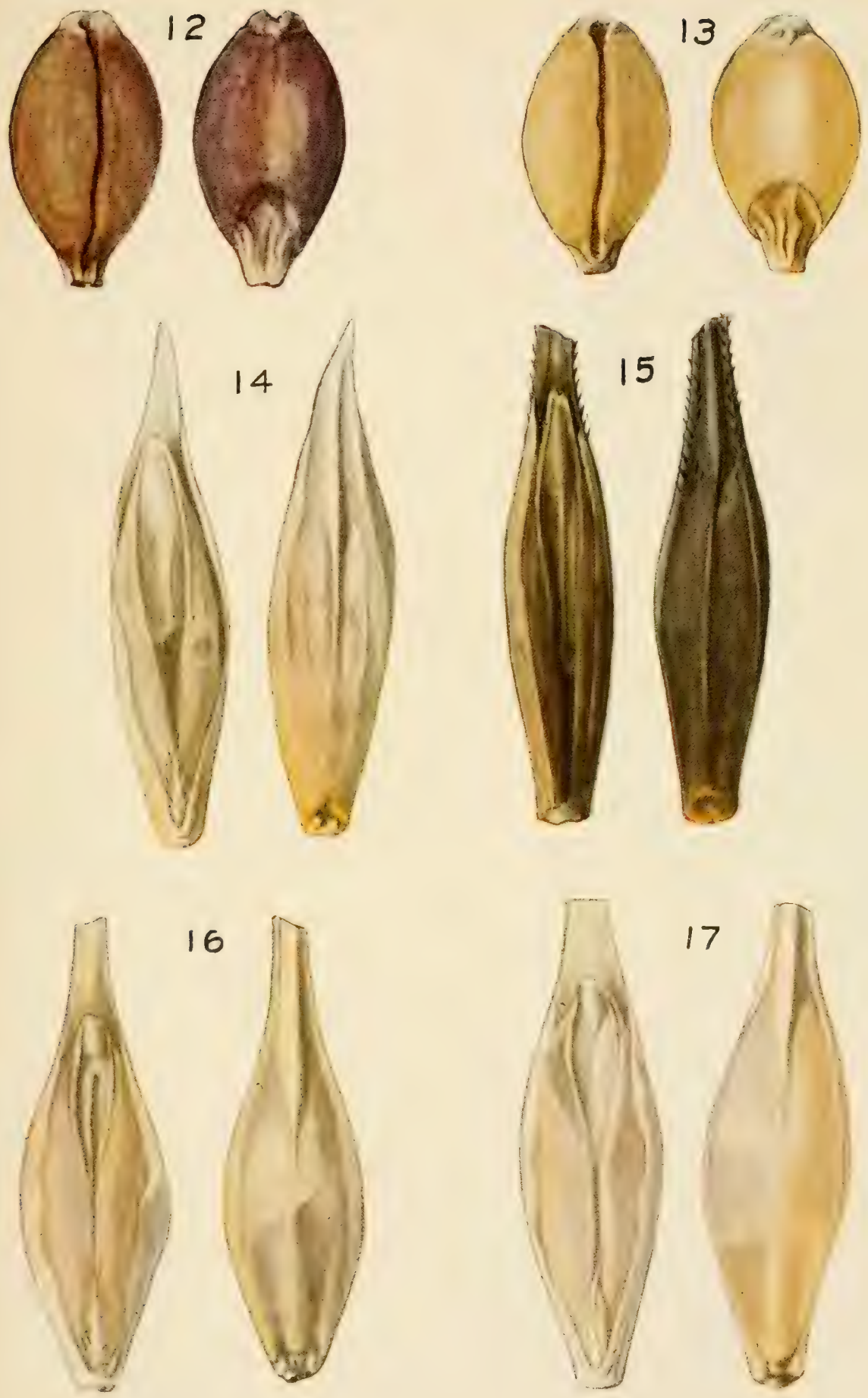

VARIETIES OF HORDEUM VULGARE, H. INTERMEDIUM, AND H. DISTICHON

H. vulgare: 12, Black Hulless; 13, White Hulless

H. intermedium: 14, Arlington Awnless; 15, S. P. I. 40326

H. distichon: 16, Hanna; 17, Cheralier 



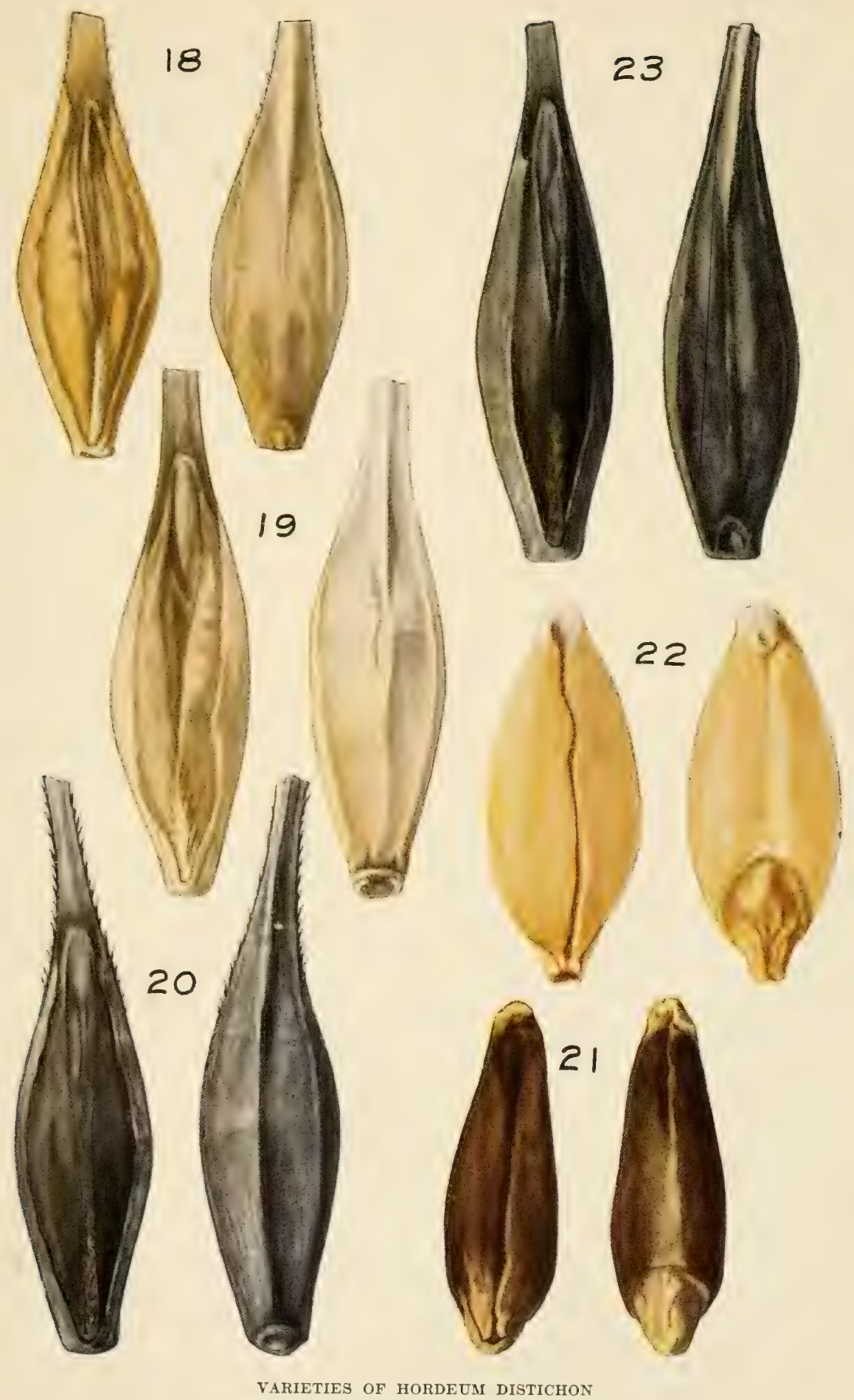

18, Manchury $\mathrm{x}$ Vermont Champion; 19, Goldthorpe; 20, Anatolian Black; 21, Black Tworowed; 22, Naked Spring; 23 , Selection 607 


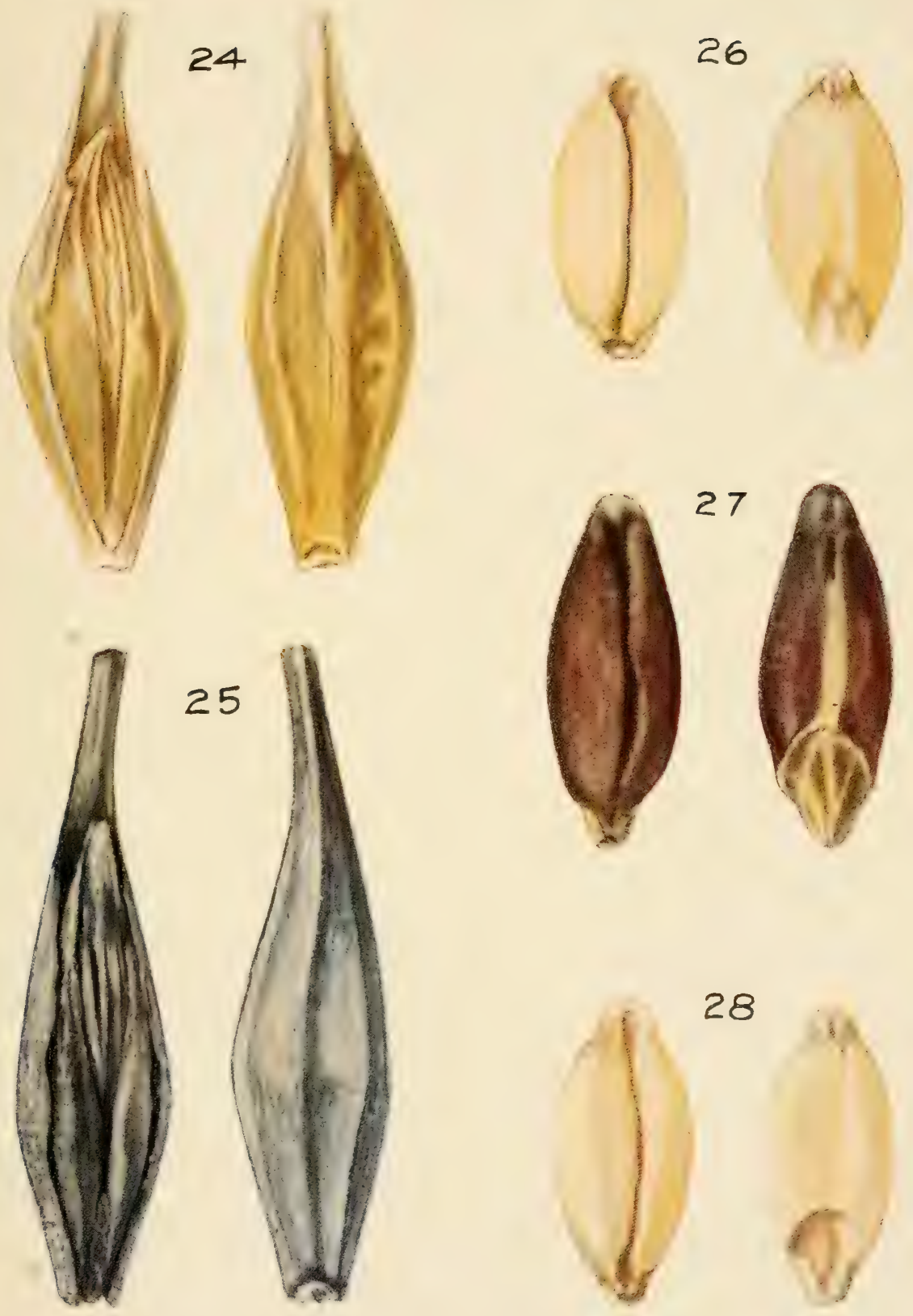

VARIETIES OF HORDEUM DEFICIENS

24, Russian Courland; 25 , Selection $621 ; 26$, S. P. I. 41155; 27, Selection 626; 28, Nepal Hulless 

internodes of rhachis, nodding; grain black, more or less glaucous, small, lemma awned; awns barbed, medium to long, stiff; lateral nerves barbed; outer glumes narrow, awn-pointed; rhachilla beset with long, straight hairs.

Additional specimens of this variety, all of which were very similar in character, were found under the following names: Asstivum Schwarze Sommergerste, Leiorhynchum (Keke.), Nigrum Schwarze Sommergerste.

Success (Plate XXXV, 8).-Foliage medium green; culms medium to long; erect in early growth; early in maturity; spikes lax; length of ten internodes of rhachis $3.6-3.8 \mathrm{~cm}$, nodding to an angle of $45^{\circ}$ to $100^{\circ}$; grain $1 \mathrm{~cm}$. or more in length, yellow, hulled and hooded, hood usually a short distance from end of grain; lemma with five rather conspicuous nerves; lateral nerves barbel; base of lemma with horseshoe-like depression; outer glumes narrow, awn-pointed, total length about same as grain; rhachilla long narrow, sparsely covered with short hairs.

The following liey separates the subraricties of the variety Success:

A. Plants very early in maturing; culms short; heads nodding only slightly; foliage dark

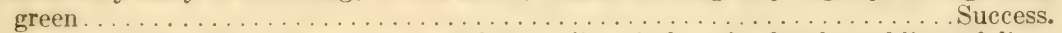

AA. Plants early to medium in maturing; culms medium in length; heads nodding; foliage

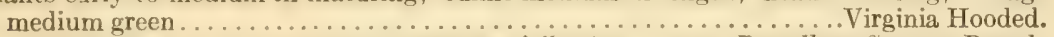
(Additional speeimens found under the following names: Beardless, Suceess Beardless, Virginia Selection 64.)

Selection 259.- Distinguished from Success by having very short, dense spikes (1.7-1.9 $\mathrm{cm}$. to ten internodes of the rhachis), long, straight hairs, a spike which never emerges completely from the sheath of the last leaf, and late maturity. Original specimen unnamed.

Coeleste (Plate XXXV, 9).-Leaves dark green, abundant, rather broad; culms medium in height and diameter, straight, strong; erect in early growth; last internode of culm long; melium early in maturity; spike lax, length of ten internodes of rhachis 3.3-3.5 cm., nodding to an angle of over $90^{\circ}$; grain broad, $0.75-0.9 \mathrm{~cm}$. long, very starchy, white; lemma free from caryopsis, bearded; beards long, broad, lax, barbed; lemma with horseshoe-like depression; outer glumes narrow, short-awned, total length twice that of grain; rhachilla beset with long, straight hairs.

Additional specimens of this rariety were found under the following names: Coerulescens Fer., Naked Barley, Naked Spring.

Hansee Hulless (Plate XXXV, 10).- Foliage medium green, abundant in early growth; culms medium in size and length, with a tendency toward lodging; spike scarcely out of sheath of last leaf at maturity; 
semi-winter in early habit of growth; somewhat earlier in maturing than Cocleste; spikes lax, $2.8-3.0 \mathrm{~cm}$. to ten internodes of rhachis, nodding: grain white, short $(0.65-0.75 \mathrm{~cm}$.), broad in proportion to length; lemmat free from caryopsis, awned; awns medium in length, rather stiff, barbed; lemma with five rather inconspicuous nerves; lateral nerves barloed; outer glumes narrow, short, awn-pointed, total length of glume and awn point slightly greater than length of glumes; rhachilla beset with long, straight hairs.

Additional specimens of this variety were found under the following names: C. I. 703, Sangatsuka.

Guy Mayle (Plate XXXV, 11).- Foliage light green; culms medium to short, weak, showing tendeney toward lodging; erect in early growth; spikes entirely emerged from sheath of last leaf; very early in maturing, the earliest of all the hull-less types; spike lax, $3.2-3.5 \mathrm{~cm}$. to ten internodes of rhachis, nodding to an angle greater than $90^{\circ}$; grain blue, pigment present in aleurone layer, $0.75-0.85 \mathrm{~cm}$. long; lemma free from caryopsis. awned; awns barbed, rather broad, stiff; lemma with horseshoc-like depression; outer glumes narrow, short-awned, total length about twice that of lemma; rhachilla beset with long, straight hairs.

Additional specimens of this variety were found under the name Blue Hulless.

Black Hulless (Plate XXXVI, 12).- Foliage medium green; culns medium in length and diameter, with a tendency toward lodging; spikes well out of sheath of last leaf at maturity; crect in early habit of growth; early in maturing; spikes lax, $3.4-3.7 \mathrm{~cm}$. to ten internodes of rhachis, nodding to an angle of $60^{\circ}$ to $90^{\circ}$; grain purple, color usually developed to the greatest extent on dorsal side near tip; grain short (0.7 cm. or less), broad in proportion to its length; lemma free from caryopsis, awned; awns straight, parallel, barbed, rather coarse; five nerves of lemma ineonspicuous; lateral nerves barbed; lemma usually showing some color development along dorsal nerve; base of lemma with horseshoe-like depression; outer glumes narrow, short-awned, total length about twice that of lemma; rhachilla beset with long, straight hairs.

Additional specimens of this variety were found under the following names: Blaue Excelsior, Blaue Nackte Gerste, Virginia Black Hulless, Violaceum.

Italian Hulless. - Foliage medium green; culms medium to short, large in diameter; erect in early growth; spilies well out of sheath of last leaf 
at maturity; medium to early in maturity; spilies very lax, $4.2-4.4 \mathrm{~cm}$. to ten internodes of rhachis; angle of inclination of kernel with rhachis, very small; grain white, long $(0.8-1.0 \mathrm{~cm}$.), narrow; lemma free from caryopsis, awned; awns $10 \mathrm{~cm}$. or more long, barberl, rather stiff; five nerves of lemma rather conspicuous, lateral nerves barbed; base of lemma with horseshoe-like kepression; outer glumes short, narrow, awns pointed, total length about same as that of lemma; rhachilla sparingly beset with short, recurved hairs.

S. P. I. 41156.- Foliage dark green; culms medium to short; semiwinter in early growth; late in maturity; spikes lax $(3.0-3.4 \mathrm{~cm}$. to ten internodes of rhachis), but usually crect; grain yellow, short $(0.6-0.7$ cm.), broad in proportion to its length; lemma free from caryopsis, awned; awns less than' $5 \mathrm{~cm}$. long. narrow, barbed, stiff; five nerves of lemma rather conspicuous, lateral nerves barbed; outer glumes narrow, short, awn-pointed, total length about the same as that of lemma; rhachilla beset with short, recurved hairs.

S. P. I. 411\%.- Foliage medium green; culms medium to short; erect in early habit of growth; spikes well out of sheath of last leaf at maturity; medium to early in maturity; spikes erect or only slightly nodkling, dense (2.2-2.4 cm. to ten internodes of spikelet); grain blue, pigment present in aleurone layer; grain $0.7 \mathrm{~cm}$. or less in length, more than half as broad as long; lemma free from caryopsis, awned; awns barbed; base of lemma cross-creased; outer glumes narrow, awn-pointed, total length about one and one-half times that of lemma; rhachilla beset with long, straight hairs.

White Hulless (Plate XXY.VI, 13).- Foliage dark green, broad; culms large, coarse, medium to tall; somewhat spreading in early growth, but inclined to lodge easily; spikes scarcely emerging from sheath of last leaf, occasionally emerging from side of sheath; medium in maturity; length of 10 internodes of spike over $3.0 \mathrm{~cm}$; s spikes nodding from $10^{\circ}$ to $90^{\circ}$; grain white to yellow, $0.7-0.8 \mathrm{~cm}$. in length, about half as broad as long; lemma free from caryopsis, hooded, hoods set close to end of kernel; five nerves of lemma rather conspicuous, lateral nerves barbed; base of lemma possessing horseshoe-like depression; outer glumes narrow, awn-pointed, total length about the same as that of lemma; rhachilla beset with long, straight hairs.

Additional specimens of this variety were found under the following: names: C. I. 595, Hulless, Nepal. 
Selection 308.- Foliage medium green; culms rather short, coarse; erect in early habit of growth; spikes emerging from side of leaf sheath, late in maturity; spikes very dense and erect; grain black, long, narrow; lemma black, free from caryopsis, hooded; five nerves of lemma conspicuous, lateral nerves barbed; base of lemma cross-creased; rhachilla beset with long, straight hairs. Original specimen unnamed.

\section{HORDEUM INTERMEDIUM}

Hordeum intermedium (fig. 68) is similar to $H$. vulgare in most characters. It may be briefly described as follows:

Nodes of rhachis solidified; spikes nodding and lax in most cases; spikelets arranged in groups of three at each node of rhachis, all sessile, all fertile, median spikelet awned (fig. 51, C, and D, and fig. 68) or hooded (fig. 69), lateral spikelets neither awned nor hooded; grain of lateral spikelets one-half to two-thirds as large as grain of median spikelets; grain varying in color and in adherence of lemma to caryopsis.

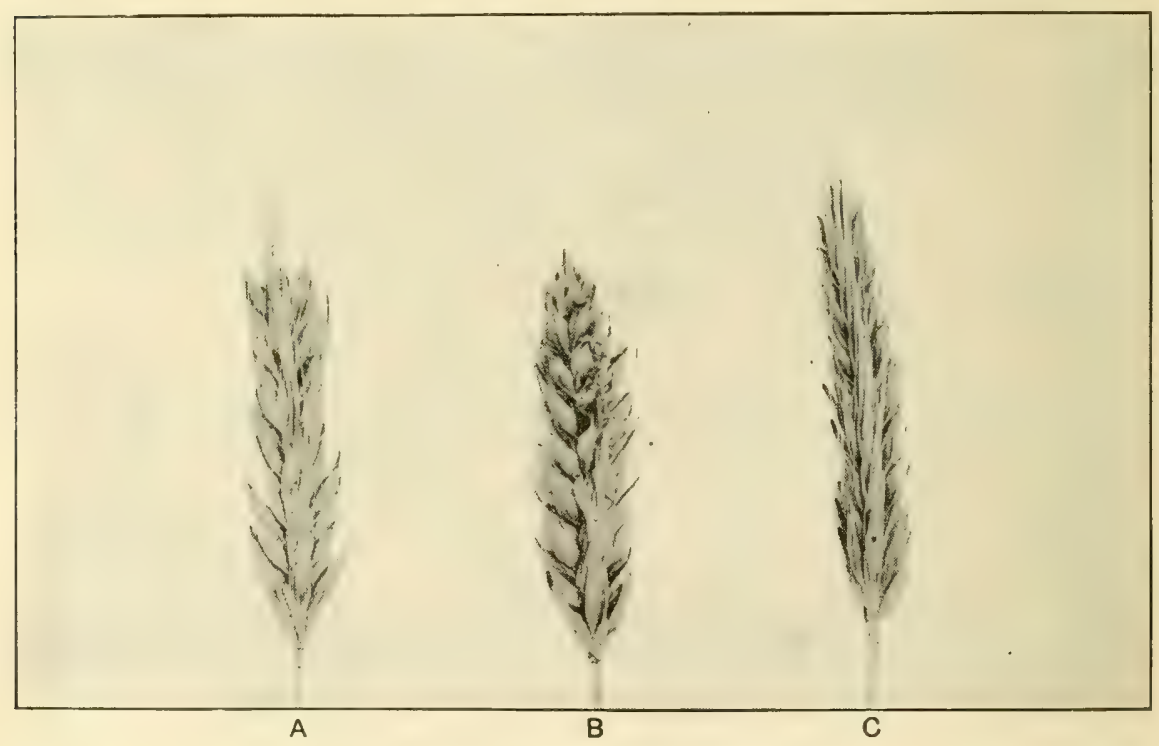

'Fig. 68. TYPES OF HORDEUM INTERMEdIUM

A, Arlington Awnless; B, South African Nepal Hulless; C, S. P. I. 40326 


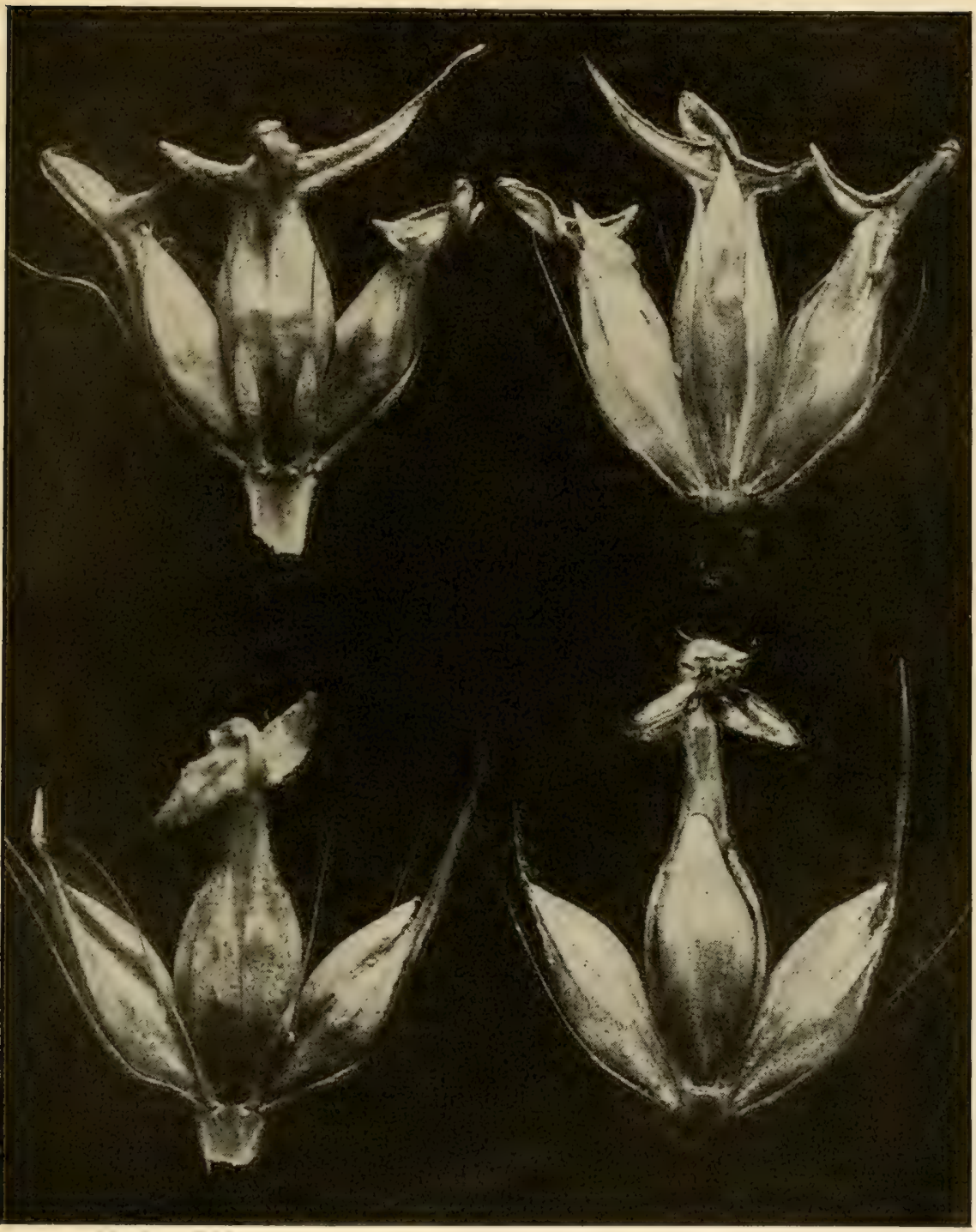

FIG. 69. COMPARISON OF SPIKELETS AT ONE NODE OF RHACHIS OF HULL-LESS TY PE OF HORDEUM VULGARE AND OF H. INTERMEDIUM

Above, Dorsal and ventral views of $H$. vulgare; below, dorsal and ventral views of H. intermedium 
This species is of limited importance, from an economic standpoint, both in the United States and in Europe. One variety, Arlington Awnless, is of some importance along the southern border of the barley-producing section of the United States.

The varieties belonging to this species are probably of hybrid origin for the most part, and have been in existence for only a short time. As an illustration, Derr (1911) gives an account of the hybrid origin of Arlington Awnless.

A. Kernels hulled.

\section{Key to varieties of $H$. intermedium}

B. Lemmas of central spikelets awned.

C. Kernels white, blue, or purple.

D. Spike narrow, lax, nodding; internodes of rhachis long $(3.0-4.5 \mathrm{~cm}$.

to ten internodes); base of lemma with horseshoe-like depression.

E. Rhachilla beset with long, straight hairs.

F. Awns short, barbed.

G. Semi-winter habit of early growth.

HH. Pigment present in aleurone layer, light blue . .........

CC. Kernels black,

Arlington Awnless. 432

D. Spike narrow, lax, nodding; internodes of rhachis long $(3.0-4.5 \mathrm{~cm}$.

to ten internodes); base of lemma with horseshoe-like depression.

E. Rhachilla beset with long, straight hairs.

F. Awn short, barked.

AA. Kernels huil-less.

G. Semi-winter habit of early growth........... S. P. I. 40326. 433

BB. Lemmas of central spikalets hooded.

C. Kernels white, blue, or purple.

D. Spike narrow, lax, nodding; internodes of rhachis long $(3.0-1.5 \mathrm{~cm}$.

to ten internodes); base of lemma with horseshoe-like depression.

E. Rhachilla beset with long, straight hairs.

F. Spring habit of early growth.

G. No pigment in aleurone layer, white or yellow .

Nepal Hulless. 433

\section{Descriptions of varieties}

Arlington Awntess (Plate XXXVI, 14).-- Foliage medium green; culms medium to short, small in diameter; semi-winter in early hathit of growth; spikes only slightly emerged from sheath of last leaf; medium in maturity; spikes lax (3.0-3.t cm. to ten internodes), nodding only slightly; grain light blue, pigment present in aleurone layer; grain of median spilielet medium to small in size, grain of side spikelets only slightly more than half the size of that of lisedian spikelet; lemma adlerring closely to caryopsis, lemma of modian spikelet short-awned (never more than 1.5 cm.), lemmas of side spikelets blunt; five nerves of lemma inconspicuous, 
lateral nerves harbed; hase of lemma horseshoe-shaped; outer glumes narrow, awn-pointed; rhachilla beset with long, straight hairs.

Specimens of this variety found under the following names: C. I. 702, Comell Selection 1. ('ornell selection 8, Cornell Selection 9.

S.P.I. 4033 rf (Pliate XXXVI, 15). - The varicty S. P. I. 40326, which is probably a selection from the original cross that produced Arlington Awnless. lliffers from the latter by possessing black-colored grains.

Nepal IIulless (Plate XXXVIII, 28).- Foliage medium green; culms short but rather large in diameter; erect in early growth, stooling very little; modium in maturity, maturing just ahead of Arlington Awnless; spikes lax. 3.()-4.0 ('m. to ten internodes of rhachis, nodding, short; grain white; grain of median spikelet medium to small, grain of side spikelets about two-thirels as large as grain of median spikelet; lemma free from (aryopsis. lemmia of median spikelet hooded, lemmas of side spikelets blunt to awn-printerl. point never more than $1 \mathrm{~cm}$. long; five nerves of lemma inconspicune- lateral nerves barbed; outer glumes narrow, awn-pointed; rhachilla beset with long, straight hairs.

\section{HORDEUM DISTICHON}

IInde In!n distichom is distinguished from $H$. vulgare and $H$. intermedium in the character of fertility. $I I$. distichon, like $H$. spontaneum, has only the central spilielet of the three spikelets at each node of the rhachis fertile, while $H$. mulyere and $I I$. intermedium have all three spikelets fertile. The lateral spikelests of $H$. distichon, although infertile, have all the floral mouns, including outer glumes, lemma, palea, and rudimentary sexual organs. The simne variations in density of spikes (fig. 70), terminal appencliages (fig. 71), rhachillas, size, shape, and color of kernels, barbing of lateral nerves, color of lemmas, and adherence of flowering glume (fig. 71), are foumd in this species as are found in $H$. vulgare, and for this reason a detailed description of these variations need not be given here.

II. distichon is of equal importance economically with $H$. vulgare, although it is not grown as extensively in the United States. It is the leading barky for malting purposes in European countries. The extensive production of varieties of this species in the United States is limited to North Dakota and South Dakota, but it is grown. to some extent over the entire barley-producing region. 


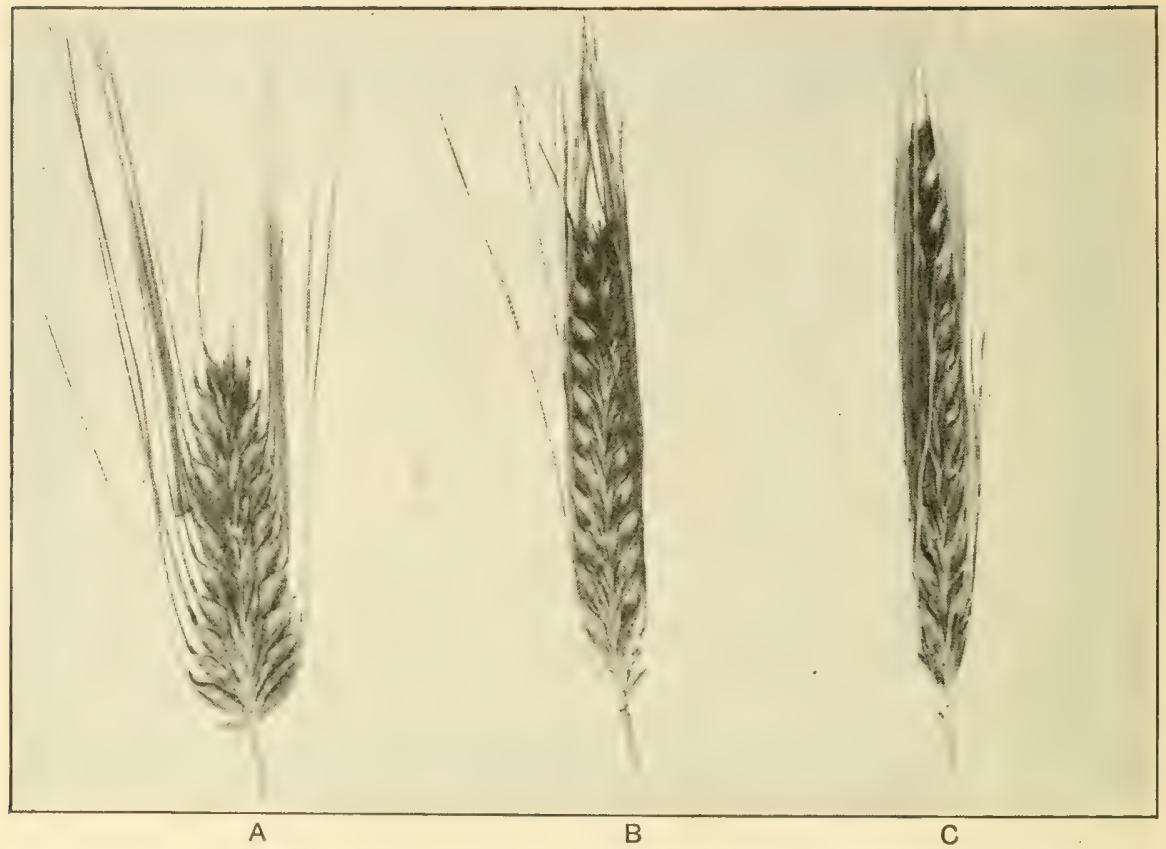

Fig. 70. THREe stages of Density in hordeum distichon

A, Fan Barley; B, Goldthorpe; C, Chevalier

A. Kernels hulled.

\section{Key to varielies of $H$. distichon}

B. Lemmas awned.

C. Kernels white, blue, or purple.

D. Spike narrow, lax, nodding; internodes of rhachis long $(3.0-4.1 \mathrm{~cm}$. to ten internodes); base of lemma with horseshoe-like depression.

E. Rhachilla beset with long, straight hairs.

F. Awns barbed from base to tip.

G. Spring habit of early growth.

H. Lateral nerves smooth.

HH. Lateral nerves barbed.

I. No pigment in aleurone layer, white or yellow .........

Vermont Champion. 438

II. Pigment present in aleurone layer, dark blue..........

Turkish Smyrna. 438

FF. Awns smooth at base for greater or less distance.

G. Spring habit of early growth.

H. Lateral nerves smooth................... Smyrna. 438

EE. Rhachilla beset with short, more or less recurved hairs.

F. Awns barbed from base to tip.

G. Spring habit of early growth. 
H. Lateral nerves smooth.

I. Spike unbranched . . . . . . . . . . . . . Chevalier. 439

II. Spike branched . . . . . . . . . . . . . . . . . . V Vessling. 439

HH. Lateral nerves barbed.

I. No pigment in aleurone layer, white or yellow........

Manchury x Vermont Champion. 440

II. Pigment present in aleurone layer, dark blue.......... Turkish Syrian. 440

FF. Awns smooth at base for greater or less distance.

G. Spring habit of early growth.

HH. Lateral nerves barbed.

I. No pigment in aleurone layer, white or yellow........

Syrian. 440

DD. Spike broad, compact, usually nearly erect: internodes of rhachis short

(2.3-3.0 cm. to ten internodes); base of lemma cross-creased.

E. Rhachilla beset with long, straight hairs.

F. Awns barbed.

G. Spring habit of early growth.

H. Lateral nerves smooth; density greater than $2.2 \mathrm{~cm}$. to ten internodes of rhachis; spike of uniform width from

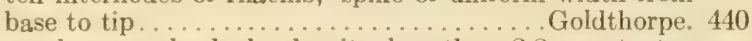

HH. Lateral nerves barbed; density less than $2.2 \mathrm{~cm}$. to ten internodes of rhachis; spikes broader at base than at tip, fan-shaped................................. Barley. 441

EE. Rhachilla beset with short, more or less recurved hairs.

F. Awns barbed.

G. Spring habit of early growth.

H. Lateral nerves smooth; density greater than $2 \mathrm{~cm}$. to ten internodes of rhachis................... Primus. 441

CC. Kernels black or containing black pigment.

D. Spike narrow, lax, nodding; internodes of rhachis long $(3.0-4.1 \mathrm{~cm}$. to

ten internodes); base of lemma with horseshoe-like depression.

E. Rhachilla beset with long, straight hairs.

F. Awns barbed.

G. Spring habit of early growth.

HH. Lateral nerves barbed................ Anatolian Black. 442

EE. Rhachilla beset with short, more or less recurved hairs.

F. Awns barbed.

G. Spring habit of early growth.

BB. Lemmas hooded.

H. Lateral nerves smooth............. Black Two-rowed. 442

CC. Kernels black or containing black pigment.

D. Spike narrow, lax, nodding; internodes of rhachis long $(3.0-4.1 \mathrm{~cm}$. to ten internodes); base of lemma with horseshoe-like depression.

EE. Rhachilla beset with short, more or less recurved hairs.

F. Spring habit of early growth.

G. Lateral nerves barbed. . . . . . . . . . . . . . . Ingrescens. 442

AA. Kernels hull-less.

B. Lemmas awned.

C. Kernels white, blue, or purple.

D. Spike narrow, lax, nodding; internodes of rhachis long $(3.0-4.1 \mathrm{~cm}$. to

ten internodes); base of lemma with horseshoe-like depression.

E. Rhachilla beset with long, straight hairs.

F. Awns barbed. 
G. Spring habit of early growth.

HH. Lateral nerves barbed.

I. No pigment in aleurone layer, white.... Naked Spring. 443

II. Pigment present in pericarp layer, purple............

S. P. I. 41153.443

DD. Spikes very broad, compact, erect; internodes of rhachis very short

(1.6-2.1 cm. to ten internodes); base of lemma cross-creased.

E. Rhachilla beset with long, straight hairs.

F. Awns barbed.

G. Spring habit of early growth.

HH. Lateral nerves barbed.

I. No pigment in aleurone layer, white or yellow.

Selection 614. 443

BB. Lemmas hooded.

C. Kernels white, blue or purple.

DD. Spike very broad, compact, erect; internodes very short $(1.6-2.1 \mathrm{~cm}$. to ten internodes); base of kernel eross-creased.

E. Rhachilla beset with long, straight hairs.

F. Spring habit of early growth.

GG. Lateral nerves barbed.

H. No pigment in aleurone layer, white or yellow ..........

CC. Kernels black.

Selection 616. 443

D. Spike narrow, lax, nodding; internodes of rhachis long $(3.0-4.1 \mathrm{~cm}$. to ten internodes); base of lemma with horseshoe-like depression.

EE. Rhachilla beset with short hairs.

F. Spring habit of early growth.

G. Lateral nerves smooth.

Selection 607. 443

\section{Descriptions of varieties}

Hanna (Plate XXXVI, 16).-Foliage medium green; culms rather long, slender, often lodging under adverse weather conditions; ereet in eatry habit of growth; spike usually well out of shrath of last leaf; medium to late in maturity, later than most of the common six-rowed barleys; spikes lax, nodding, length of internodes varying from 3.3 to 4.1 cm. with an average length of from 3.6 to $3.8 \mathrm{~cm}$.; grain rather short $(9 \mathrm{~mm}$.), very plump, symmetrical; lemma and palea cross-wrinkled, ycllow in color, often darker at base; awns long, more or less spreading; five nerves of lemma more or less conspicuous, lateral nerves smooth; base of lemmia with a slight horseshoe-like depression; thachilla beset with long. straight hairs.

The following subvarieties may be distinguished within the Hamna variety. These divisions cannot be made with absolute certainty, however, as the differences are in degiee and are naturally more or less indefinite. Such characters as height and maturity, as already explained, cannot be relied upon because of variations produced under different conditions. 


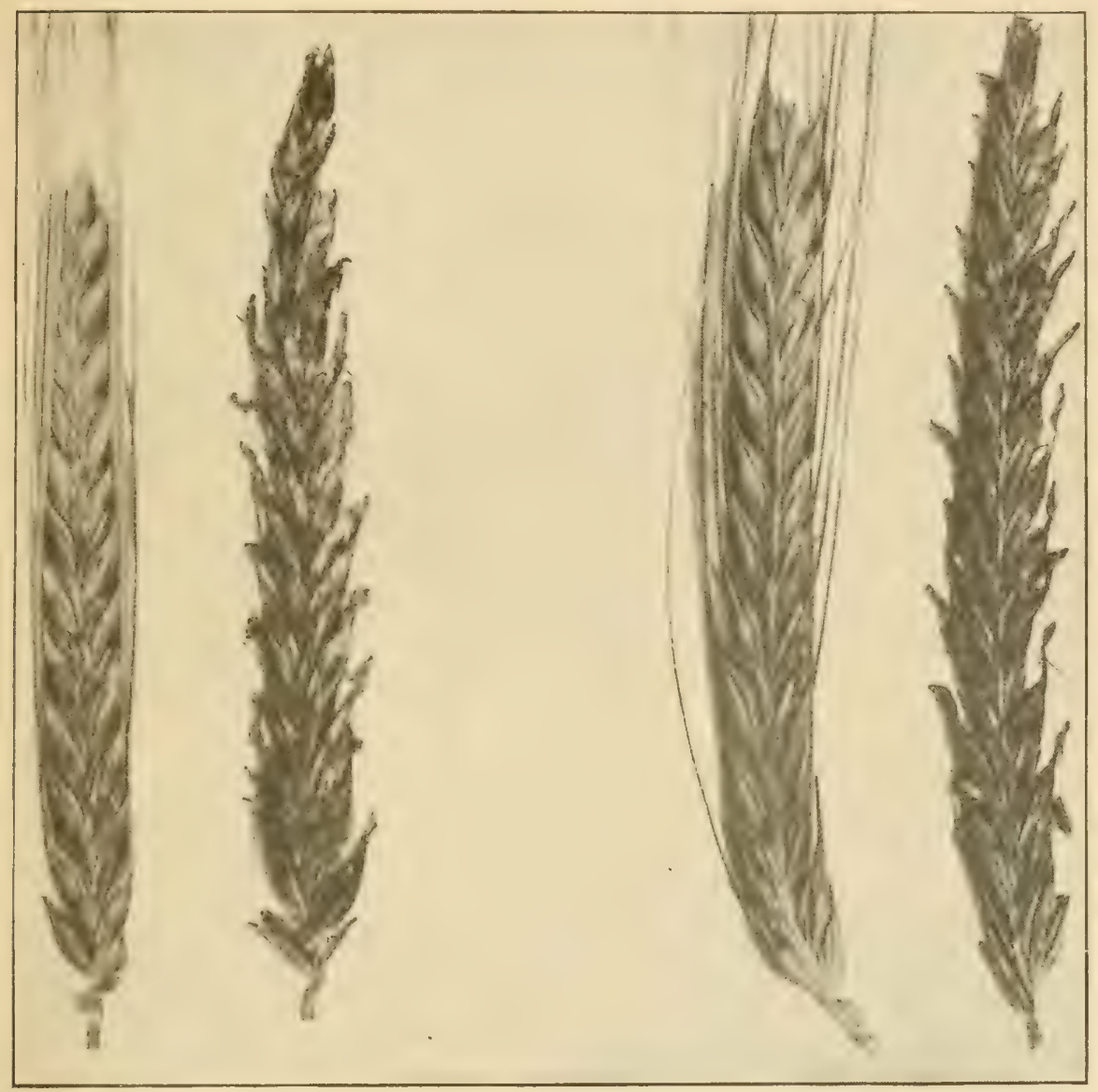

A

B

C

D

Fig. 71. VARIATion in terminal appendage AND adierence of lemma

A, Hanna; B, Hordeum ingrescens; C, Naked Spring; D, H. nigrilaxum

A. Foliage light green; very early maturity; short culms............. Selection 423. AA. Foliage medium to dark green; culms medium to long.

B. Nedium to early in maturity

Hanna.

(Considerable vatriation oceurs here both in maturity and in attitude of the spike. In general, the specimens named Humblen are somewhat earlier in maturity, and possess a slightly denser spike which droops to a greater angle, than the true Hanna). 
(Additional specimens of the subvarieties Selection 423 and Hanna found under the following names: Abed Binder, Ackermans Niedebayrische, Austin Hanna, Australian, Australian Early, Australian Hollischauer, Australian Loosdorfer, Austrian Hanna, Austrian Proskowetz, Bavarian, Bayerische Landgerste, Bohemia, California Chevalier, California Moravian, Canadian, Chevalier, Chinese (King Kua), Frankergerste Stamm, French, German, German Bavaria, German Hanna, German Heils Granken, German Nole Early, Gold Foil, Hanakische Gerste, Hansche, Hungarian Hanna, Hungarian Loosdorfer, Japanese, Kwassitzer Hanna, Lechrainer, Loosdorfer, Mahrische, Niederbayerische Landgerste, Noles Bohemia, Proskowetz, Pure Bred Spring, Roumanian Chevalier, Roumanian Common, Roumanian Hanna, Rud. Bethges, Scottish Lothian Chevalier, Sechsamter, Steigun, Svalöf, Svalöf Hannchen, Swedish Gold, Swedish Gotland, Swedish Oland, Swiss Spring, Two-rowed Black, Zeiness Vered.)

BB. Late to very late in maturity, a much greater constant difference between this subvariety and Hanna than between Hanna and Hannchen.................. Princess.

(Additional specimens of this subvariety found under the following names: Heines Verbessert Chevalier, Italian, Mahndorfer, Netherlands, Svalöf Princess, Swedish Princess, Unterfrankische Zuchtaus-schussgerste.)

Vermont Champion.- The variety Vermont Champion has the same general characteristics as has the variety Hanna, except that barbs appear on the lateral nerves of the lemma. Some variation in the degree of barbing has been found, but during the period of the present study the specimens named below have always been found to have some barbs present.

Additional specimens of this variety were found under the following names: Chiligerste, French, German Bavaria, Gerste aus dem Banat, Hanna x Vermont Champion, Jerusalem Gerste, Jutlandische Gerste, Swedish Oland, Ungarische Hanna.

The specimen named Hanna $\mathrm{x}$ Vermont Champion was somewhat taller and a little denser than the other subvarieties.

Turkish Smyrna.-Foliage medium green; number of nodes in culm small; culms short; erect in early growth; spikes scarcely emerged from sheath of last leaf; early in maturity; spikes medium in length, lax, nodding; internodes of rhachis long $(3.5-4.2 \mathrm{~cm}$. to ten internodes); grain large, dark blue; lemma closely adhering to caryopsis, usually discolored, awned; awns barbed from base to tip; nerves of lemma barbed; base of lemma with horseshoe-like depression; outer glumes awn-pointed, extending just beyond lemma; rhachilla beset with long, straight hairs, the hairs occasionally rather sparse.

Additional specimens of this variety were found under the following names: Syrian, Turkish (Smyrna Highland).

Smyrna.- The variety Smyrna is distinguished from Turkish Smyrna by possessing (1) awns which are only partly barbed, the barbs appearing 
at the tip of the awn and extending from one-third to two-thirds of the distance to the base of the awn, the base of the awn being perfectly smooth, (2) smooth lateral nerves, and (3) nonpigmented grain.

The following key separates the.subvarieties of the varicty Smyrna:

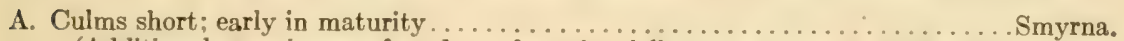

(Additional specimens found under the following names: African (Anatolia), Australian Hollischauer (Hanna), California Chevalier, Ouchac, Smyrna 521, Turkish, Turkish Afrokarchissar, Turkish Anatolian, Turkish Smyrna Highland.)

AA. Culms medium to long; medium to late in maturity................... Schaley's.

Cheralier (Plate XXXVI, 17).- The variety Chevalier is distinguished from Hanna only by the characters of the rhachilla. The rhachilla not only is beset with short, fine hairs which are more or less recurved at the tip, but is about one-half longer in Chevalier than in Hanna. Otherwise the two varieties seem exactly the same in adaptation as well as in observable morphological characters.

The names as applied to these two varieties might be reversed and still be just as correct. The only reason for applying them as they are applied is because more specimens with the name Hanna attached appeared with the characteristies of Hanna as here given, than appeared with the characteristies of Chevalier as here given; while no specimens appeared with the name Hanna with the Chevalier characters.

The following key separates the subvarieties of the variety Chevalier:

A. Foliage dark green, broad; very early in maturity .................. Bavarian. (An additional specimen found under the name Rieser Gerste.)

AA. Foliage medium green, average width; medium to late in maturity ......... Chevalier. (Additional specimens found under the following names: Australian, Balton, Bergstrassen, Bohemian, California Chevalier, Challenge, Chevalier (Kinvers), Chilian Chevalier, English Chevalier, Golden Drop, Gold Foil, Gold Melonen Chevaliergerste, Horn, Idaho, Manchuria, New Zealand, Pfelzer, Probsteier Perlgerste, Scottische Annat, Scottische Perlchevaliergerste, Scottish Chevalier, Silver King, South African Golden Grain, Tasmanian Battledore. The specimen named Balton was found to be more dense $(3.0-3.2 \mathrm{~cm}$. to ten internodes) than the others of this group.)

Wessling. - The variety IVessling differs from other two-rowed barleys by possessing (1) a more or less branched spike and (2) a triplication of spikelets at some of the nodes. In this variety, instead of one set of three spikelets, one fertile and two sterile, there are at a number of nodes near the base of the spike three sets, thus giving three fertile and six sterile spikelets at one node. In some cases, also, a secondary rhachis is produced in the place of the fertile median spikelets. This secondary rhachis then 
bears three spikelets at each node, all of which arise on the outer side. In other morphological characters this variety is similar to Chevalier.

The original specimen name was Wessling's Trounengerste.

Manchury $x$ Vermont Champion (Plate XXXVII, 18).- The variety Manchury $\mathrm{x}$ Vermont Champion is distinguished from Chevalier by the presence of barbs on the lateral nerves. This difference has been found to be eonstant, although the degree of barbing varies to some extent with different seasons. This group has the same adaptations as Chevalier but has not been grown so extensively.

The following key separates the subvarieties of the variety Manchury $\mathrm{x}$ Vermont Champion:

A. Kernels medium-sized; awns rather fine, more or less deciduous

Manchury x Vermont Champion.

(Additional specimens of this variety found under the following names: Austrian, California Chevalier, Chevalier, German, Noles Moravia Chevaliergerste, Princess, Svalöf Chevaliergerste, Swedish Chevalier II.)

AA. Kernels very large; awns coarse, showing no tendency toward deciduousness. . .......

Selection 503.

Turkish Syrian.- Feliage medium green; culms very short; erect in early growth; spikes failing to emerge completely from sheath of last leaf; early in maturity but somewhat uneven; spikes short, erect; internodes of rhachis long (3.5-3.S cm. to ten internodes); grain rather long but not plump; aleurone layer pigmented. dark blue; lemma adhering tightly to caryopsis, awned; awns barbed for entio length; lateral nerves of lemma harbed; base of lemma with horseshoe-like depression; outer glumes narrow, awn-pointed, scarcely extending beyond lemma; rhachilla beset with short hairs.

Syrian.-Distinguished from Turkish Syrian hy possessing (1) awns barbed from one-third to two-thirds the distance from tip to base, the base being perfectly smooth, and (2) nonpigmented grain.

Goldthorpe (Plate XXYVII, 19).-Foliage medium green; culms long; leaves rather broad. abundant; erect in early growth; very late in maturity; sick spilielets somewhat more developed than in ('hevalien'; spikes dense, length of ten internodes 2.0-3.0 em; angle of inclination of kernel with rhachis, great, making spike broad; spikes same width from base to tip. nodking to considerable extent but not so much ats in laxer types alrearly described; grain white, long, rather broal; lateral nerves forming rather prominent shoulder's; palea and lemma not so much cross-wrinkled ats in 
more lax types: Iemma allhering closely to caryopsis, rather coarse, awned; awns barbed. long. sureading; nerves of lemma conspicuous, smooth; base of lemma cross-created; outer glumes awn-pointed; rhachilla beset with long, straight hairs; rhachis in some cases more or less articulate at nodes.

Two important eommercial subvarieties of Coldthorpe, Svanhals and Goldthorpe, have only one distinguishing characteristic, which is one of degree and not abolutely reliable: Svamhals is a few days later in maturity than Goldthorpe.

Additional specimens of Croldihorpe were found under the following names: Australian, Bavarian, Bestehorns Diamant. Bestehorns Kaiser, Bohmische (icrste. Chile. Frenlerisksons (ierste, Hungarian, Imperial, Jewel, Norarian, New Burton Malting, Norwegian Imperialleyg, Seottish Lothian standwell. Apirgelgerste aus Ltuma. Virginia Selection 4, Virginia Selection 7, Webbs Bartlose.

Additional sperimens of sranhats were found under the following names: Goldthorpe. Hordemm distichum nutans, Noles Imperialgerste Type A,

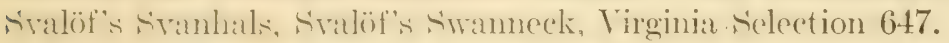

Fan Burley. Foliagre medium green; culns merlium to short, rather large in diameter; creet in eatly growth; spikes searecly emerging from sheath of last leaf: ranlior thatn other erect types of two-rowed barleys; sick spikelets infertile hut large, containing rudimentary pistils; spike short, very dense (longth of ten internotes of rhachis less than $2.2 \mathrm{~cm}$.), broader at hase than at tip); angle of inclination of kernels with rhachis, very great at hase, decersing toward tip); spike very erect; grain white or yellow, medium to litrere, lemma athering closely to caryopsis, awned; arns barberl. rery spreatiog, giving the general appearance of a fan; latoral nerves of lemmal hathed; hase of lemma cross-creased; outer shlumes short-awnerl, extending at least to twice length of lemma; rhachilla beset with long, straight hairs.

Aclditional specimens of this varicty wore found under the following names: Hordeum distichum, Pfauengerste.

Primus. - Distinguished from Goldthorpe in that the rhachilla is beset with short, more or less recurvel hairs, rather than with long, straight hairs.

Additional specimens of this variety were found under the following names: Australlian, Breustedts Horzer Cierste, Fruhwirts Fruhe Goldthorpe, Hordeum distichum erectum, New Burton Malting, Standwell, 
Svalöf's Primus, Swedish Upland, Tasmanian, Tasmanian Ideal, Upland. The specimens under the second and third names are somewhat earlier than the others.

Anatolian Black (Plate XXXVII, 20).- Foliage medium green; culms short to medium in length; leaves rather short, narrow; erect in early growth; stooling very little; spikes scarcely emerging from sheath of last leaf; medium to early in maturity; spikes lax, nodding to only a small angle; kernels forming only a slight angle of inclination with rhachis; grain rather large, long, brown to black, black pigment in both pericarp and glumes; lemma adhering closely to caryopsis, awned; awns and lateral nerves barbed; base of lemma with horseshoe-like depression; outer glumes awn-pointed; rhachilla beset with long, straight hairs.

An additional specimen of this variety was found under the name Asia Minor.

Black Two-rowed (Plate XXXVII, 21).-Foliage light green; leaves large, broad, long; culms long, medium in size; erect in early growth; stooling well; spikes completely emerging from sheath of last leaf; late in maturity; spikes lax, long, nodding; grain black, pigment in both glumes and pericarp; lemma adhering elosely to caryopsis, awned; awns long, more or less pigmented, barbed, somewhat spreading; lateral nerves smooth, conspicuous, forming prominent shoulders; base of lemma with horseshoe-like depression; outer glumes narrow, awn-pointed; rhachis beset with short hairs.

Additional specimens of this variety were found under the following names: Hordeum distichum erestum, Schwarze Zweizeilige Gerste.

Ingrescens. - Foliage medium to dark green, abundant; culms tall; spikes lax, nodding; grain black or dark brown, large; lemma closely adhering to caryopsis, hooded; hoods small, set on short awns; lateral nerves barbed; base of lemma with horseshoe-like depression; outer glumes awn-pointed, narrow; rhachilla often reduced, beset with short hairs.

This variety is of no economic inaportance. Only two specimens were obtained, which may be separated by the following key:

A. Very late in maturing; foliage dark green; leaves very broad; spikes very long; grain

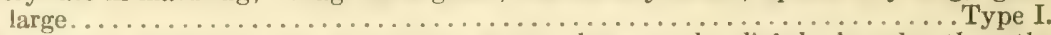
AA. Medium in maturity; foliage medium green; leaves only slightly broader than the average for barley; spikes medium in length; grain medium in size....... Type II. 
Naked Spring (Plate XXXVII, 22).- Foliage dark green; culms short and weak, with strong tendency toward lodging; ereet in early growth; early in maturity; spikes lax, long, nodding; grain white, very large, almost oval in shape; lemma free from caryopsis, awned; awns very long, barbed; lateral nerves of lemma barbed; base of lemma with horseshoe-like depression; rhachilla beset with long, straight hairs.

An additional specimen of this variety was found under the name Gerste aus der Krim.

S. P I. 41158.- Foliage medium green; culms medium to short; erect in early growth; average in maturity; spike of medium length, usually erect; grain small, purple; lemma free from caryopsis, slightly pigmented, short-awned; awns and lateral nerves of lemma barbed; rhachilla beset with long, straight hairs.

An additional specimen of this variety was found under the name S. P. I. 41162.

Selection 614.- Foliage dark green; culms short, rather large; erect in early growth; medium in maturity; spikes dense, broad, short, ereet, emerging from side of leaf sheath; grain nonpigmented, oval, medium in size; lemma free from caryopsis, awned; awns very spreading, barbed; nerves of lemma barbed; rhachilla beset with long, straight hairs.

This variety is of no economic importance at present.

Selection 616.- Foliage very dark green; culms short, large; leaves very short, broad; medium in fertility; spikes very short, broad, emerging far down side of leaf sheath; side spikelets very large but infertile; grain nonpigmented, large; lemma free from caryopsis, hooded; nerves of lemma barbed; rhachilla beset with long, straight hairs.

This variety is of no economic importance at present.

Selection 607 (Plate XXXVII, 23).-- Foliage dark green; culms medium to tall; erect in early growth; late in maturity; spikes long, narrow, nodding; internodes short; grain black, narrow but medium in length; lemma free from caryopsis, hooded; lateral nerves barbed; rhachilla beset with short hairs. This variety is of no economic importance at present.

\section{HORDEUM DEFICIENS}

Hordeum deficiens (probably first described as $H$. decipiens) is distinguished from $H$. vulgare and $H$. intermedium by the sterile side spikelets, 
and from $I I$. distichon by a great reduetion in the structures of the side spikelets. The side spikelets of $H$. deficiens (fig. 72) not only are sterile, but also are reduced in all the floral parts to a much greater extent than in $H$. distichon. In some cases all that remains in evidence of a side spilielet is one outer glume. Neither pistil nor staners ate erer present.

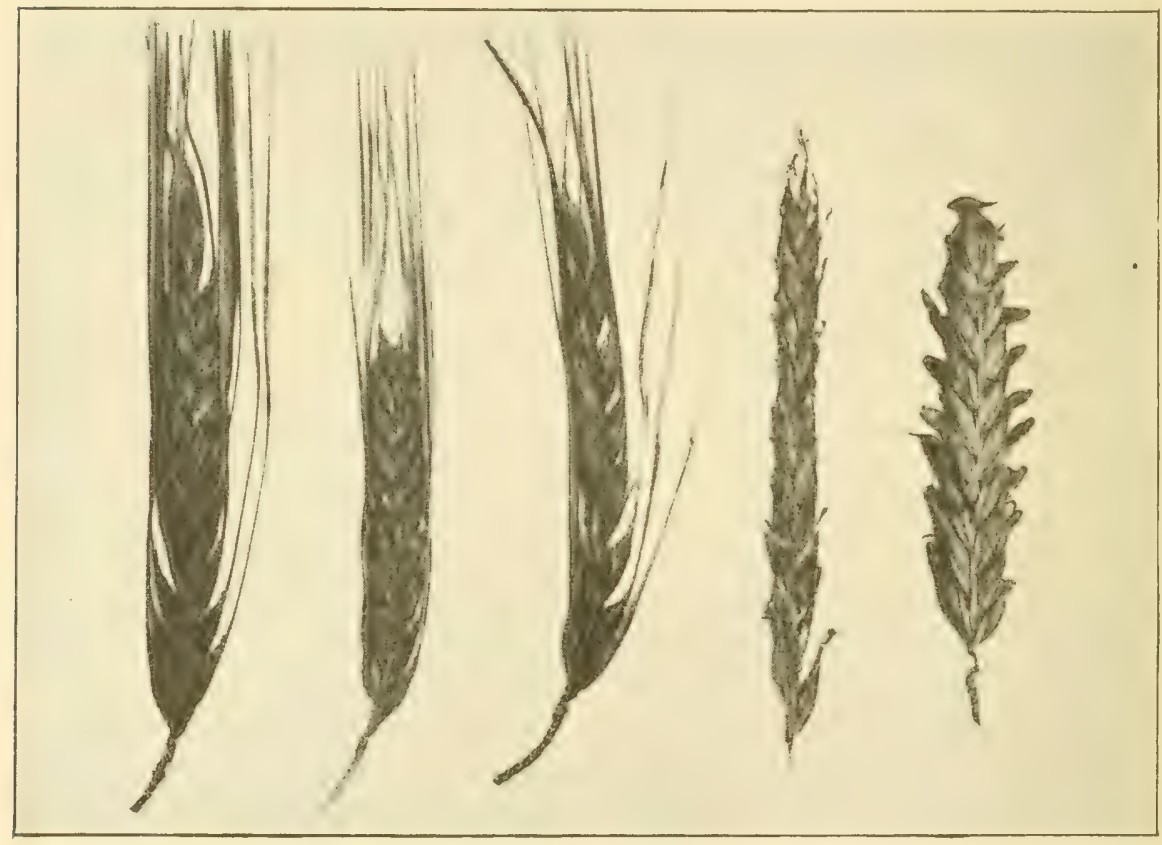

A

B

$\mathrm{C}$

D

$\mathrm{E}$

Fig. 72. VARTOUS TYPES OF HORDEUM DFFtCIENS

A, Selection 621; B, Russian Courland; C, S. P. I. 411.5; D, selection fi-f; E, Solection 625

II. deficiens has not lecome of economie importane in the Tnited states. Abyssinia is the soure of practically all the varieties belonging to this species.

A. Kernels hulled.

Key to varieties of $H$. deficiens

B. Lemmas awned.

C. Kernels white, blue, or purple.

D. Spike narrow, lax, nodding; internodes of rhachis long $(3.0-4.1 \mathrm{~cm}$. to ten internodes); base of lemma with horseshoe-like depression. 
E. Rhachilla beset with long, straight hairs.

F. Awns barbed.

PACE

G. Spring habit of early growth.

H. Lateral nerves smooth............Russian Courland. 445

EE. Rhachilla beset with short hairs.

F. Awns barbed.

G. Spring habit of early growth.

HH. Lateral nerves barbed, outer glumes very broad.........

CC. Kernels black.

Selection 44. 446

D. Spike narrow, lax, nodding; internodes of rhachis long $(3.0-4.1 \mathrm{~cm}$. to ten internodes); base of lemma with horseshoe-like depression.

E. Rhachilla beset with long, straight hairs.

F. Awns barbed.

G. Spring habit of early growth.

HH. Lateral nerves barbed.

EE. Rhachilla beset with short hairs.

.Selection 621.446

F. Awns barbed.

G. Spring habit of early growth.

BB. Lemmas hooded.

HH. Lateral nerves barbed.

CC. Kernels black.

D. Spike narrow, lax, nodding; internodes of rhachis long $(3.0-4.1 \mathrm{~cm}$. to ten internodes); base of lemma with horseshoe-like depression.

E. Rhachilla beset with long, straight hairs.

F. Spring habit of early growth.

AA. Kernels hull-less.

G. Lateral nerves smooth................... Selection 657. 446

B. Lemmas arwned.

C. Kernels white, blue, or purple.

D. Spikes narrow, lax but erect; internodes of rhachis long $(3.0-4.1 \mathrm{~cm}$. to ten internodes); base of lemma with horseshoe-like depression.

E. Rhachilla beset with long, straight hairs.

F. Awns barbed.

G. Spring habit of early growth.

BB. Lemmas hooded.

HH. Lateral nerves barbed.................. P. I. 41155. 446

C. Kernels white, blue, or purple.

D. Spike broad, erect, but internodes of rhachis long $(3.3-3.6 \mathrm{~cm}$. to ten internodes); base of lemma with horseshoe-like depression.

E. Rhachilla beset with long, straight hairs.

F. Spring habit of early growth.

GG. Lateral nerves barbed, lemma seven-nerved. . . . Selection 625. 447

CC. Kernels black.

D. Spike narrow, lax, slightly nodding; internodes of rhachis long (3.0-4.1 $\mathrm{cm}$. to ten internodes); base of lemma with horseshoe-like depression.

E. Rhachilla beset with long, straight hairs.

F. Spring habit of early growth.

GG. Lateral nerves barbed. ................. Selection 626. 447

\section{Descriptions of varieties}

Russian Courland (Plate XXXVIII, 24, and fig. 72, B).- The variety Russian Courland is characterized by the same general appearance and 
adlaptation as Hanna, in $H$. distichon species, with the one exception of the development of the side spikelets. In this variety these are very rudimentary, consisting only of the outer glumes and a very small, undeveloped lemma without palea or pistil.

An additional specimen of this variety was found under the name Early Chevalier.

Selection 44.- Foliage dark green; erect in early growth; spikes emerging from side of sheath of last leaf, rather lax but broad and nearly erect; grain nonpigmented, usually somewhat discolored at base; lemma adhering closely to caryopsis, base with horseshoe-like depression; awns short, broad; outer glumes of median spikelet half as broad as lemma, short-awned; lateral spikelets much reduced, with outer glumes awnpointed and one-third width of outer glumes of median spikelet; rhachilla beset with short hairs.

Selection 621 (Plate XXXVIII, 25, and fig. 72, A).- Foliage dark green; culms average in height; erect in early habit of growth; spike lax, nodding; grain black, glaucous; lemma adhering closely to caryopsis, awned; awns barbed; lateral nerves barbed; outer glumes very pubescent, awn-pointed; rhachilla beset with long, straight hairs.

Selection 62.2.- Foliage medium green; culms average in height; erect in early habit of growth; late in maturity; spike lax, nodding; rhachis showing strong tendency toward brittleness; grain black, medium to large; lemma adhering closely to earyopsis, awned; awns black, barbed; lateral nerves barbed; outer glumes small, black, glabrous, awn-pointed; rhachilla beset with short hairs.

Selection 65\%.- Foliage dark green; leaves broad; culms average in height; semi-winter in habit of early growth; late in maturity; spike lax, nodkling; grain black, more or less glaucous; lemma adhering closely to caryopsis, hooded, hoods set on short awns; outer glumes very narrow, short, blunt; lateral nerves of lemma smooth; rhachilla beset with long, straight hairs.

S. P. I. 41155 (Plate XXXVIII, 26, and fig. 72, C).- Foliage medium green; culms short; erect in early growth; early in maturity; spike lax, nodding, short; grain short, broad, nonpigmented; lemma free from caryopsis, awned; awns broad, barbed; lemma occasionally possessing an extra pair of lateral nerves; outer glumes narrow, long, awn-pointed; lateral nerves barbed; rhachilla sparingly beset with straight, rather short hairs. 
Selection 625 (fig. 72, E).-Foliage dark green; leaves broad; culms large, coarse, but medium in length; erect in early growth; spikes emerging from side of sheath of last leaf; late in maturity; spikes broad, nearly erect, ten internodes $3.3-3.6 \mathrm{~cm}$. in length; angle of inclination of kernel with rhachis, rather large; grain long, narrow, nonpigmented; lemma adhering closely to caryopsis, hooded; lemma possessing an extra pair of lateral nerves; rhachilla beset with long, straight hairs.

Selection 626 (Plate XXXviII, 27, and fig. 72, D).-Foliage dark green; culms medium to long; erect in early growth; late in maturity; spikes narrow, lax, nodding; grain black, large; lemma seven-nerved, hooded, hoods sessile; lateral nerves barbed; outer glumes awn-pointed, narrow, very puhescent; rhachilla beset with long, straight hairs.

\section{SUMMARY}

In the classification presented in this paper, sixty varieties have been distinguished in the four cultivated species of barley, as follows: twentynine in Hordeum rulgare; three in $H$. intermedium; twenty in $H$. distichon; and eight in $H$. deficiens. The rarieties in each species are systematically arranged accordingly to stable morphological characters - the same characters being used in the separations within cach species - and as far as possible according to natural adaptation. An attempt has been made to avoid placing varieties with similar adaptations but with one or more distinct morphological differences too far apart in the key. This, however, could not be aroided in a few instances. The varieties as described are separated by one or more morphological characters which have proved constant for a period of five years under New York environment and which are probably constant under all environmental conditions. For this reason, the keys to the varieties should prove effective in the identification of specimens, at least within narrow limits, in a wide range of conditions. However, the divisions within the varieties as given in the keys to subvarieties are based on more variable characters, and therefore cannot be relied upon in a given environment until proved.

The naming of varieties, as given in the keys, is not an attempt to standardize the nomenclature, as this cannot be done by the efforts of one individual. The choice of a name for a given variety was based on the following rules in the order given: (1) the frequent occurrence of a wellknown name; (2) names indicating geographical origin; (3) descriptive 
names; and (4) names of producers, discoverers, or introducers. In cases in which no name was given and the specimen was separated on the basis of some stable morphological character, selection numbers were employe:!

In conclusion, it should be understood that yield has not been given consideration in the present classification. Without doubt there are represented, among the synonyms of a given variety or subvariety, various strains which differ materially in yicld.

\section{ACKNOWLEDGMENTS}

The writer wishes to acknowledge the help given him and to express his appreciation of the valualle suggestions and criticisms offered by Professor E. G. Montgomery, of the Deparment of Fam Crops, Comell University, under whose direction this investigation wat made. He wishes to acknowledge also his indebtedness to Mrs. IV. (C. Etheridge for the accurate drawings from which the color plates were made, and to C. B. Wiggans for the drawings of the structural parts of the plant. 


\section{BIBLIOGRAPHY}

Atterberc, Albert. Die Erkennung der Hauptvarietäten der Gerste in den nordeuropüischen siati- und Milzgersten. Landw. Vers. Stat. $36: 23-27.1889$.

Stat. 39:77-80. 1891. 1899.

Die Varietiaten und Formen der Gerste. Journ. Landw. 47:1-41.

Bentex, E. s. Varietic of barley. Fed. Inst. Brewing. Journ. 8:542594.1902.

Boissier, Edmoxd. IIomleum. In Flora orientalis 5:686-689. 1884.

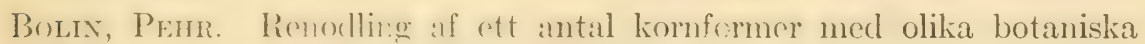
Kännetecken. Sveriges Utsädesfor. Tidskr. 1893.

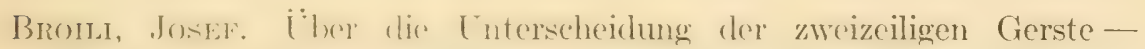
Hordeum distichum - an Korne. Inaug. Diss., Univ. Jena. 1906.

İber die Interscheidhugsmorkmale dor I) istichumgruppe (zweizeilige Gerste). Journ. Landw. 56:121-139. 1908.

Brows, A. J. (oloriag matter in barleys. Fed. Inst. Brewing. Journ. 6:480-488. 1900 .

(Arletox, Mark Alfred. Barley. In The small grains, p. 115-146. 1916.

Derr, H. B. Barley: erowing the erop. U. S': Agr. Dept. Farmers' bul. 443:1-48. 1911.

DöLt, J. C. Flora des Grossherzogthums Baden, 1:- 1857.

Harlay, Harry. Some distinctions in our cultivated barleys with reference to their use in plant hreeding. U. s. Agr. Dept. Bul. 137:138. 1914.

- The identification of varieties of barley. U. S. Agr. Dept. Bul. 622:1-32. 1918. 
Heuze, Gustave. Les plantes alimentaires, 2 vols. 1872.

—_ Les plantes céréales, 2d ed., 2 vols. 1896-97.

Hochstetter, Ch. F. Nachträglicher Commentar zu meiner Abhandlung: "Aufbau der Craspflanze, ete." Flora 31:105-118, 121-135, 140-152, 154-167, 171-188. 1848.

Hubert, M. The classification of brewing barley from a technical and agricultural standpoint, with special reference to its nitrogen content. Mens. Off. Renseig. Agr. Bul. 6:839-844. 1907.

Jessen, C. Samenkatalog̣ des eldenaer botanischen Garten. 1855.

Körnicke, F. Die Saatgerste. Hordeum vulgare L. sensu latoire. Ztschr. Gesam. Brauw. 5:113-128. 1882.

- Handbuch des Getreidebaues (Körnicke and Werner), I:1-470. (Reference on p. 147-189.) 1885.

—_ Die hauptsachlichsten Formen der Saatgerste, p. 1-15. 1895.

- (Communicated by M. Körnicke.) Die Entstehung und das Verhalten neuer Getreidevarietäten. Arch. biontol. 2:393-437. 1909.

Le Clerc, J. A., and IVail, Robert. Chemical studies of American barleys and malts. U. S. Chem. Bur. Bul. 124:1-75. 1909.

Linnaeus, Carl von. Hortus Upsaliensis, p. 1-306. (Reference p. 2223.) 1748.

Hordeum. In Species plantarum, I:84-85. 1753.

Munro, John M. H., and Beaven, E. S. Various conditions affecting the malting quality of barley. Roy. Agr. Soc. England. Journ., ser. 3: I I : 185-251. 1900.

NeergaArd, T. D. Bestaming a Kornets varieteter och sorter efter pâ Kärnorna befintliga Kännetecken. Allm. Svenska Utsadesför. Arsber. I889:54-61. 1889.

Nilsson, A. Identification of American barleys based upon the Swedish system. Soc. Brew. Tech. Journ. x:263-280. 1909. 
Persival, John. Cultivated barley. In Agricultural botany, p. 500511. 1914.

Post, George E. Hordeum. In Flora of Syria, Palestine, and Sinai, from the Taurus to Ras Muhammad, and from the Mediterranean Sea to the Syrian Desert, p. 902-903. 1883.

Quante, H. Die Gerste, p. 1-195. 1913.

Regel, Robert. Les orges cultivées de l'empire Russe, p. 1-39. 1906.

- Glattgrannige Gerste. Bur. Angew. Bot. Bul. x:5-85. (German translation, p. 64-85.) 1908.

Regel, Robert, And others. Bazhneiishiia formy pshenits iachmenei i sornykh rastenü Rossiñ. Bur. Angew. Bot. Bul. 36:209-282. 1910.

RüMkER, - voN. The systematic classification and naming of grain varieties for practical purposes. Deut. landw. Gesell. Jahrb. 23:137160.1908.

Schübler, Gustay. Dissertatio inauguralis botanica sistens characteristicen et descriptiones cerealium in Horto Academico Tubingensi et in Würtembergia, p. 1-47. 1818.

Schulz, August. Die Abstammung der Saatgerste. Naturf. Gesell. Halle. Mitt. I:- 1911.

Die Saatgerste. In Die Geschichte der kultivierten Getreide, I:86-116. 1913.

Séringe, N. C. Monographie des Céréales de la Suisse. In Mélanges botaniques, $2: 65-244.1819$.

- Déscriptions et figures des céréales européennes. Soc. Roy. Agr. Lyon. Ann. 4:321-384. 1841-42.

Voss, A. Versuch einer neuen Systematik der Saatgerste. Journ. Landw. $33: 271-282$. 1885 .

Memoir 40, Liberation of Organic Matter by Roots of Growing Plants, the sixth preceding number in this series of publications, was mailed on November 16, 1921. 



\section{INDEX TO VARIETIES AND SUBVARIETIES}

(Synonyms and subvariety names are in italics)

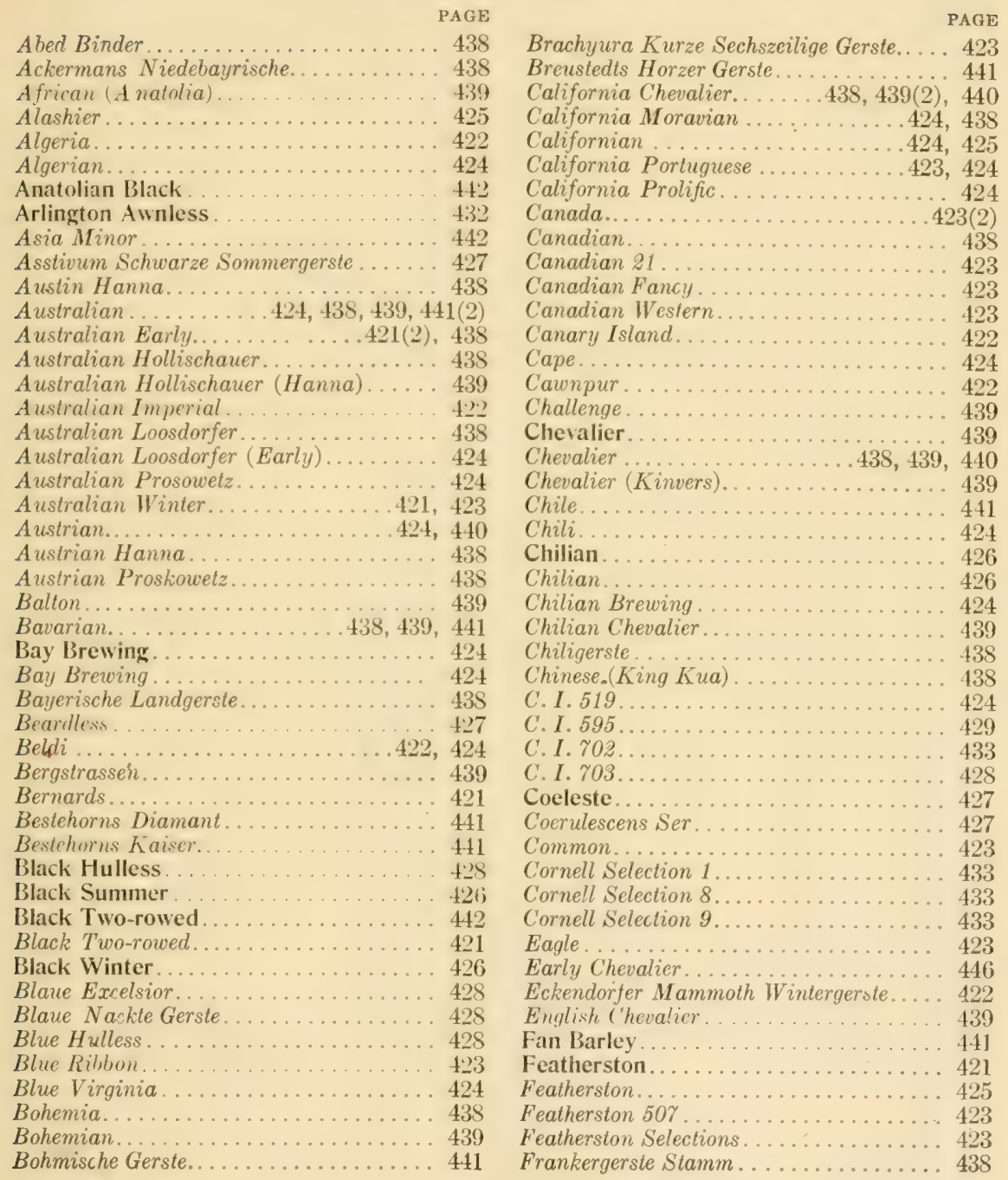


Frederisksons Gerste................441

French ..................... 438(2)

French Early . ............421, 423(2)

French Gerste aus Denmark.......... 421

Friedrichswerther Mammoth Wintergerste, 422

Fruhwirts Fruhe Goldthorpe........... 441

Gatami....................... 426

Gaza........................ 422

German..................438, 440

German Bavaria................ 438(2)

German Hanna. . . . . . . . . . . . . . 422, 438

German Heils Granken. . . . . . . . . . . 438

German Nole Early. . . . . . . . . . . . . 438

German Winter................. 425

Gerste aus Ajaccio................. 423

Gerste aus Cypern................ 423

Gerste aus Dalekantien............. 423

Gerste aus dem Banat..............443

Gerste aus der Krim................ 443

Gerste aus der Mandschursi.......... 423

Gercte aus Japan... . . . . . . . . . . . . . 423

Gerste aus Lulea. . . . . . . . . . . . . . . . 423

Gerste aus Morocco... . . . . . . . . . . . . 421

Gerste aus Norwegen............... 423

Golden Drop....................... 439

Goldethorpe....................441

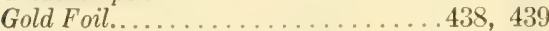

Gold Melonen Chevaliergerste ... . . . . . . 439

Goldthorpe . . . . . . . . . . . . . . . . . . 440

Goldthorpe...................... 441

Grecian....................... 424

Grecian Hordeum sp.............. 425

Groniger..................... 425

Guatemalan Tontonicipan........... 424

Guy Mayle ... . . . . . . . . . . . . . . 428

Guzerat .......................4422

Hanakische Gerste. . . . . . . . . . . . . 438

Hanna . . . . . . . . . . . . . . . . . . . 436

Hanna. . . . . . . . . . . . . . . . 437

Hanna $x$ Vermont Champion. ........ 438

Hannchen .................... 437

Hansche...................... 438

Hansee Hulless . . . . . . . . . . . . . . . . 427

Heavy Moldavian............... 423

Heines Verbessert Chevalier. . . . . . . . . 438

Heines Vierzeilige Gerste............. 423

Hitakawa ................... 426

Hordeum distichum................ 441

Hordeum distichum erectum..... . . 441, 442

Hordeum distichum nutans. . . . . . . . . 441

Horn ........................ 439

Hulless. . . . . . . . . . . . . . . . . . 429

Hungarian. ..................... 441

Hungarian Hanna. . . . . . . . . . . 438
Hungarian Loosdorfer. . . . . . . . . . . . . 438

Idaho . . . . . . . . . . . . . . . . . 439

Idaho Callow.................. 423

Idaho Winter. . . . . . . . . . . . . . . . . 425

Idaho Winter. . . . . . . . . . . . . . . . 425

Imperial. . . . . . . . . . . . . . . . . . 441

Imp. Manchuria................ 423

India Cawnpur................. 422

Indian Sind................422, 423

India Punjake.................... 422

Ingrescens. . . . . . . . . . . . . . . 442

Italian....................... . 438

Italian Hulless. . . . . . . . . . . . . . . 428

Japanese . . . . . . . . . . . . . . . . 438

Japanese Hitakawa............... 426

Jerusalem Gerste. . . . . . . . . . . . . . . . 438

Jewel......................... 441

Jutlandische Gerste............... 438

Kleine Warthebruch............ 423

Klein Wanzlehener Wintergerste...... 422

Kwassitzer Hanna. . . . . . . . . . . . 438

Lechrainer. . . . . . . . . . . . . . . . . . 438

Leiorrhynchum (Kcke.) . . . . . . . . ... 427

Long-grained Winter . . . . . . . . . . . 421

Loosdorfer...................... 438

Mahndorfer................ 438

Mahrische .................... 438

Maltese Island. . . . . . . . . . . . . . . 424

Mammoth Winter................ 422

Manchuria.................. 423, 439

Manchurian................... 423

Manchuria=Oderbrucker.......... 422

Manchuria-Oderbrucker............. 423

Manchuria Selection.............. 420

Manchuria Selections.............. 423

Manchury................423(2)

Manchury x Vermont Champion...... 440

Manchury $x$ Vermont Champion. . . . . . 440

Mariout . . . . . . . . . . . . . . . . . . 423

Mariout...................... 424

Marwar...................422(2)

Mezoeijes Handgerste aus Ungarn..... 421

Minnesota 6................... 423

Montana...................... 425

Moravian...................... 441

Moroccan.................... 421

Moroccan..................422, 424

Naked Barley . . . . . . . . . . . . . 427

Naked Spring . . . . . . . . . . . . . . . 443

Naked Spring. . . . . . . . . . . . . . 427

Nepal........................ 429

Nepal Hulless ... . . . . . . . . . . . . . 433

Netherlands.................. 438

Netherlans................... 425 
PAGE

$441(2)$

439

New Burton Malting

Niederbayerische Landgerste........... 438

Nigrum Schwarze Sommergerste....... 427

Noles Bohemia................ 438

Noles Imperialgerste Type A....... 441

Noles Moravia Chevaliergerste........ 440

Norwegian I.................. 421

Norwegian II ................ 423

Norwegian Bamsleyg.............. 423

Norwegian Bjorneleyg..........421, 423

Norwegian Imperialleyg............. 441

O. A. C. 21 .................... 423

O. A. C. 21 ................... 423

Oderbrucker................... 423(2)

Odessa.......................423(3)

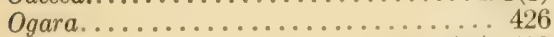

Ouchac..................421, 424, 439

Peru...................... 424

Pfauengerste.................. 441

Pfelzer......................... 439

Poda.......................... 424

Primus........................ 441

Princess......................438, 440

Probsteier Perlgerste.............. 439

Proskowetz.................. 438

Pure Bred Spring....................... 438

Red River....................... 423

Red's Triumph....................... 423

Rieser Gerste.................. 439

Roumanian Autumn............. 423

Roumanian Chevalier.............. 438

Roumanian Common............. 438

Roumanian Hanna............... 438

Roumanian Spring................ 423

Rud. Bethges.................. 438

Rumanian Autumn.............. 423

Russian Courland............... 445

Russian Livonian. . . . . . . . . . . . . . . 423

Sandrel.......................... 424

Sangatsuka.................... 428

Schaley's.................. 439

Schlesische Zeilgerste............... 423

Schwarze Zweizeilige Gerste.......... 442

Scottische Annat............... 439

Scottische Perlchevaliergerste......... 439

Scottish Chevalier................. 439

Scottish Lothian Chevalier............ 438

Scottish Lothian Standwell........... 441

Sechsamter....................... 438

Selection $44 \ldots \ldots \ldots \ldots \ldots \ldots \ldots \ldots . . . \ldots \ldots$

Selection $259 \ldots \ldots \ldots \ldots \ldots \ldots \ldots \ldots . . . \ldots 27$

Selection $308 . . . \ldots \ldots \ldots \ldots \ldots \ldots .430$

Selection $423 . . . \ldots \ldots \ldots \ldots \ldots \ldots . . . . . .6437$
Selection $509 \ldots \ldots$ PAGE

Selection 607 .................. 440

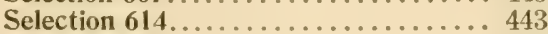

Selection $616 \ldots \ldots \ldots \ldots \ldots \ldots \ldots . . \ldots 43$

Selection $621 \ldots \ldots \ldots \ldots \ldots \ldots \ldots .446$

Selection $622 \ldots \ldots \ldots \ldots \ldots \ldots \ldots . \ldots \ldots$

Selection $625 \ldots \ldots \ldots \ldots \ldots \ldots \ldots .447$

Selection 626................ 447

Selection $657 . . . \ldots \ldots \ldots \ldots \ldots . . . . .446$

Short Six-rowed Winter.......... 426

Siberian................... 423

Silver King.............423(2), 439

Smyrna.................... 438

Smyrna...................424; 439

Smyrna $521 \ldots \ldots \ldots \ldots \ldots \ldots \ldots . . \ldots 439$

Smyrna Yerli................... 424

South African Cape Early..........423, 424

South African Golden Grain........... 439

South African Six-rowed........... 424

South Russian................423(2)

Spanish Sierra Yiqua........... 422

S. P.I. 18922................... 421

S. P. I. $40326 \ldots \ldots \ldots \ldots \ldots \ldots \ldots \ldots . . .633$

S. P.I. $40645 \ldots \ldots \ldots \ldots \ldots \ldots \ldots . \ldots . \ldots 23$

S. P.I. $40648 \ldots \ldots \ldots \ldots \ldots \ldots \ldots \ldots . \ldots . \ldots . \ldots 23$

S. P.I. $40649 \ldots \ldots \ldots \ldots \ldots \ldots \ldots \ldots \ldots$

S. P. I. $41153 \ldots \ldots \ldots \ldots \ldots \ldots \ldots \ldots \ldots \ldots$

S. P. I. $41155 \ldots \ldots \ldots \ldots \ldots \ldots \ldots . \ldots 46$

S. P. I. $41156 \ldots \ldots \ldots \ldots \ldots \ldots \ldots 429$

S. P. I. $41157 \ldots \ldots \ldots \ldots \ldots \ldots . \ldots 429$

S. P.I. $41158 \ldots \ldots \ldots \ldots \ldots \ldots \ldots . \ldots 22$

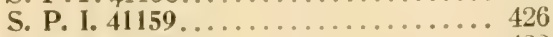

S. P.I. $41160 \ldots \ldots \ldots \ldots \ldots \ldots \ldots . \ldots 22$

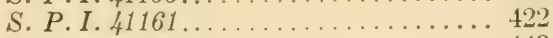

S. P.I. $41162 \ldots \ldots \ldots \ldots \ldots \ldots \ldots \ldots, 443$

Spiegelgerste aus Utuna............ 441

Standwell....................... 411

Steigun........................ 438

Success . . . . . . . . . . . . . . . . . 427

Success..................... 427

Success Beardless..................... 427

Svalof ............................ 438

Sval of Cheraliergerste................ 440

Sval of Hannchen.................. 438

Svalö Princess................... 438

Svalof's Primus.................. 442

Svalof's Svanhals.................... 441

Svalof's Swanneck................... 441

Svanhals........................ 441

Swedish Chevalier II.............. 440

Swedish Gold.................... 438

Swedish Gotland. .................. 438

Swedish Oland...................438(2)

Swedish Princess................. 438 
PAGE

Swedish Six-rowed.............. 423

Swedish Upland................. 442

Swiss...................424, 425

Swiss Spring..............423, 438

Syrian...................... 440

Syrian...................... 438

Tasmanian................. 442

Tasmanian Battledore. . . . . . . . . . 439

Tasmanian Ideal. ................. 442

Telli........................ 425

Tenkan...................... 425

Tripolitan................... 422

Triumph................... 425

Tunisian..................422, 424

Turkish................... 439

Turkish A frokarchissar. . . . . . . . . . . 439

Turkish Alasheir................ 424

Turkish Albanian.............. 423

Turkish Anatolian. . . . . . . . . . . 439

Turlish (Rhodes to Sea of Marmora).... 424

Turkish Smyrna. . . . . . . . . . . . . . . . 438

Turkish (Smyrna Highland). . . . . . . 438

Turkish Smyrna Highland.......... 439

Turkisk Smyrna Lowland. . . . . . . . . . 425

Turkish Syrian. . . . . . . . . . . . . . 440
PAGE

Two-rowed Black................. 438

Ungarische Hanna.................. 438

Unterfrankische Zuchtaus-schussgerste... 438

Upland........................ 442

Utah Winter. . . . . . . . . . . . 425

Utah Winter..................... 425

Vermont Champion.............. 438

Tiolaceum................... 428

Virginia Black Hulless. . . . . . . . . . 428

Virginia Hooded. . . . . . . . . . . . . . . 427

Virginia Selection 4.............. 441

Virginia Selection 7.............. 441

Virginia Selection.64............ 427

Virginia Selection 647........... 441

Webbs Bartlose. . . . . . . . . . . . . . 441

Wessling . . . . . . . . . . . . . 439

Wessling's Trounengerste........... 440

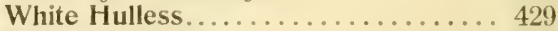

Wisconsin 5................. 423

Wisconsin $6 \ldots \ldots \ldots \ldots \ldots \ldots . . . . .423$

Wisconsin Pedigree.............. 423

Wisconsin Winter................ 424

Wustermarsch Wintergerste. . . . . . . . . 422

Yerli....................... 424

Zeiness Vered................ 438 



